\title{
Climorphysiological Architecture: Latent
}

\author{
by \\ Cassandra Murphy
}

A thesis submitted to the Faculty of Graduate and Postdoctoral Affairs in partial fulfillment of the requirements for the degree of

Master of Architecture

in

Architecture

Carleton University

Ottawa, Ontario

C 2015, Cassandra Murphy 


\section{Abstract}

The architectural industry must reach across several disciplines to embrace the knowledge and foresight nature intrinsically possess. This thesis wishes to challenge industry standards and adopt both biodesign and biomimetic approaches to construction. Organisms behavioral, morphological, and physiological mechanisms for surviving extreme climate fluctuations will be factors incorporated into the design. The proposal will exploit seasonal changes as a means to optimize building responsiveness and explore new forms of architectural expression.

Climorphysiological architecture is defined as a type of living architecture that is derived from \& evolves to a site's specific climatic conditions. The project will relate and appropriate natural processes as a means of dealing with temperate climate zones to produce a cladding system that works symbiotically with seasonal fluctuations.

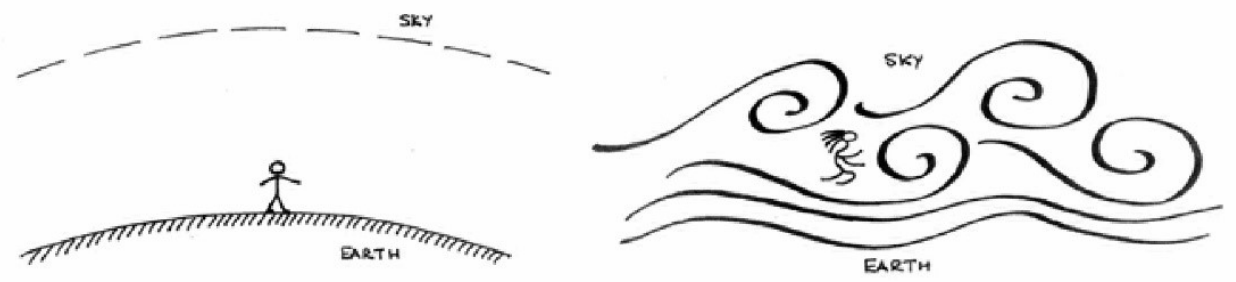

Illustration 1 The image above is an illustration showing the western tradition of dividing the earth, atmosphere, and sky into divisible categories. The illustration on the right is representative of the meshwork interweaving the earth, atmosphere, and sky into one another, where categories are not distinguishable. (Ingold, 2013) 


\section{Acknowledgements}

This thesis is dedicated to my family who have taught me that every problem in life is not a problem but rather an opportunity or challenge to improve. Knock us down and we'll come back swinging...twice as hard... every time.

Additionally I would like to thank my advisor Manuel Baez who has been my toughest critic and has helped steer this project in the right direction. 


\section{Table of Contents}

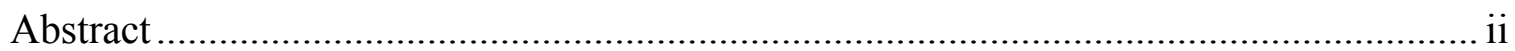

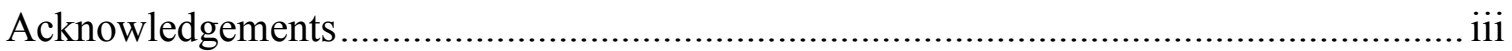

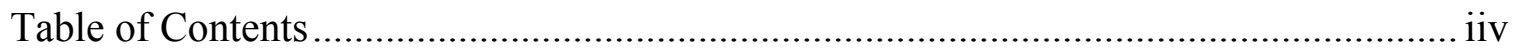

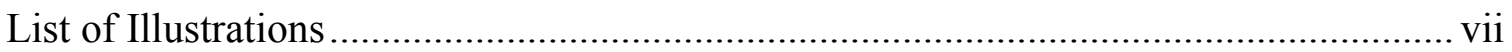

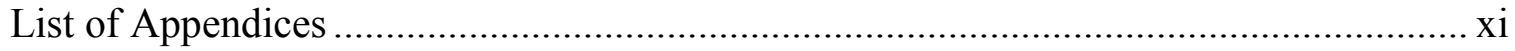

Introduction: Contextual Situation of Climorphysiological Architecture ………............. 2

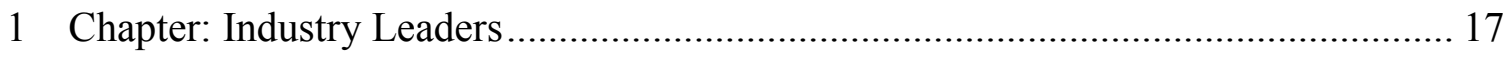

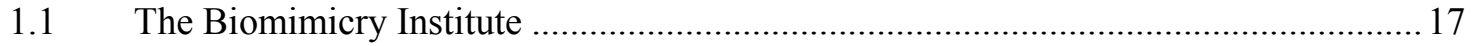

$1.2 \quad$ W.Y.S.S. Institute of Harvard University ………………………………………..... 18

1.3 The Center for Architectural Science \& Ecology ………………………………….... 19

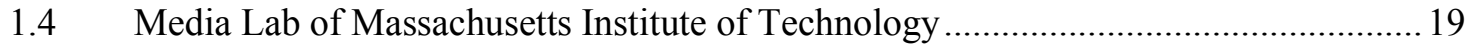

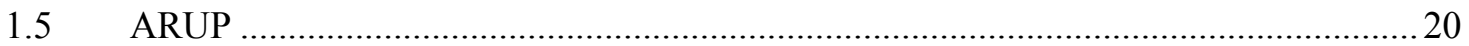

2 Chapter: Temperate \& Cold Climate Adaptations....................................................... 21

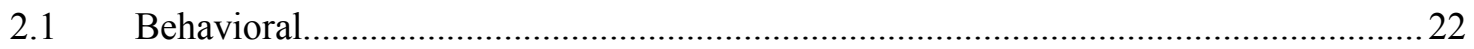

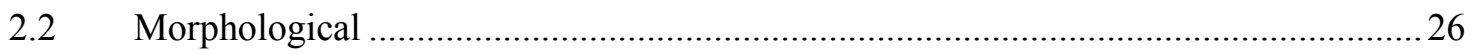

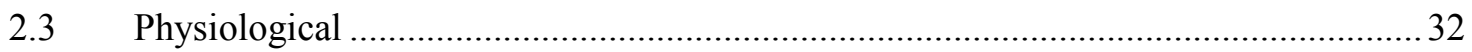

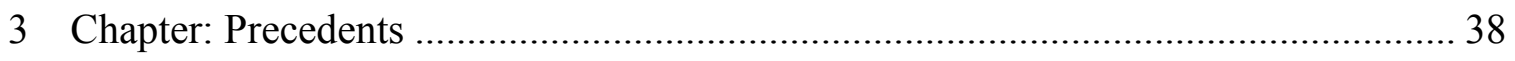

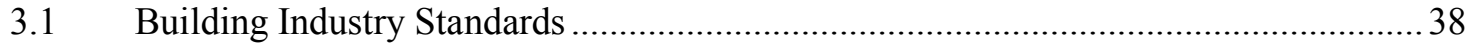

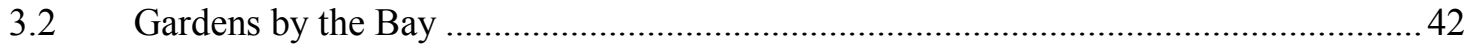

3.3 The Evergreen Brickworks ……………………………………………………....46

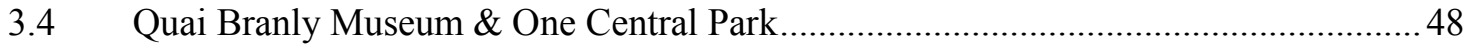

3.5 Planting Medium Systems .................................................................................... 51

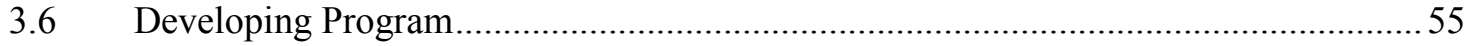




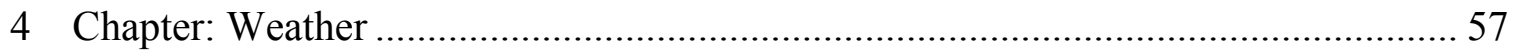

4.1 Weather \& Climmorphophysiological Architecture ..................................................57

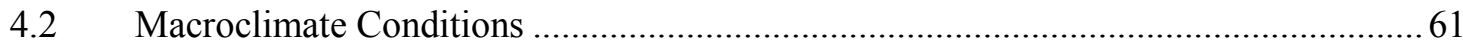

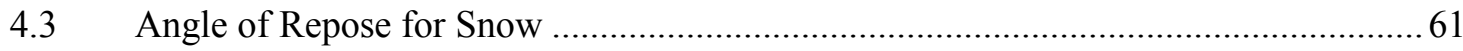

4.4 Percipitation Records, Prominent Wind Direction, \& Sun Angles............................... 62

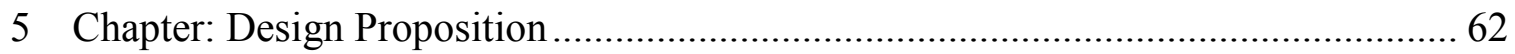

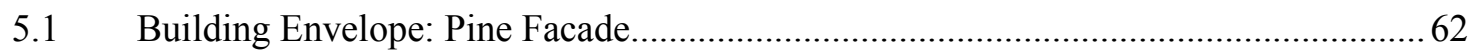

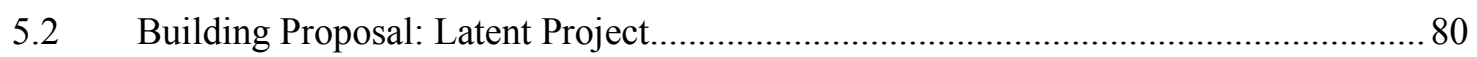

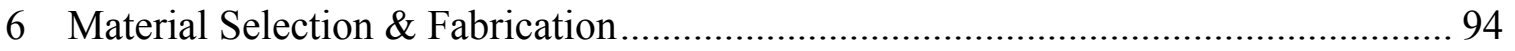

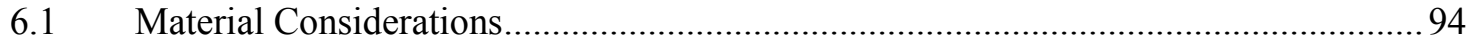

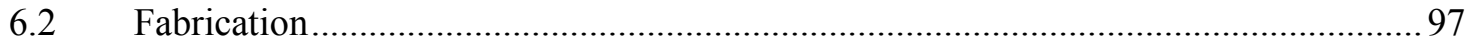

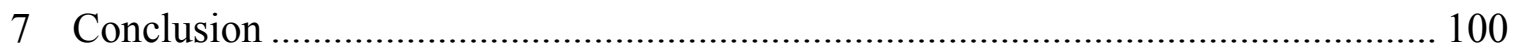

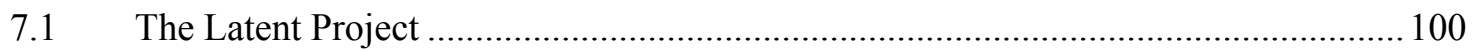

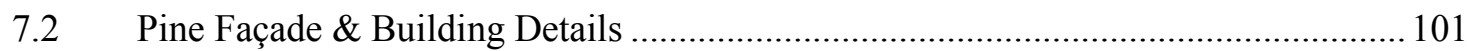

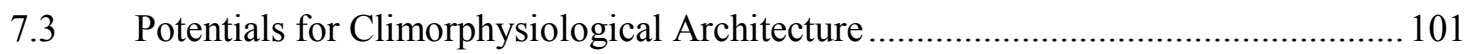

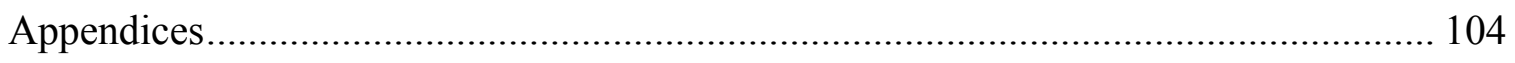

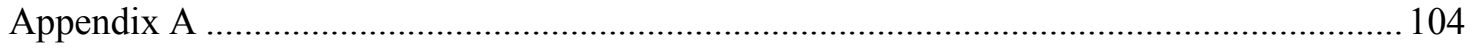

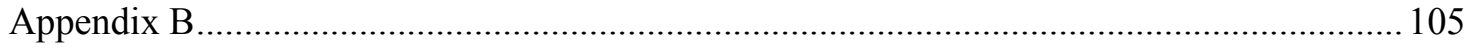

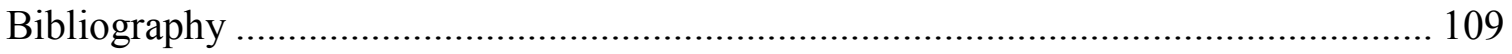




\section{List of Illustrations}

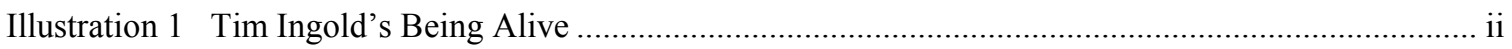

Illustration 2 Definition of Climorphysiological Architecture ….............................................................2

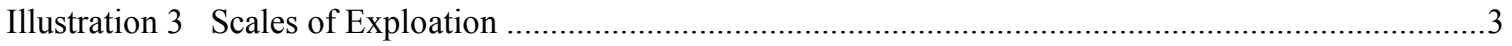

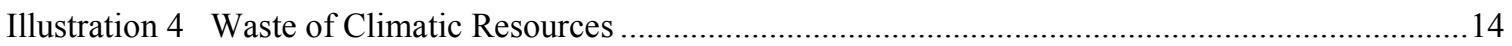

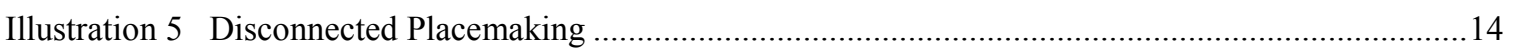

Illustration 6 Visualization fo Seasonal Architecture ..............................................................................16

Illustration 7 Mechanisms For Temperate and Cold Climate Adaptations...................................................21

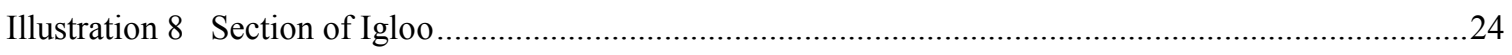

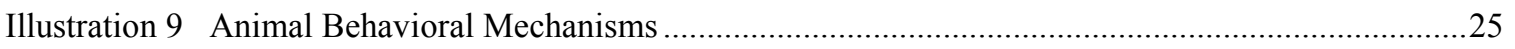

Illustration 10 Deciduous \& Coniferous Tree Morphological Mechanisms ................................................29

Illustration 11 Tundra Plant Morphological Mechanims ..........................................................................

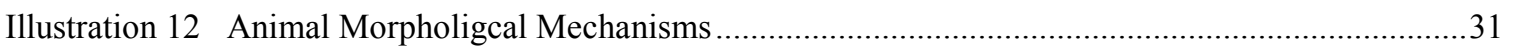

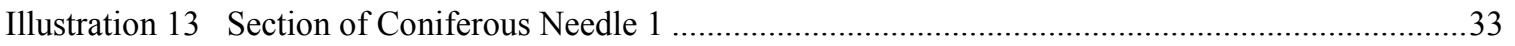

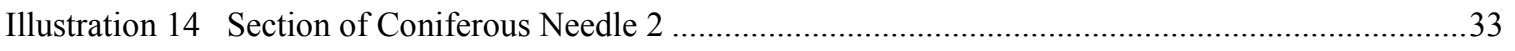

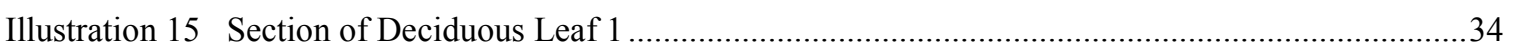

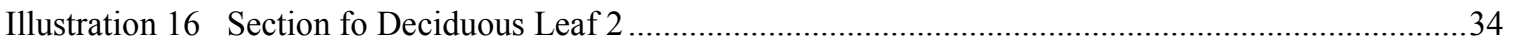

Illustration 17 Deciduous Tree Physiological Mechanisms .......................................................................35

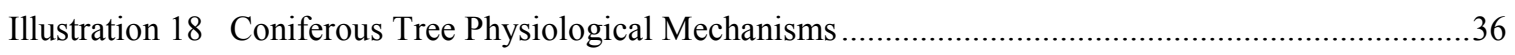

Illustration 19 Animal Physiological Mechanisms .............................................................................. 37

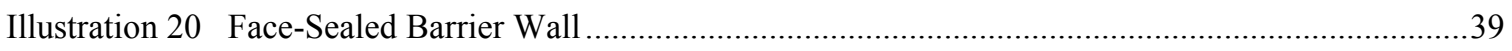

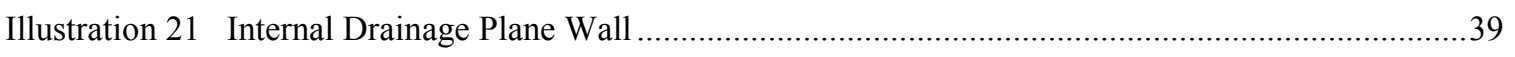

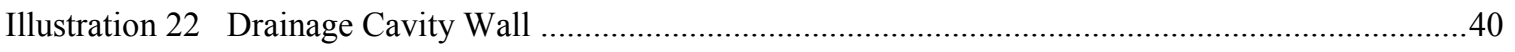

Illustration 23 Pressure-Equalized Rain-Screen Wall ......................................................................... 40

Illustration 24 Green Facades \& Green Wall Types............................................................................. 41

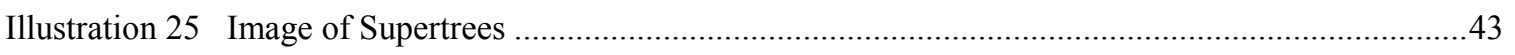

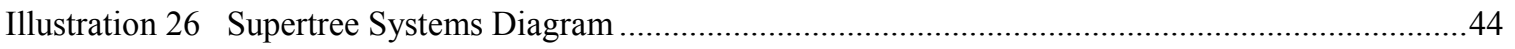

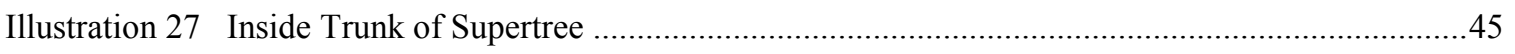


Illustration 28 Exterior Trunk of Supertree …………...........................................................................

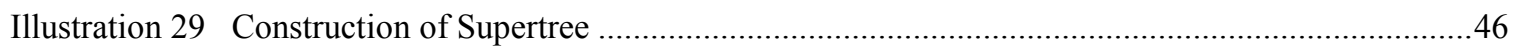

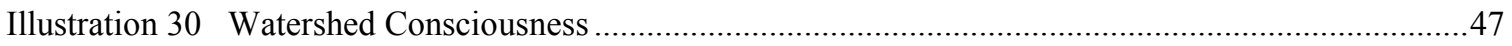

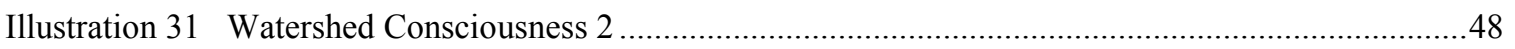

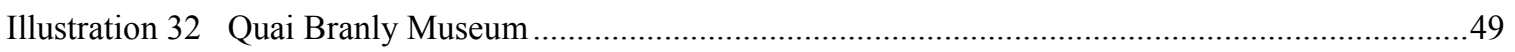

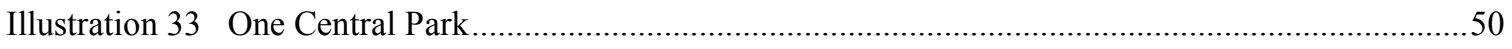

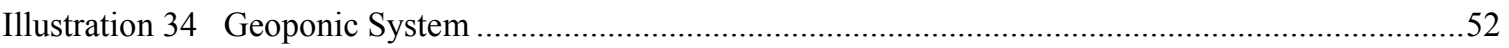

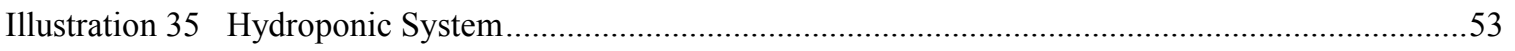

Illustration 36 Aeroponic System ..................................................................................................5

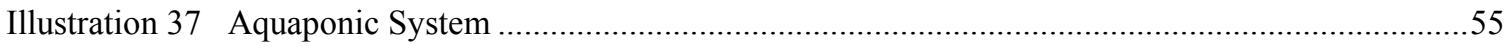

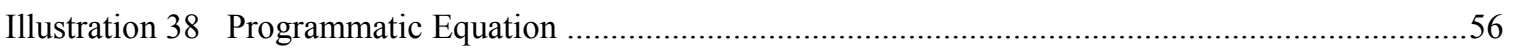

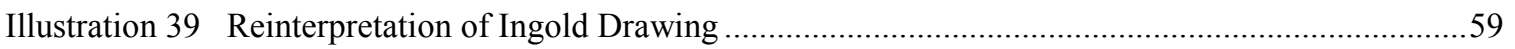

Illustration 40 Pine Façade Iteration 1 Components..................................................................................63

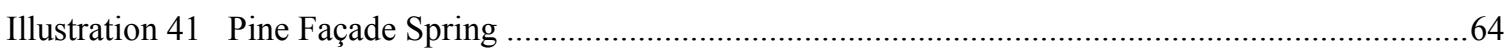

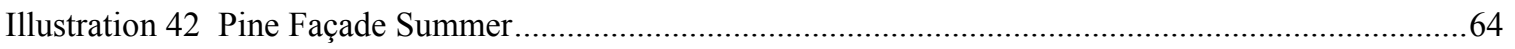

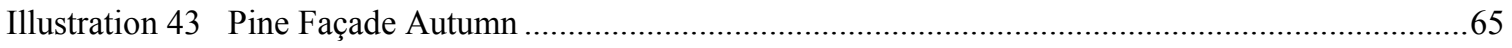

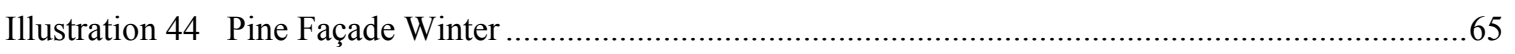

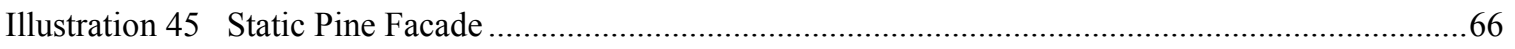

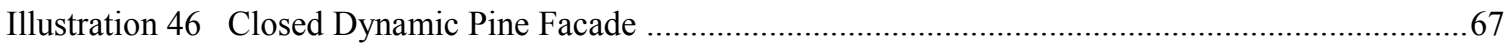

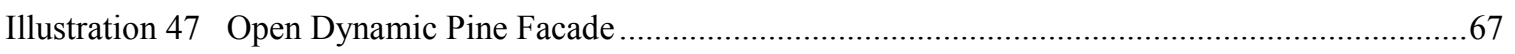

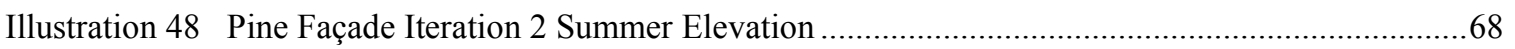

Illustration 49 Pine Façade Iteration 2 Winter Elevation .......................................................................69

Illustration 50 Pine Façade Iteration 3 Components 1 .........................................................................

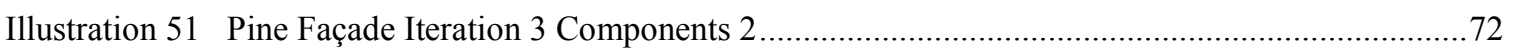

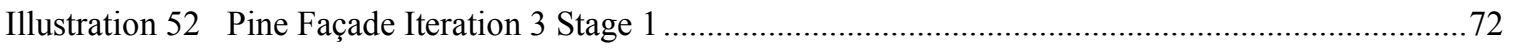

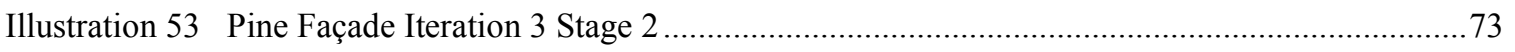

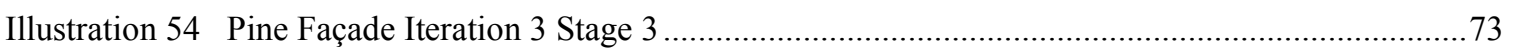

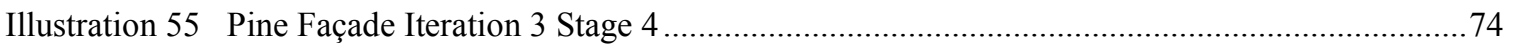


Illustration 56 Pine Façade Iteration 3 Stage 5 ........................................................................................ 74

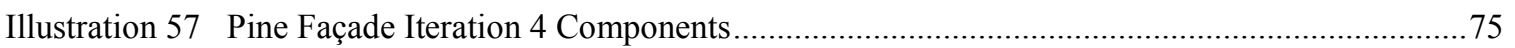

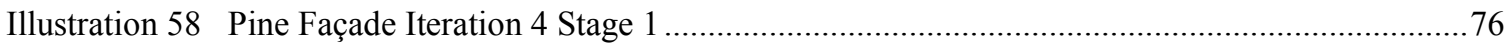

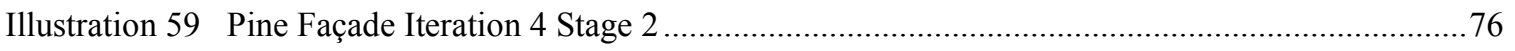

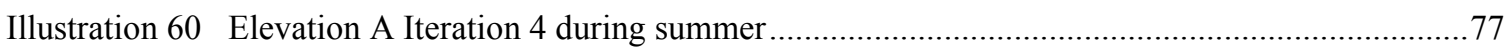

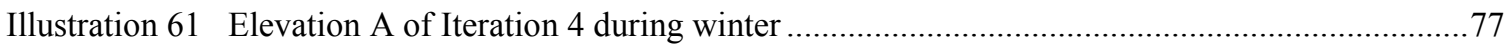

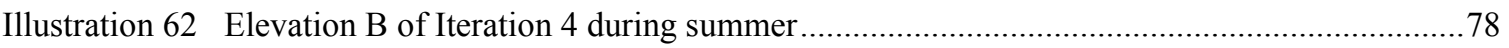

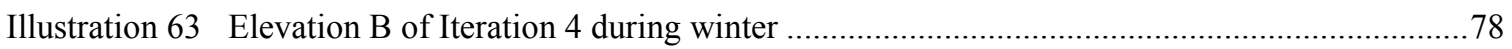

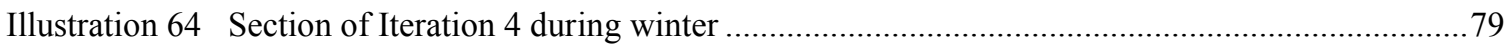

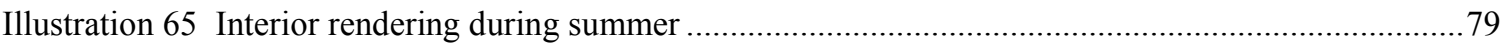

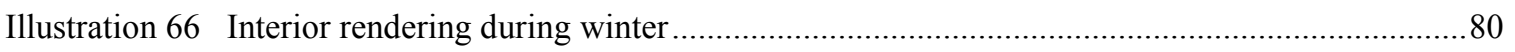

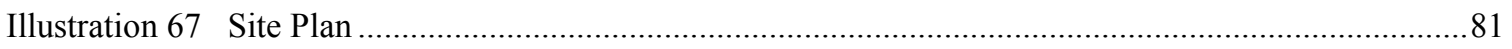

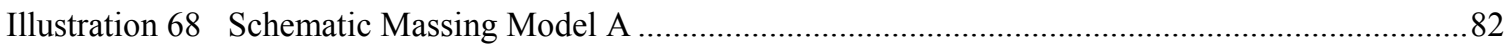

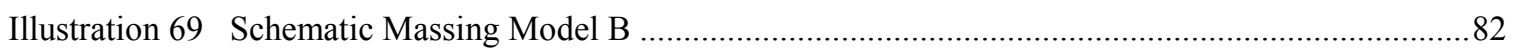

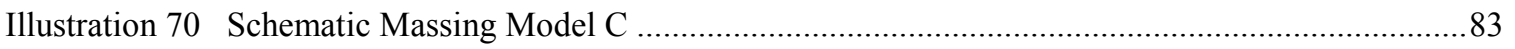

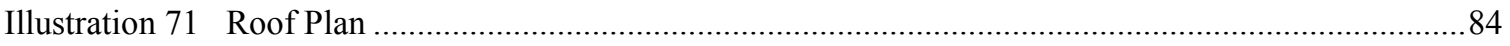

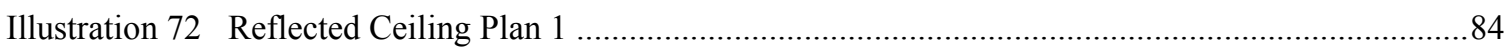

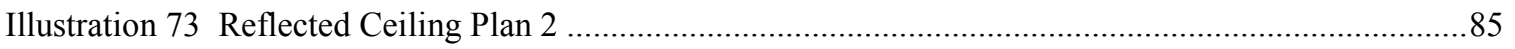

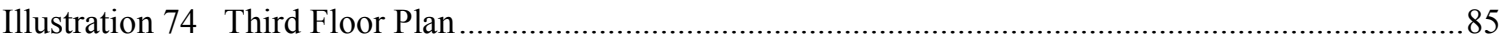

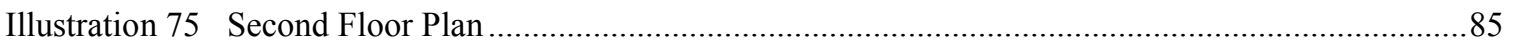

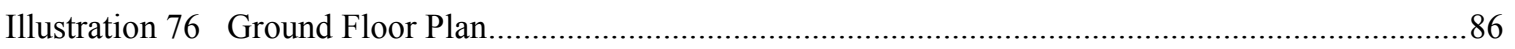

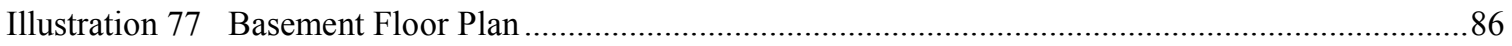

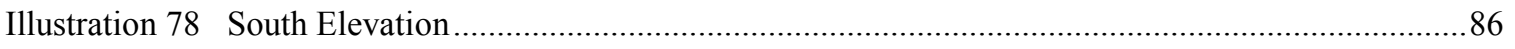

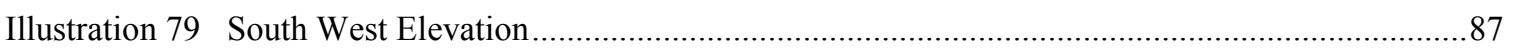

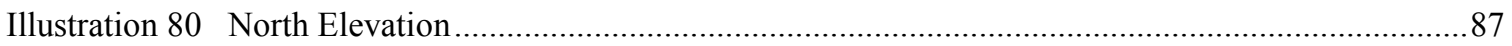

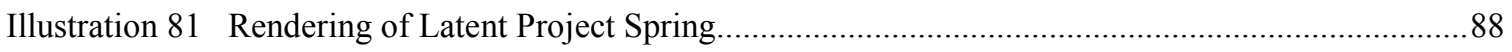

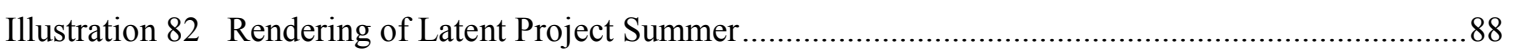

Illustration 83 Rendering of Latet Project Early Autumn..................................................................... 89 
Illustration 84 Rendering of Latent Project Late Autumn ............................................................................ 89

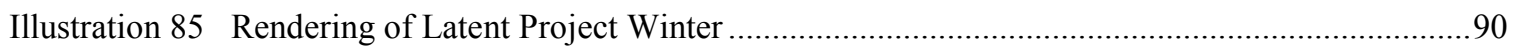

Illustration 86 Rendering of Latent Project early evening ........................................................................90

Illustration 87 Rendering of Latent Project in the Middle of the Night...................................................91

Illustration 88 Rendering of Latent Projet dock during Summer ..............................................................91

Illustration 89 Rendering of Latent Project dock during Winter ...........................................................92

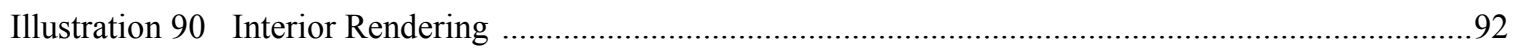

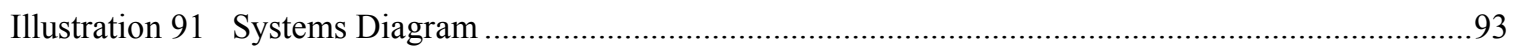




\section{List of Appendices}

Appendix A.......................................................... 104

A.1 Angle of Repose

Appendix B. ........................................................... 105

B.1 Solar Orientation

B.2 Monthly Snow and Rainfall Averages

B.3 Monthly Rainfall Averages

B.4 Monthly Snowfall Averages

B.5 Monthly Temperature Averages

B.5 Seasonal Wind Directions 


\section{Introduction: Contextual Situation of Climorphysiological Architecture}

Climorphysiological architecture is a term developed for this thesis to identify a type of architecture that is derived \& evolves from a site's specific climatic conditions. The building's assembly, purpose, form, and aesthetics turn to the site with a series of questions: Why should the architecture take one form over the other? What resources could be taken advantage of? What could be born within its' property limits and how would the site respond? Climorphysiological architecture has its theoretical foundation in a series of arguments that have arisen in the last two centuries. This form of architecture spans between disciplines and broadens the defining boundaries of what architecture can expand to incorporate. Biomimicry, construction standards, weather analysis, and architectural history were a few of the initial fields explored to formulate a critique all while striving to improve upon any problems, challenges, or opportunities revealed. Historically man's interaction with "nature" dates back to the beginning of civilization. However, we will focus on the last two centuries and the influence of the biological world has had on design.

Definition

CLIMORPHYSIOLOGICAL ARCHITECTURE

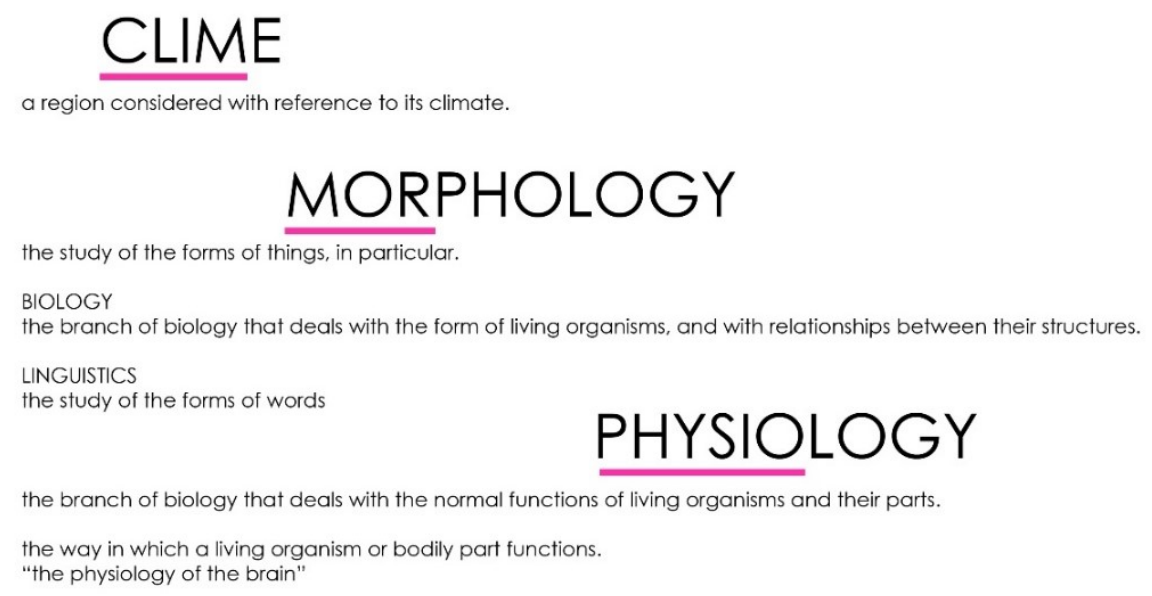

Illustration 2 Breaking down the definition of Climorphysiological Architecture 


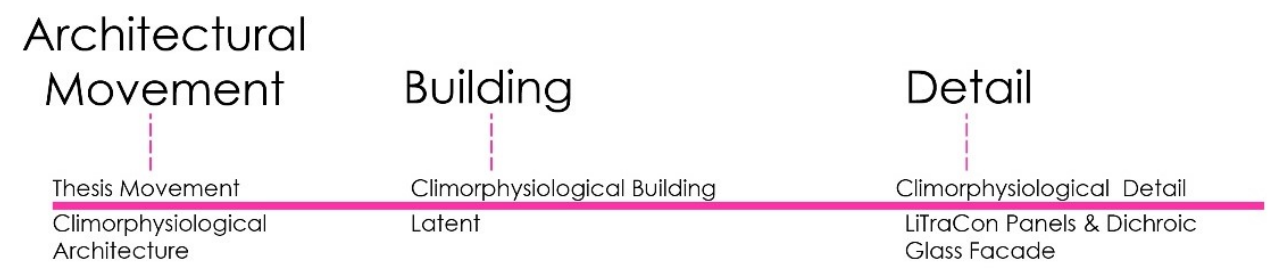

Illustration 3 Scales of exploration within the thesis project

The Art Noveau movement dates back to the 1880's where nature was inspiration to its formalistic style. The movement impacted artists and architects alike. The major features of this style included ornate curves, organic surfaces and natural hues. Charles Renee Mackintosh was a Scottish architect who practiced in the United Kingdom during the peak of Art Noveau. His designs such as the Glasgow School of Art used a holistic language throughout the entire building. Lighting fixtures, furniture design, and building details all incorporate similar nature based motifs that tied the building together.

"Art is the Flower. Life is the Green Leaf. Let every artist strive to make his flower a beautiful living thing, something that will convince the world that there may be, there are, things more precious more beautiful - more lasting than life itself." - Charles Rennie Mackintosh (Glasgow School of Art, 2015)

Similarly, Frank Lloyd Wright drew from nature as his source for motifs but began to experiment with the site and materiality as themes for architectural design. Many of his designs use geometric patterning through a single unit that is modulated throughout the house in plan, section, and elevation. This patterning and replication of a given module acts as the cell that composes the entire building. Wright referred to the architect as a weaver where the project "thread" must be woven into all elements of the building to 
achieve a complete internal and external composition. Floor heat, openings from the interior to exterior, and overhangs to shade large windows were aimed to improve the buildings function holistically. The horizontal line was a reoccurring theme that attempted to give authentic ornamentation for the process of fabrication used and relating back to the site. His projects embodied environmental design but did not follow biodesign nor biomimetic principles. The designs use modules much like natures cell but did not follow through with questioning the organisms function or purpose. How and why nature functioned in a particular manner was not the prime objective for this period in architecture. "What shape? Well, the answer lay in what material?"- Frank Lloyd Wright (Frampton, 2001)

Both Charles Rennie Mackintosh \& Frank Lloyd Wright serve as two prime examples of architects that strove to create an architecture inspired from the natural world. Both architects achieved a poetic and aesthetic relationship with nature but do not seek a further understanding as to why nature selected specific forms. This is a question Climorphysiological architecture inherently wishes to address.

Modernism was a totalitarian force that eradicated the old in favor for a new way of construction and theory. This had global effects on architecture as minimalist or reductionist approaches stripped architecture around the world of any decoration. Viewed as unnecessary, any additional décor was eliminated in an attempt to cleanse the built world. Modernism paved the way for the machine's promise to improve urban life. The 
aftermath of this revolution forced the architectural community to discern whether all of its impacts had been beneficial.

Kenneth Frampton \& Jane Jacobs from a critical perspective unveiled the detrimental attributes of modernism that needed to be readdressed in the following decades. These critiques have been influential in forming the basis of Climorphysiolocial architecture as they question the intelligence of globalized detailing and the compromises this architecture makes towards a "cultural whole".

Kenneth Frampton's Essays on Postmodern Culture: Towards a Critical Regionalism: 6 Points for an Architecture of Resistance explained the complications that came with globalized architecture. Generalized architecture that strips the city of any cultural identity will be one that is both placeless and meaningless to our society. (Frampton, 1983) He argues that modernization should not necessarily throw away inherited wisdom discovered by the evolution of vernacular architecture.

Within his writing the point "Culture \& Civilization" argues that modernism has actually limited urban forms. Architecture transcends purpose and beauty and has influential impacts on culture and civilization. If we adopt a globalized style and technique in building there is a loss of reason and expression. He explains Hannah Arendt's thesis where she argues if "in order to" becomes "for the sake of" all architectural meaning would be lost. (Frampton, 1983) Climorphysiological architecture standpoint that this meaning and purpose should be addressed by a case to case basis that looks specifically to the site and climatic conditions first for criteria to develop the project.

Frampton's point “The Rise and Fall of The Avant-Garde" discusses the continuous wave of agreement and disagreement in architectural history. Modernism was once viewed to 
be architecturally liberating with the intent of cleansing the industry of unneeded decoration, clutter, and disease. However as this philosophy was globally adopted, it became destructive to niche cultures that were flattened to make way for the utopian ideals of modernism. (Frampton, 1983) The detailing of a building no longer looked to the historical traditions, materials, and culture of a region but instead used globalized building standards. Climorphysiological architecture is in agreement with these statements. However in nature the best material and form are selected for the job. Vernacular architecture typically has risen out of a historical improvement upon traditions catered specifically to the region. These traditions will be studied but do not limit the thesis to the specifics of one form or methodologies of vernacular architecture. However, the reasoning behind the rational for choosing a technique, material, or process over another will be articulated.

Kenneth Frampton's point on "Critical Regionalism \& World Culture" argues that as modern technology is used globally the architectural motifs and cultures begin to blend together with one another. (Frampton, 1983) This point is left open to criticism. If the intent is that each specific region should have its' own identifier then the same generalized rule of "critical regionalism" is applied globally. Climorphysiological architecture runs into the same theoretical problem. Its strategies can be applied at global and localized levels of architecture. Globally, the earth is sectioned off into a variety of macroclimates based upon the earth's rotation and orbit, proximity to the sun during these rotations, and topographical characteristics. Naturally these macroclimates have existed and are where specific animals and plants have thrived while others have not. The manifestations of Climorphysiological architecture at a local level would all be drastically different from that 
at a global level. The best metaphor to describe this condition is seen in nature; a polar bear has adapted to life in the artic and is equipped to prosper there, much as a cactus is able to survive in desolate environments. Similarly architecture can adapt this view and question whether it is logical to continue building with standardized techniques. As the polar bear is to the artic, and the cactus is to the dessert, buildings should be to the site. Kenneth Frampton's point on "The Resistance of The Place-Form" reveals the importance of the "polis" for architectural survival. He infers that buildings that will withstand the test of time will come directly from a site specific architectonic approach. (Frampton, 1983) Arendt goes on to explain that power lies where there is a potential for action. (Arendt, 1998) Architecture both spatially and theoretically allow action to occur, whether that be social aggregation or a societal display of resonating cultural importance, it exists. The Place-Form is made from the site but bound to the polis of that region. Climorphysiological architecture takes this approach as a starting point. Climate changes and environmental awareness are topics for consideration. Architects need to engage these notions within their designs. Expanding society's collective technological intelligence and honing sustainable practices are on either ends of the spectrum. These two ends are in dire need of finding common ground. This mediation point or outcome between the two has the opportunity to become the Place-Form Frampton was discussing. This form of architecture has the potential to resonate with civilization as an overarching message of communal importance.

Frampton's point “Culture Versus Nature: Topography, Context, Climate, Light, and Tectonic Form" discusses the opposition that exists between modernization and the vernacular. One demolishes all in its path while the other seeks to preserve the natural 
condition or minimally have a relationship with it. (Frampton, 1983) Climorphysiological architecture however strives to exploit the benefits of both forms of architecture. Modernity strives to simplify the assembly processes and components integrated while the vernacular inherently has adapted to the climatic conditions and materials present. Topography, context, climate, light, and tectonic form are all elements analyzed in Frampton's critique but biomimetics is one missing element essential to the foundation of Climorphysiological architecture.

Frampton uses "The Visual Versus the Tactile" as a point to discuss the experiential qualities of architecture. Modernism has stripped our buildings tactile features. Light, darkness, heat, cold, smell, and sound have been reduced to sight. The hygienic, safety, and organization restrictions that modernism has brought to architecture have been customized to appeal to the eye. Frampton explains that modernism uses perspective as a means to engage society with architecture which only removes the occupant further from the sensorial experience. (Frampton, 1983) He suggests that architects re-engage all senses opposed to just the visual which brings things back to the proposed site. The haptic experience of a building will be evaluated in the field of Climorphysiological architecture. The other senses should be equally emphasized, instead of sight remaining the predominant sense. How the site blends with the building sensually will be fully emphasized. The smell, touch, sound, and taste should be incorporated to elevate the occupants' experience and interaction with the site. The human occupant is not the only consideration for this form of architecture though. The wildlife found on the site and their experience with the built form should be taken into account. How will the building engage, invite, and interact with any wildlife present? How will the ecosystem be influenced and would the building 
have a positive role on non-human occupants? These are questions the Latent project will explore further. ${ }^{2}$

Jane Jacobs was an influential journalist that proceeded to critique modernist urban planning in her book The Death \& Life of Great American Cities. Her thesis explained why modernism was a domineering force that destroyed fundamental principles attributed to thriving communities. (Jacobs, 1993) She stresses that diversity in built form is need to congregate a variety of people to help populate and maintain an area. Limited building program and restrictive zoning can be harmful to a neighborhood as it naturally minimizes the range of participating citizens. Areas that are more successful often program the space to be activated by a plethora of occupants throughout the day and during different times of year. The principle of programming a community that is diverse and can be multifunctioning can also be seen in the majority of symbiotic relationships in nature. Although Jacobs did not touch upon biomimicry, several underlying themes that are readily seen in nature are found within her writings on producing an effective neighborhood. Climorphysiological architecture looks to the natural world to draw inspiration and understanding but Jacob's recommendation in regards to programming and contextual understanding will be acknowledged.

William McDonough in Cradle to Cradle: Remaking the Way We Make Things explains how a healthy ecosystem relies on the waste of one organism being used as resource for another. This process creates a closed loop system which is crucial to solving problems of current disposal systems. (McDonough, 2002) In nature the term "garbage" does not exist as everything is recycled and used by other organisms. To prevent further damage to the environment a similar approach should be adapted by society. This concept relates directly 
back to architecture. How resources are being wasted and managed can reveal opportunities to be reused for other purposes. This philosophy is inherently adopted by Climorphysiological architecture. If nature looks to maximize the potential of every organism, architecture should similarly maximize the potentials of the given site.

The term "Vertical Garden" was coined by the leading expert in green wall technology, Patrick Blanc. Blanc is a landscape architect and botanist that has been designing experimental green walls since the 1970s. (Blanc, Vertical Garden Patrick Blanc, 2014) Blanc travels around the world collecting and observing plant specimen prior to constructing any green wall. He uses native and foreign plants to increase the likelihood of survival. He uses his knowledge of plant specimen to understand how they are found in the wild and why they thrive in certain conditions that replicate their natural environment and why others do not. Blanc's expertise in understanding plants and how they take to an environment is ideal for introducing wildlife to a new setting. Blanc's work will be discussed further in understanding building details failures and strengths when designing green walls. Where Climphysiological architecture departs from Blanc's work is in the customization of foreign plants to an alien habitat. His expertise on biology will be referred to but Climorphysiologically architecture argues against the use of foreign plant species having to adapt to unnatural settings. Specific plant species have evolved over generations to survive in a given climate and this branch of architecture is highly informed by biomimicry. If a given situation is not supported or found in nature then this solution should be reconsidered.

Dr. Dickson Despommer is acknowledged for coining the term "Vertical Farming". Like Blanc, Despommer envisioned plants as having a leading role in architecture. Where Blanc 
uses plants as an aesthetic device for improving the urban environment, Despommer wants to use it for agricultural purposes within the city. The vertical farms was designed to efficiently produce large quantities of produce for a growing global population. Current agricultural systems destroy soil nutrition and pollute water systems so much that in time civilization will render the land uncultivable. (Despommier, 2010) Climorphysiological architecture grows out of this theoretical foundation and the global food debate. Although farms in the form of skyscrapers seem like a farfetched idea, they mimic nature as it keeps man's food supply within reach of their habitat. As cities continue to grow vertically to avoid expanding agricultural land, alternative solutions need to be considered. No other mammal has the luxury of food coming to their dinner table from around the globe and it is time for this mindset to shift. Climorphysiological architecture addresses the importance of growing native plants but as it evolves and expands, this should go further to encourage local food growth. This form of architecture should address this concern as another branch that can use the specific microclimate of a given site as a way of gaining native agricultural knowledge.

Philip Beesley is one of the leading designers working towards creating a form of living architecture. Characterized by the ephemeral qualities of his work he has successfully created interactive installations that respond to occupants' touch, sound, and movement. Although these systems have not been implemented to become a building enclosure, his work brings a series of unanswered questions to the architectural world. He envisioned the architecture of the future to be embedded within nature where components would become integral to the ecosystem particularly through geotextiles. (Beesley, 2010) For installation purposes this form of architecture was more experiential then performative. The sentient 
city is one that can respond and sense its surroundings. This form of urban form opens up architecture to a series of new possibilities. Should architecture rely upon a highly complex open-source Arduino system to function or should it use basic principles of kinetic physics to perform? Should architecture have a form of programmable personality? How would the public respond to such a building through the course of their lifespan? How would society react to the demolition of a living building? Climorphysiological architecture has the potential to use similar concepts from Beesley's architecture but does so with extreme caution. The "personality" or "character" of a building is secondary to the need to engage with the elements and context of a given site. The dynamic qualities of the architecture should seek to fulfill a purpose first and foremost.

Biomimicry as defined by the Biomimicry Institute, "is an approach to innovation that seeks sustainable solutions to human challenges by emulating nature's time-tested patterns and strategies. The goal is to create products, processes, and policies - new ways of living - that are well-adapted to life on earth over the long haul". (The Biomimicry Insitute, 2014) Biomemetic architecture is the closest theoretical branch to Climorphysiological architecture. Both use nature as inspiration for design, however biomimetics focuses on one design element inspired by a specific organism or structure found in nature, while Climorphysiological architecture incorporates a variety of organisms as teaching mechanisms for the building as a whole. Building details to building mass is addressed within Climorphysiological architecture. This branch of design and science acknowledges 
nature's wisdom and the tremendous amount of untapped potential to solve the problems the machine has failed to do.

Biodesign is another subcategory of architectural green movement that differentiates itself from biomimicry by using actual living organisms within the architecture instead of copying its function. Plants, algae, bacteria, tissues, and fungus are all many examples that are integrated into the design.

"Biodesign goes further than other biology-inspired approaches to design and fabrication. Unlike biomimicry, cradle to cradle, and popular but frustratingly vague 'green design,' biodesign refers specifically to the incorporation of living organisms as essential components, enhancing the function of the finished work. It goes beyond mimicry to integration, dissolving boundaries and synthesizing new hybrid typologies." - William Myer (MoMA, 2012)

Climorphysiological Architecture embraces biodesign but does not limit itself to just using living organisms in its design explorations. Instead it uses biomimetic and biodesign principles collaboratively for determining which method is contextually appropriate and which is most beneficial to the building at hand. 
Wroblem

SPRING

Rain

Snow

Condensation

Fog

SUMMER
Rain
Hail
Condensation
Fog
Hign Sun Angle

AUTUMN

Rain

Frost

Snow

Condensation

Fog

Falling Leaves

WINTER

Rain

Freezing Rain

Snow

Ice

Fog

Low Sun Angle
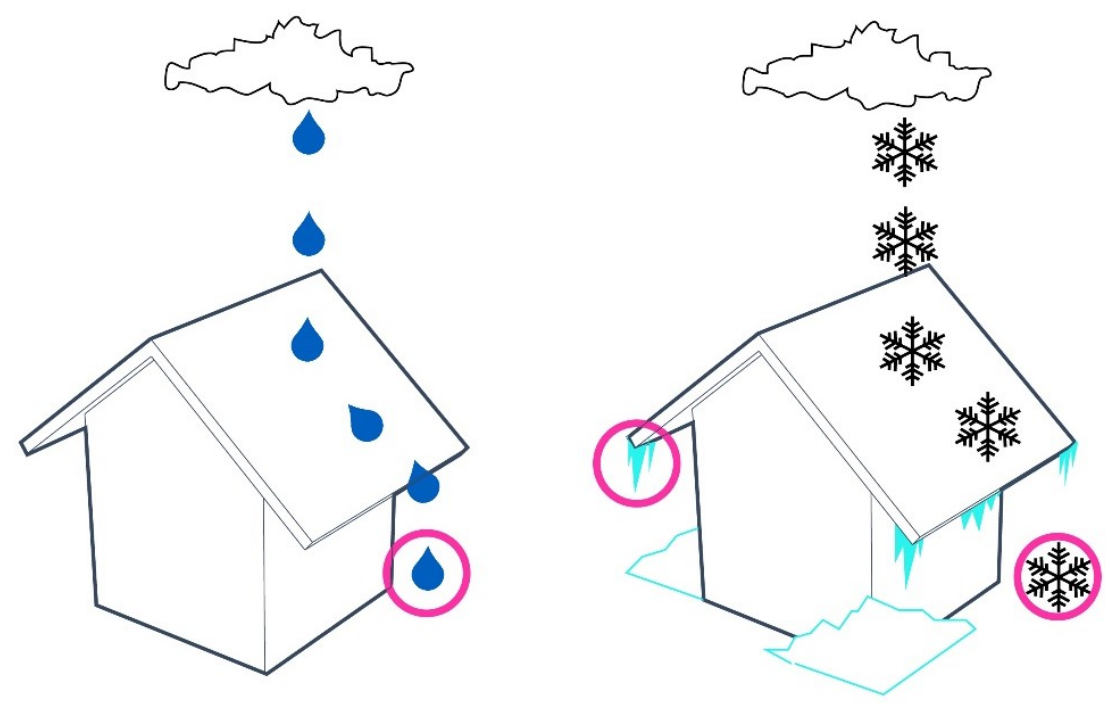

Illustration 4 The image depicts the four seasons and the associated wasted resources.

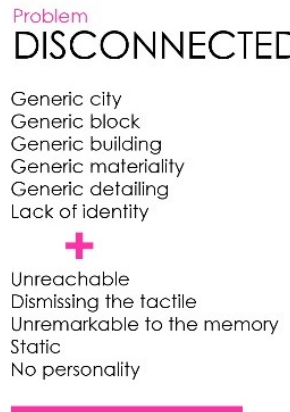

Monotonous Architecture

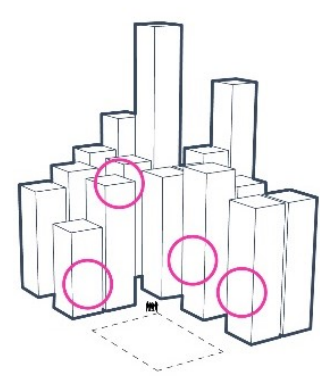

Modern
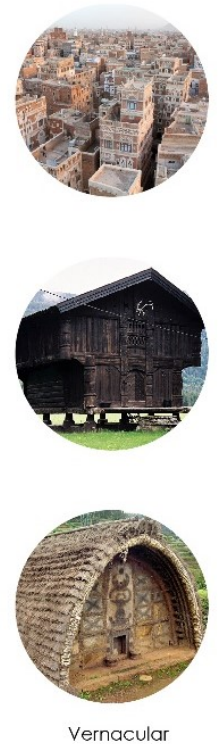

Illustration 5 The above illustrates strangers placed into a built context. The natural response to determine where they are located would be to turn to the architecture. Vernacular architecture on the other hand reveals the modules and materials found in the immediate environment. 
Climorphysiological architecture, as stated earlier, is a type of living architecture that is derived from \& evolves to a site's specific climatic conditions. If the site had the ability to evolve to develop an architectural proposition how would it respond? The response, without human intervention, would be one that would naturally thrive, evolve, and become an active component to the existing ecosystem. The microclimatic conditions such as sunlight exposure, soil composition, seasonal wind patterns, seasonal temperature predictions, annual precipitation, \& humidity records would inform the initial shaping of a building. The morphology of the building will be shaped to enhance performative function while the physiological (internal workings) of the building's respiratory (mechanical), metabolic rate (energy combustion), and vein distribution (plumbing and irrigation) must work symbiotically. The program and purpose of the building should come directly from its context and seeks to fill the gaps that the current community is missing. The following chapters discuss the main considerations in developing this new form of architecture. The global and local contextual implications of Climorphysiological architecture will also be explored. 


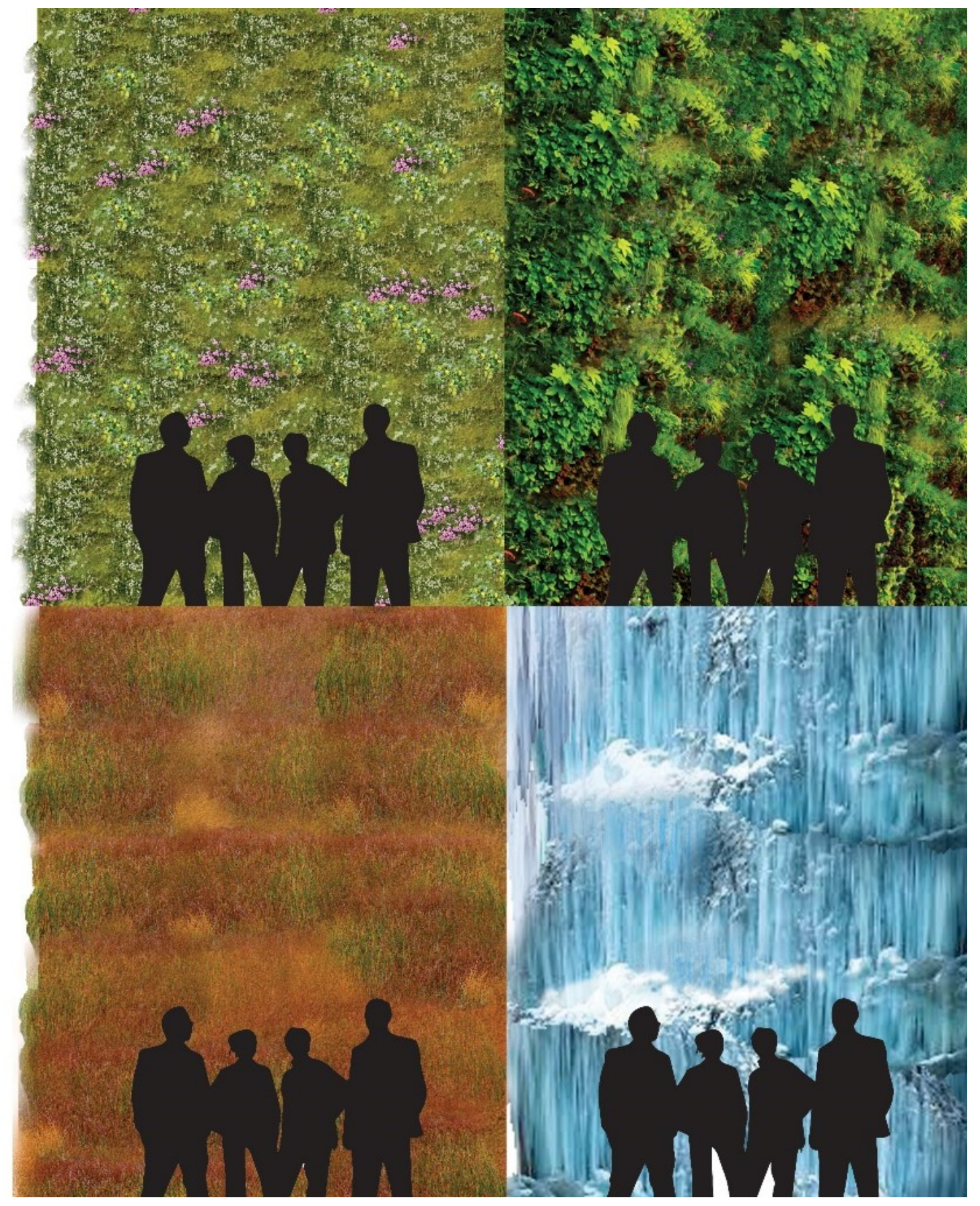

Illustration 6 The illustrations begin to describe a seasonal architecture. The initial conceptual drawings show a wall assembly that would alter seasonally. Although four distinct seasons are shown, weather is continually transitioning and the qualities of the wall should do the same. 


\section{Chapter: Industry Leaders in Biomimetics}

Biomimicry is a fast developing field that can be incorporated into the design industry to improve the discipline holistically. Defined by The Biomimicry Institute as "an approach to innovation that seeks sustainable solutions to human challenges by emulating nature's time-tested patterns and strategies. The goal is to create products, processes, and policiesnew ways of living - that are well-adapted to life on earth over the long haul". (The Biomimicry Insitute, 2014) This way of designing is beginning to break ground in developing sustainable solutions to everyday problems which further adds value to this thesis.

Academics and professionals in the building industry desire to develop and implement biomimetic technologies. Academically, students and professors are working collaboratively to access new ideas for exploration in both the theoretical and manufacturing worlds. While on the professional side, engineering and architectural firms are investing in in-house research units with the capacity to experiment with biomimetic technologies for building application. Biomimetic principles are considered noteworthy, such that a series of large institutes are being funded by the government, educational facilities, and private investors in order to pursue its' potential and applied possibilities.

\subsection{The Biomimicry Institute}

The Biomimicry Institute is an organization located in Missoula, Montana, USA, created by Janine Benyus and Bryony Schwan in 2006. (The Biomimicry Insitute, 2014) The main objective of the Institute is to create an open network of educational facilities, professionals, and designers able to spread knowledge regarding lessons nature inherently 
presents. This online resource allows designers to look to and ask what solutions nature has for problems we are facing in the built world. Sustainability, efficiency, and high intelligence are all goals interwoven within the institute's mandate. The online resource provides clear explanations of biomimicry and examples on how it can be utilized in the

design process. AskNature.org is a sister website that answers simple questions related to how nature solves problems. (AskNature, 2015) The database was started in 2008 and continues to grow.

\subsection{W.Y.S.S. Institute of Harvard University}

Harvard University located in Boston, Massachusetts, USA has focused a great deal of attention and funding to The W.Y.S.S. Institute for Biologically Inspired Engineering. At the Institute biomimicry has been used with the integrated design process to produce environmental and medical solutions. (The Wyss Institue for Biological Inspired Engineering, 2015) Their research is broken down into subcategories that are continuing to expand academic knowledge but have architectural applications as well. Adaptive Material Technologies, Bioinspired Robotics, Synthetic Biology, Biomimetic Microsystems, Programmable Nanomaterials, and Living Materials are several areas of interest for the Institute. (The Wyss Institute for Biologically Inspired Engineering, 2015) How could architecture evolve if a building could breathe in fresh air like lungs opposed to using mechanical devices? How could a building retain heat and evolve to insulate itself? How could a building modulate light as it enters? With the developments of such 
advanced materials and technologies it could be possible to combine the best of the technological and biological worlds.

\subsection{The Center for Architectural Science \& Ecology}

The Center for Architectural Science \& Ecology located in New York, New York, USA is another Institute involved in the industrial and academic biomimetic worlds. (CASE Centre for Architecture Science and Ecology, 2014) Acting as Rensselaer Polytechnic Institute (RPI) and Skidmore, Owings, and Merrill's (SOM) research division, it relies on experimental graduate and doctorate work for possible implementation into actual in-house commissioned work. Biomimetic principles are the main focus of sustainable design when striving to introduce innovative building technologies to the industry.

\subsection{Media Lab of Massachusetts Institute of Technology}

The Massachusetts Institute of Technology located in Cambridge, Massachusetts, USA, is working with Neri Oxman in the Media Lab with the main purpose of synchronizing advancing technologies and materials. (Oxman, About, 2015) Oxman oversees the Mediated Matter course that is establishing a discourse between emerging fabrication methods with the design of new systems and products. Her work with dual 3D printing analyzes organisms found in nature that use hard opaque structures as support for flexible translucent materials. (Oxman, Monocoque 1, 2015) Although the prints are tiny in size, one can imagine an entire building made of such materials. A structure of this sort would 
maximize functional interior space while the qualities of light filtering though would be modulated for both performative and experiential qualities.

\subsection{ARUP}

Arup Group Limited is a multidisciplinary engineering firm established throughout the world. Known for their diverse approach and ability to apply engineering expertise into new territories, their research division has begun to incorporate biomimetic principles. The building industry has used steel in various forms and applications but only recently has it begun to question the use of standardized components such as beams and columns. Recently they have been developing a 3D printed steel structural joint that acts much like bone found in mammals. (Lizotte, 2014) The areas receiving the force increase in thickness while those that do not are narrower. Arup acknowledges the potential that these new fabrication methods and design approach can have on the building industry by reducing both waste and cost using biomimetics. Biomimetics in this sense solves both problems related to environmental sustainability and bottom line profit.

Nature can provide answers to simplifying forms down to the minimum while optimizing function. The industry leaders have decided to take a different approach to design, one that may have previously been overlooked for mere aesthetic consideration. Climorphysiological architecture addresses this discourse with biomimetics by asking 
similar questions and considering what may be learned from nature, specifically within the Canadian context.

\section{Chapter: Temperate \& Cold Climate Adaptations}

Climorphysiological architecture was discussed as a theoretical concept in the last chapter but its implemention brings on an entirely new set of questions regarding the building and its details. What was the program of the building specifically? How could the scope of the project be narrowed down? The Dow's Lake site was selected for the design proposition to begin developing a form of Canadian architecture that could extract specific weather statistics for design analysis. Prior to the design proposition the biological world was explored in an attempts to understand what existed and more importantly why it existed that way.

Canada has four distinct seasons with varying temperature fluctuations. The extremes of hot summers and frigid winters exist in many regions across Canada. This knowledge directed the research towards animal and plant coping mechanisms that have adapted to cold climates. From this, three categories emerged; behavioral, morphological, and physiological. (Russell, et al., 2009) As each category was investigated the question of how each could be applied to architecture followed suite.

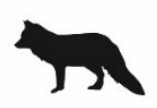

Morphological

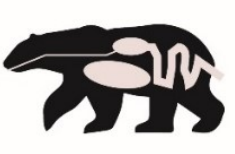

Physiological

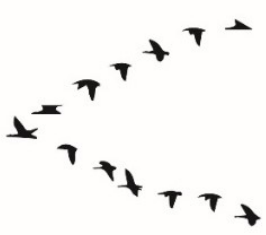

Behavioral

Illustration 7 Three main mechanisms for temperate and cold climate adaptations 


\subsection{Behavioral}

Behavioral is defined as "involved, relating to, or emphasizing behavior". (Google Dictionary, 2015) In this thesis, it refers to the behavioral coping mechanisms that animals have developed to survive in extreme temperature fluctuations. Plants were not considered in this category as they are not capable of having behavioral attributes. Depending upon the animal the research revealed several behavioral methods an animal could choose: to migrate, seek shelter, or alter their posture.

The Canadian Goose is a prime example of an animal that migrates south to warmer climates in the heart of winter. For survival purposes certain animals cannot withstand the drastic temperature drop and, in order to maintain healthy body temperatures, migration towards the equator is necessary. (World Science Festival, 2014)

This thesis did not adopt this mechanism as a methodology. This would entail a form of nomadic architecture that would remain consistent in form but could be easily moved from one place to another. Due to practicality issues this was not considered. Additionally, underlying theoretical problems would still exist with this form of architecture.

An alternative behavioral trait utilized for surviving cold climates was to seek shelter or use available materials to make one. Nests made of twigs, leaves, and grass are additive structures, while burrows are subtractive structures made from digging into snow or earth. These structures create a barrier of protection from the immediate environment. The body heat of the animal would be emitted and circulate in the confinement of the shelter to warm the inner microclimate. (Russell, et al., 2009)The temperature difference from the exterior to the interior of the shelter is enough to keep the mammal's heart rate and body temperature above freezing. 
This behavioral mechanisms of survival can also be seen while examining North American Aboriginal Peoples. They needed to cope to extreme climates with the resources available to them prior to modern technology and building materials. A series of sheltering strategies that would adjust to temperature drops were adapted. The two most notable forms of shelter being the longhouse and the igloo. Similarly, each shelter was built from the materials that were available within travelling distances.

The longhouse was most commonly found within the temperate regions of Southwestern Ontario and Quebec, Canada. The longhouse was used for several families within an aboriginal tribe. Constructed from bent saplings, tree bark and hardwood the wood formed the main structural elements of the longhouse while the bark acted as a wind break and protective barrier. Grasses, twigs, and hide were used as insulation between the bark and the interior. The heat attained from the fire pit and body heat warmed the interior. (McMinn \& Polo, 2005) A series of rudimentary chimneys lining the length of the longhouse allowed the smoke to escape the enclosure. 
The Inuit people of the artic had minimal materials to work with as there was little to no vegetation in the region during winter months, leaving construction materials to snow and hunting by-products. The Igloo was dug into the snow and constructed from cut blocks of compacted snow and ice. These blocks were stacked in a spiraling arch form to make the vault of the igloo and an entrance tunnel was made to prevent heat from escaping and wind from entering. A lantern, a fire, and emitted body heat is enough to maintain a comfortable temperature for occupation. Even with minimal heat sources it was recorded that the interior of an igloo can be kept up to 40 degrees Celsius higher than the exterior temperature. (Hoyt, 2014) The igloos interior temperature being drastically different from the exterior temperature causes the inner layer of the igloo to go through freeze thaw cycles. The molecules of the snow increased the igloo's structural stability as the snow compresses and solidifies.

Inuit $\mathrm{LOO}$

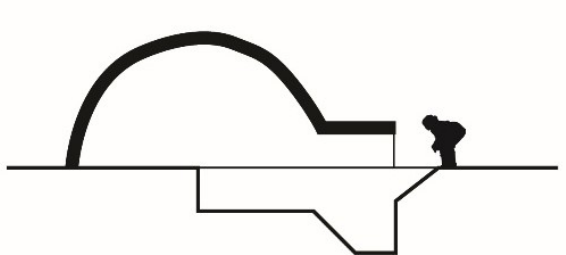

Constructed of packed snow \& ice

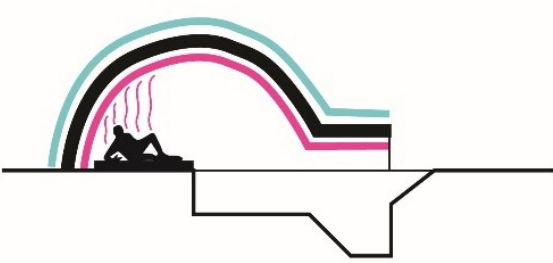

Body heat warms space

Illustration 8 Shows a diagrammatic igloo in section and its method of retaining heat. 
Climorphysiological architecture already seeks to provide shelter using knowledge attained from the surrounding environment so this behavioral coping mechanism is readily incorporated into both the design and theoretical portion of the discussion.

The last behavioral mechanism to deal with extreme climate fluctuations is posture. The basic principles of thermodynamics explains that heat wants to dissipate from the hottest location to the coldest or where heat transfer is attempting to reach a state of equilibrium. The heat source being the warm blooded mammal will lose its heat to the external environment which is cooler. In order to reduce the rate of heat exchange the mammal reduces its surface area by curling up and compacting its body. The artic hare for example will withdraw its extremities and become as spherical as possible. (O'Neil, 2012)

The alternative to posture is for the animal to move around. In doing so heat is generated but it is at the cost of energy expulsion. This method is not used by animals unless necessary as food sources are low during winter months.

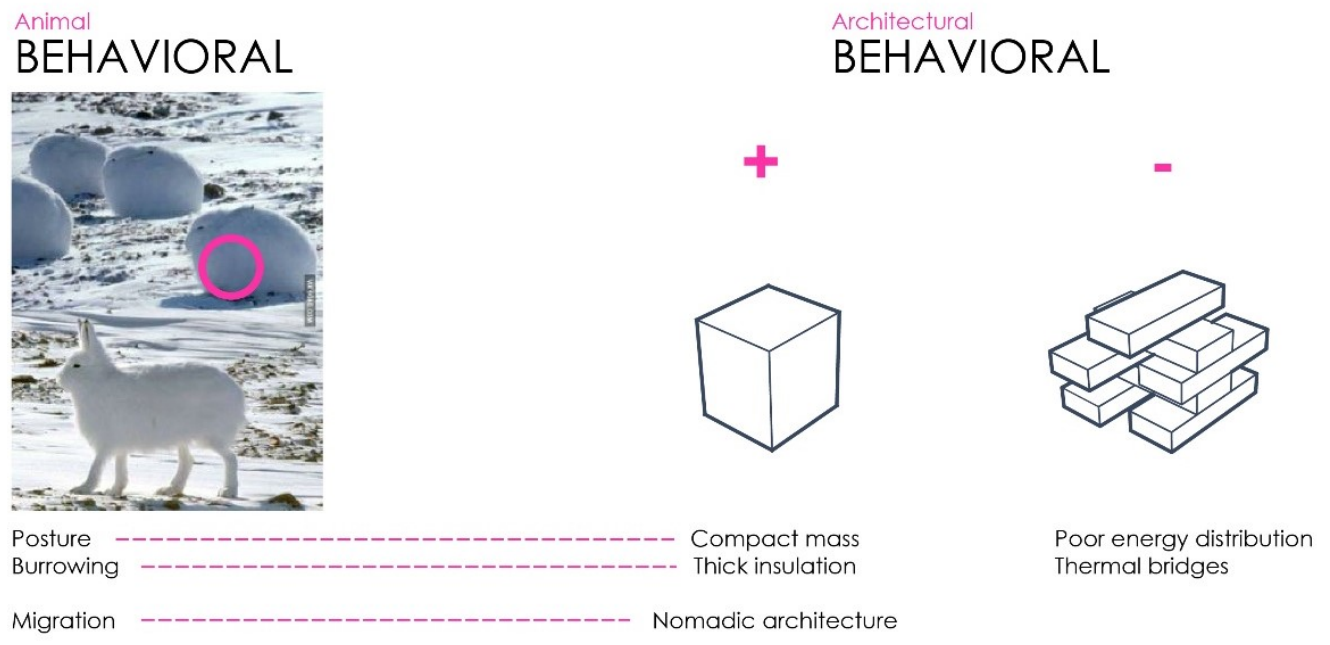

Illustration 9 Illustration shows the behavioral mechanisms seen in nature and potential applications to the architectural world. Positive and negative attributes of how this tactic could be drawn into Climorphysiological Architecture were evaluated. 
This behavioral mechanism returns to Climorphysiological architecture and how it may have the capability to transform depending on the given seasonal conditions. During summer months exposed surface areas (fenestrations, openings, or building envelope) should increase in value to cool the building, while during winter months these forms and openings should be restricted to maintain building heat. This notion could be pushed to the extreme where an entire building could physically compress and expand during a given season to conserve energy. In short this form of architecture should be able to sense climatic changes and alter its "bodily" composition accordingly for optimized building performance.

\subsection{Morphological}

Morphology is defined as "the branch of biology that deals with the form of living organisms, and with relationships between their structures." (Google Definitions, 2015) In this thesis it refers to the morphological coping mechanisms that animals have exhibited to improve tolerance and endurance to extreme temperature fluctuations. Plants and animals were both taken into consideration for this category. It should be noted that morphological and physiological survival mechanisms can be interrelated and ones discussed will be reinterpreted in separate potions of the chapter.

\section{Plants}

Vegetation can be categorized into annual and perennial plants and deciduous and coniferous trees. Each category has a distinguished way of surviving cold climates.

In the case of annual plants they live for three seasons and the cold winter kills the plant entirely while perennial plants have the ability to regrow each year. Perennial plants die 
down to the root during winter but are able to regenerate plant growth the following spring. (Russell, et al., 2009)

The potential implications of these adaptations are not practical solutions to Climorphysiological architecture. The building could not retreat underground for the duration of winter and re-establish itself in the spring. The alternative suggested a building that could grow and die much like an annual plant. However, how a building would be able to safely "die" brings more questions than solutions. How could a building safely become biodegradable for both the occupants interacting with the building and the environment responsible for absorbing it into its' soil? These solutions could have been an appropriate avenue Climorphysiological architecture had the opportunity to explore but was not ideal for the designing of a stable and long-lasting building. This shifted the focus to deciduous trees and coniferous trees which unlike the perennial and annual plants survived throughout the winter both exhibiting different morphological attributes.

A [lants survival relies on water and essential nutrients. During the winter months a plant goes through desiccation. Although water can be found surrounding the plant in the form of ice and snow this type of water cannot be utilized or absorbed by the plant. As the temperature dips below zero ice crystals form which become detrimental to the plant. These ice crystals block water dispersion from the plants root system to its leaves or conifers. This is where deciduous and coniferous trees vary. (Russell, et al., 2009) Deciduous trees, morphologically speaking, can be examined at three separate levels; looking at the tree as a whole, the leaves, and its microscopic components. The deciduous tree is composed of a trunk and a network of branches. The branches themselves extend out and upward to enlarge the canopy. The upward facing canopy and leaf arrangement 
optimizes solar collection for photosynthesis to occur. The broad shaped leaves on deciduous trees are packed with chlorophyll and stomata. The leaf's surface area optimizes photosynthesis to occur while on the underside of the leaf the stoma are located to conserve water loss through transpiration. (Russell, et al., 2009)

Although the leaves are efficient energy collectors, during warmer weather as the weather shifts, ice crystals accumulate and block water transportation to the leaves. As desiccation occurs the leaves do not have enough nutrients and water to produce healthy amounts of enzymes. The active enzymes necessary to keep the leaf healthy are no longer being produced and therefore the leaves dry out, change colour, and fall off. (Russell, et al., 2009) Additionally the weight of the snow on this form of leaf would be detrimental to the tree. The large surface area of the leaf would collect snow and the additional weight on the tree would result in branch damage. This regeneration of leaves has allowed to optimize the energy collection in the summer months while in winter the tree remains in a state of rest until warmer weather can allow sufficient water flow to the branches tips.

Coniferous trees are prone to the same weather fluctuations as deciduous trees but have adapted to have year round photosynthesis. The tree as a whole unlike the deciduous tree slopes downward. The branches additionally are much more flexible and able to tolerate seasonal weight oscillations. (BBC, 1984) The physical shape of the needles (conifers) becomes important when understanding snow accumulation. A flat surfaced leaf would accumulate snow but the weight accumulation would damage the tree. A needle on the 
other hand punctures the snow breaking it down to be shed off of its downward slopped branches.
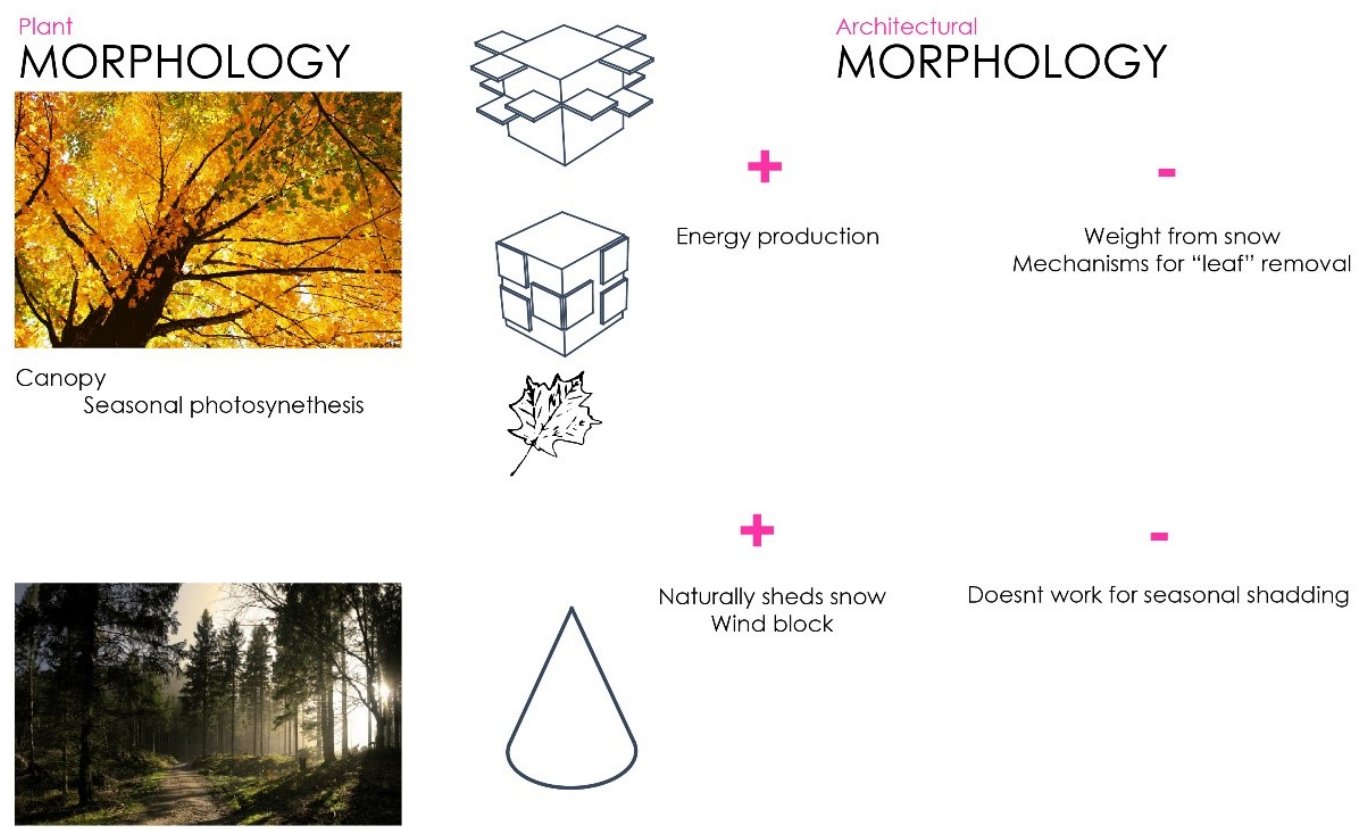
Mechanisms for "leaf" removal
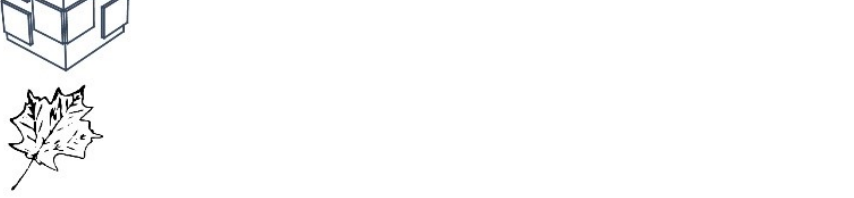

Seasonal photosynethesis

Downward Slope

Year round photosynthesis

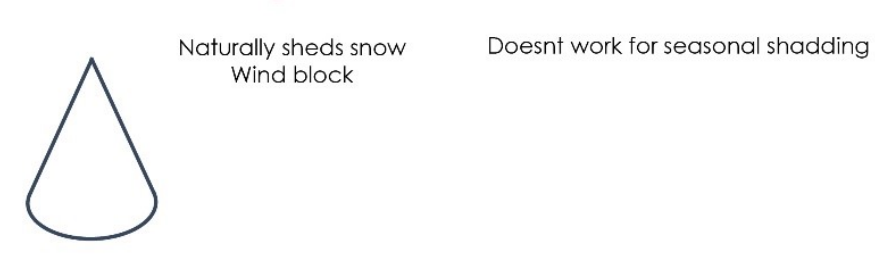

Illustration 10 Deciduous \& Coniferous tree morphological considerations for Climorphysiological Architecture

These two approaches, the coniferous and deciduous approaches could be used in Climorphysiological architecture. An architecture that optimizes its structures for efficient resource and energy conservation are all prime objectives for the future. Deciduous trees however do not endure winter survival as coniferous trees. Coniferous trees are responsible for year round energy collection and effective water distribution during cold months. 
Climorphysiological architecture could argue both methods of approach, but the coniferous tree is one of resilience and strength opposed to dismissing the elements winter brings. Tundra vegetation was also examined to see the principles exhibited in one of the most extreme climates, the artic. The main morphological qualities included short in height, grew in clumps, followed the sun, was dark in colour, and leaves had a waxy resin coating. (O'Neil, 2012) The small height and growth formations was a direct cause of high wind altitudes. If the plant grew individually and too high the lift of the wind would remove the plant off the growing medium and it would not survive. These plants need to follow the sun to optimize their photosynthetic potential, as not collecting enough energy could be futile to the plant. The dark colour and waxy resin is used to retain water and heat.
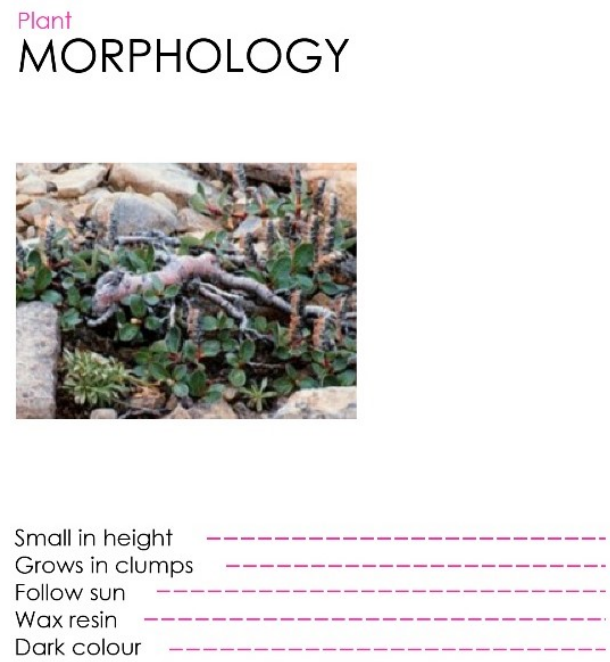
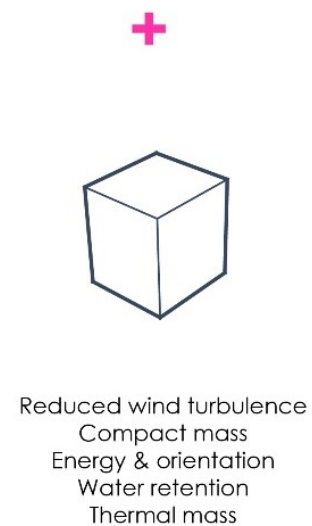

Architectural

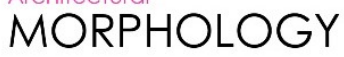

Thermal mass

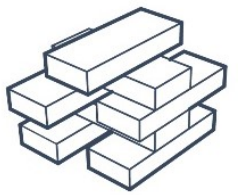

Wind turbulence Wind turbulence Ineffective orientation \& production Water distribution Overheating in summer months

Illustration 11 Tundra plant consideration for Climorphysiological Architecture

\section{Animals}

Animals, dependent upon the species, had several morphological adaptations to effectively sustain life in Northern climates. As a generalization, the main features were a stout body shape, thick fur, layers of fat, minimized appenditures, and camouflaged fur. (O'Neil, 2012) 
The body shape and minimized appenditures are necessary to minimize heat loss. As flesh cools, blood flow is restricted, limiting the amount of oxygen to the tissue which can be detrimental to the animal. (Tattersall, et al., 2012) The more compacted the body, the less surface area exposed to the elements. Ears, noses, and paws all have a high surface area to volume ratio which equates to large heat losses for the animal. Minimized bodily extensions avoids heat exchange with the exposed portion of the animal, therefore increasing its likelihood for survival. Wind \& water from the external environment would cool the body temperature. Thick layers of fur and fat on the animal in short create a barrier that traps in heat and protects from the exterior elements. Lastly, camouflage is used to hide oneself from predators and provide opportunities to attack ones pray.
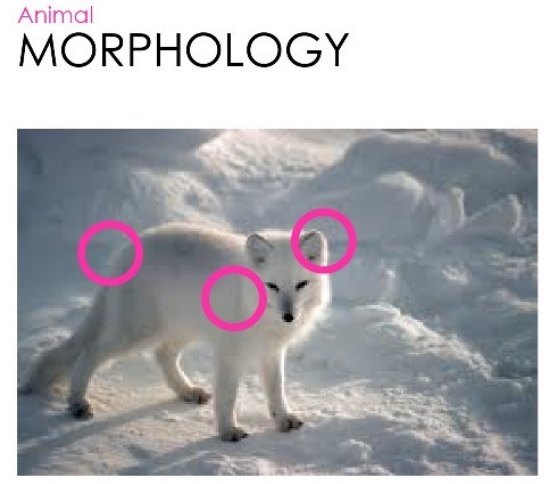

Stout body shape

Thick fur

Layers of fat

Minimized appendatures

Camouflage

Architectural

MORPHOLOGY

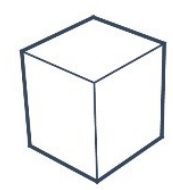

Compact mass

Thick insulation Sealed openings \& minimal surface area

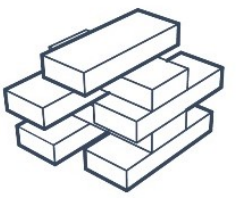

Poor energy distribution Thermal bridges

Exposed surface area

Illustration 12 Morphological considerations of animals to be integrated into Climorphysiological Architecture.

Climorphysiological architecture should strive to incorporate these principles into its design process and building details. In Canadian climates the most appropriate form the building could take is one that is as compacted as possible. This form would reduce heating and cooling loads, and minimize heat transfer from exposed surface area. The building 
envelope and associated insulation should be customized for the region the building is situated.

\subsection{Physiological}

Physiology is defined as "the branch of biology that deals with the normal functions of living organisms and their parts: the way in which a living organism or bodily part functions." (Google Definitions, 2015) In this thesis it refers to the physiological coping mechanisms that both plants and animals have exhibited to survive extreme temperature fluctuations. Plants and animals were both taken into consideration for this category. It should be noted that morphological and physiological survival mechanisms can be interrelated. Discussions will be reinterpreted through both lenses in separate portions of the chapter.

\section{Plants}

The coniferous needle and the deciduous leaf function on a physiological level extremely differently. The coniferous needle produces year round photosynthesis while the deciduous leaf only produces photosynthesis during summer months. The stoma are extremely important for water conservation and the survival of any given plant. 


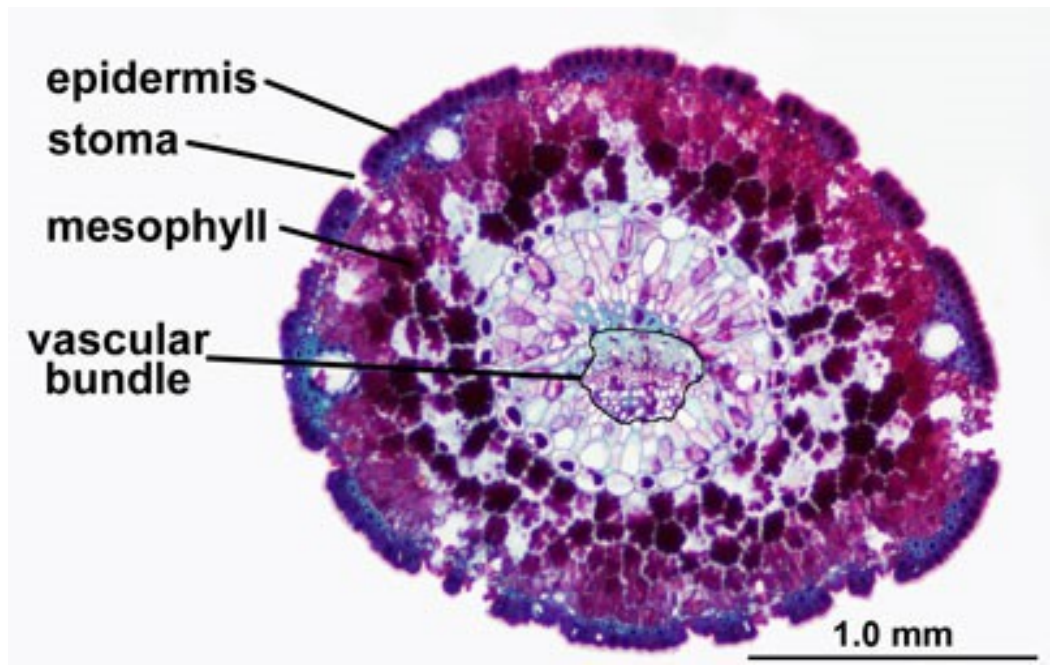

Illustration 13 The microscope slides show the section of a needle taken from a coniferous tree. (McCauley, 2015)

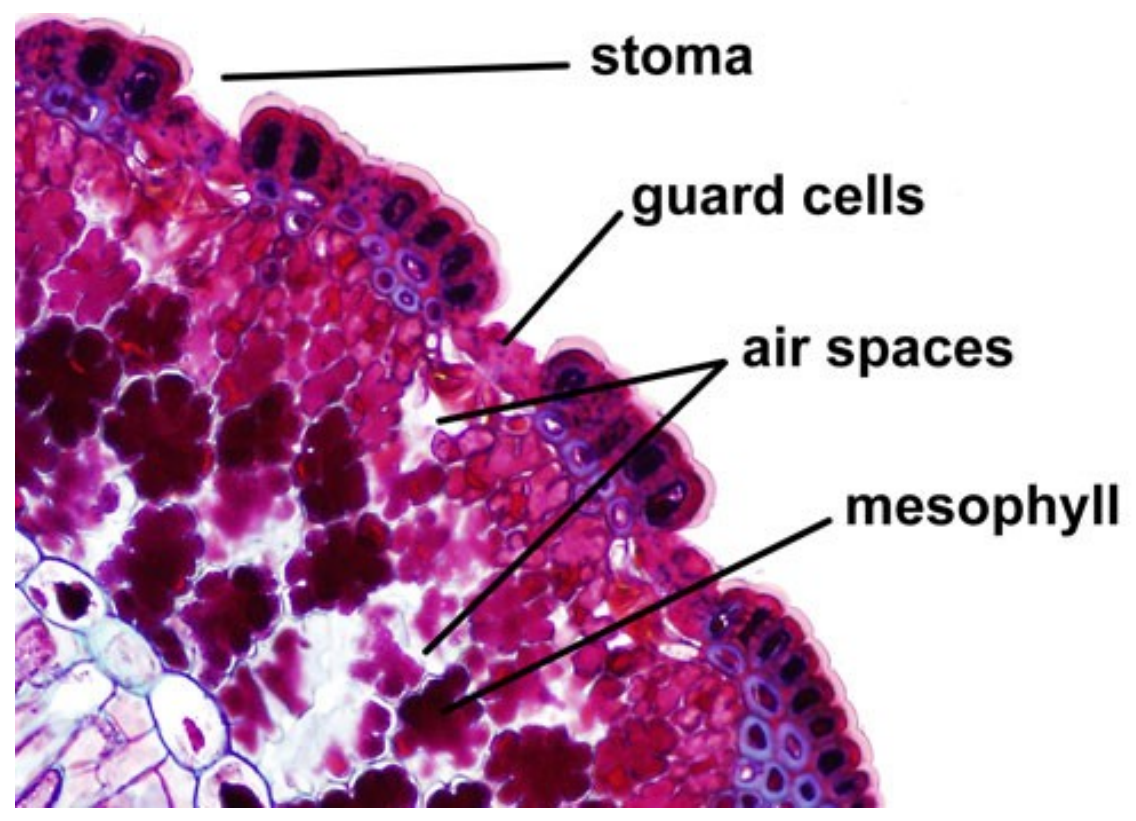

Illustration 14 The microscope slides show the components of a needle taken from a coniferous tree. (McCauley, 2015) 


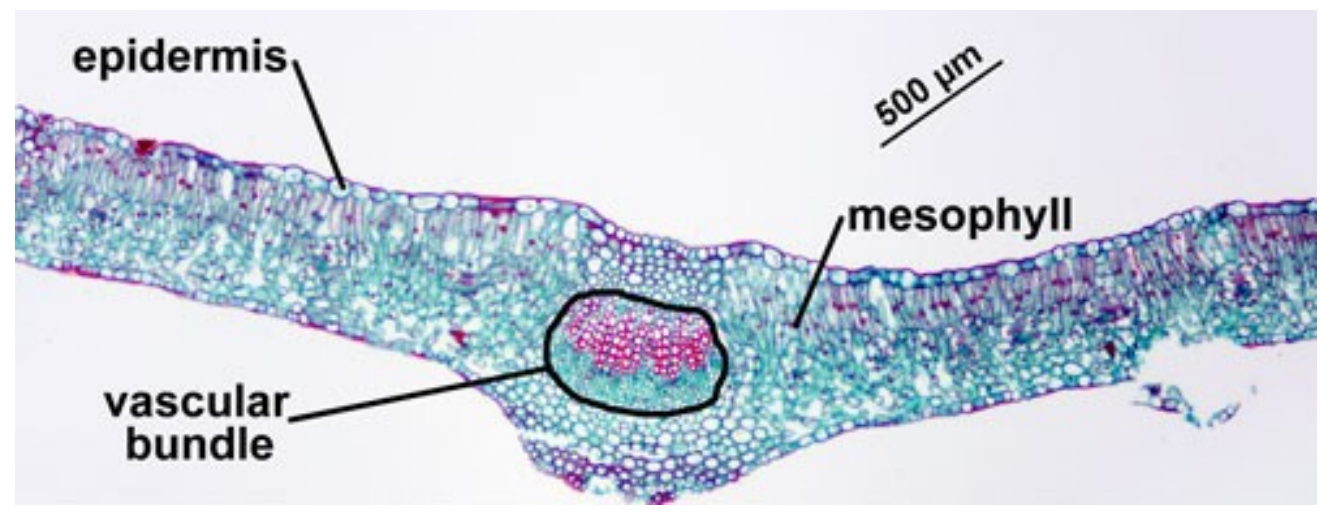

Illustration 15 The microscope slides show the section of a leaf taken from a deciduous tree. (McCauley, 2015)

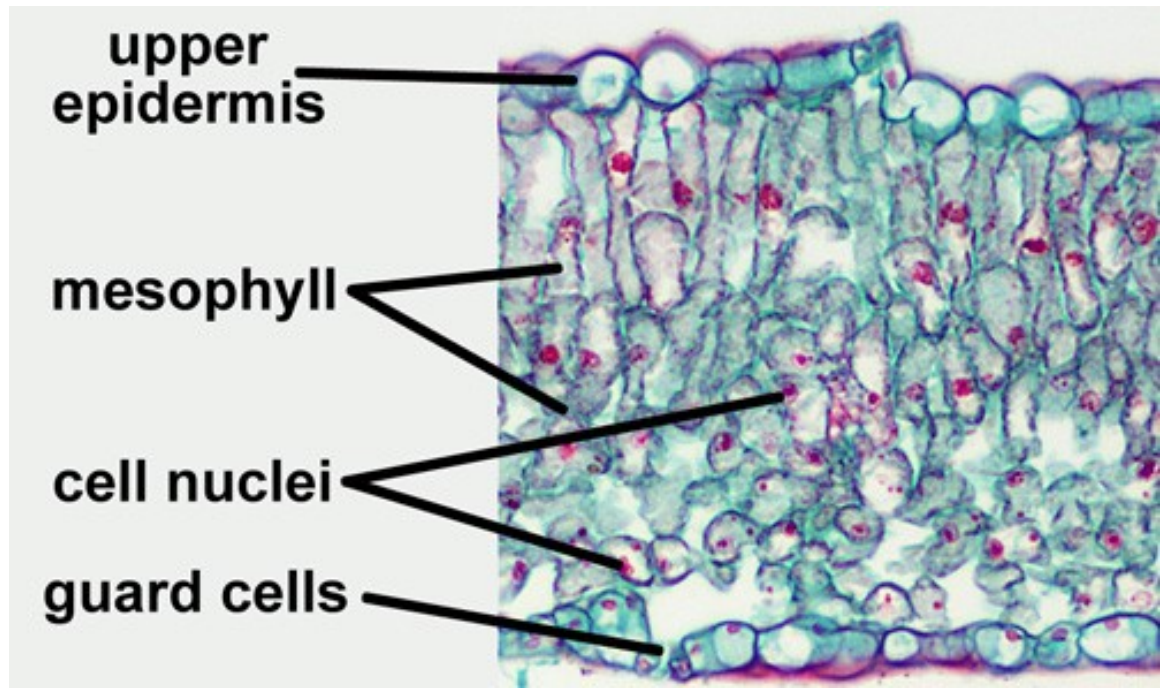

Illustration 16 The microscope slides show the components of a leaf taken from a deciduous tree.

(McCauley, 2015)

A deciduous leaf has excessive amounts of stoma located on the bottom side of the leaf. In summer months, rapid energy absorption and production are occurring in the form of 
photosynthesis. As energy is created water is transpired through the stoma. As ice crystals form in winter, water cannot reach the leaf and transpiration still occurs killing the leaves.

(Russell, et al., 2009)

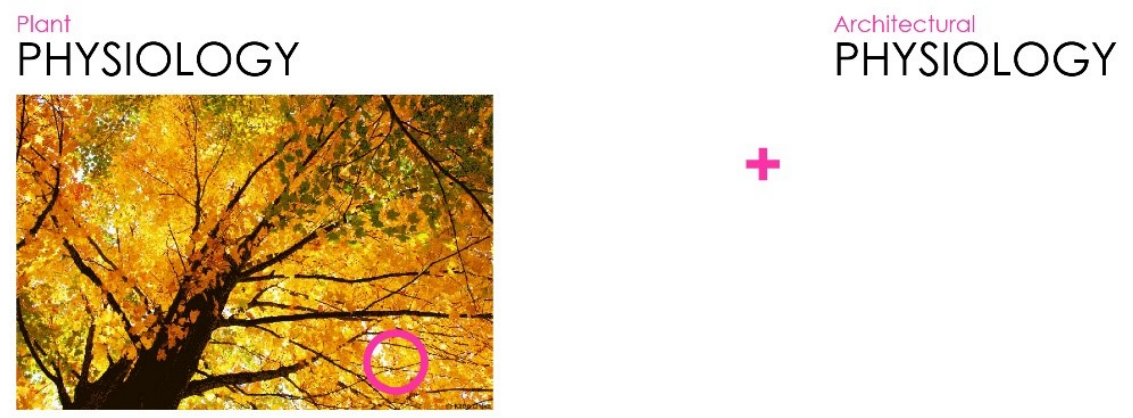

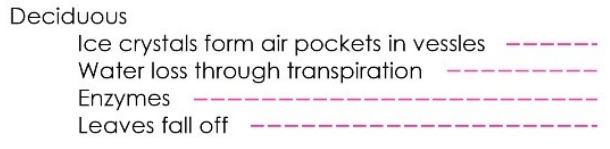

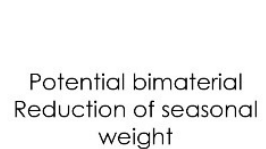
weight
Inconsisent water supply Water evaporation
Mechanisms needed for movement

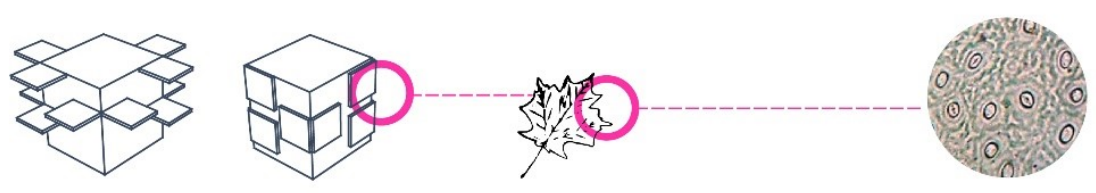

\section{Illustration 17 Physiological considerations exemplified by deciduous trees and potential} architectural implications

Coniferous trees on the other hand have conifers (needles) that are built to conserve water lost through the stoma. The needle stoma population is not as numerous of that of a 
deciduous leaf. Specialized ridges are located on the exterior of the needles that trap in water lost through transpiration. (BBC, 1984)
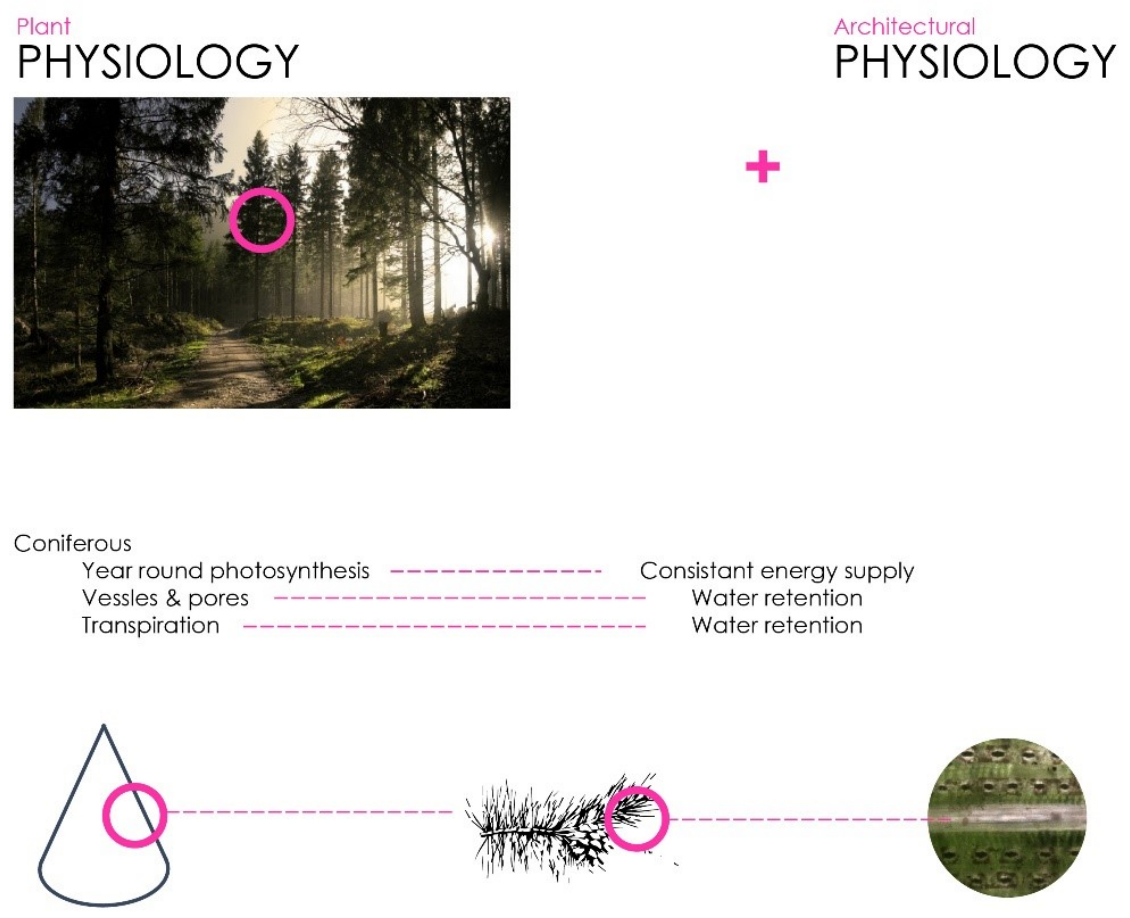

Illustration 18 Physiological considerations exemplified by coniferous trees and potential architectural implications.

\section{Animals}

Creatures that stay in their environments over the duration of winter have several physiological coping mechanisms to survive. Warm blooded animals need to maintain a body temperature above zero degrees Celsius to survive. The majority of these animals go through a state of hibernation. During hibernation the body rests to conserve energy. A reduced metabolic rate, decreased heartrate, and slowed respiration are states the body 
naturally takes. (Tattersall, et al., 2012) The body syncs these rhythms to maintain blood flow to keep the animal alive while it reduces the amount of food consumption and energy expended during winter months when food is scarce.
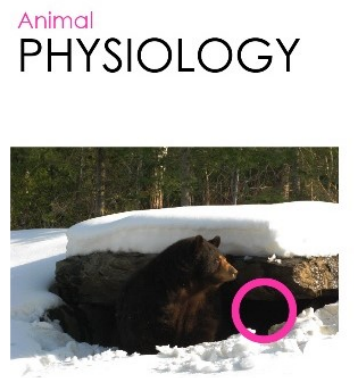

Hybernation

Reduced metabolism ---------------- Energy \& heat conservation

Decreased heartrate

Slowed respiration

Regional Heterothermy
Energy \& heat conservation Energy \& heat conservation Rationalized Program
Architectural

PHYSIOLOGY

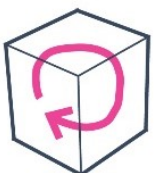

Increased energy use

Increased air exchanges

\section{Illustration 19 Physiological considerations exemplified by animals and potential architectural} implications.

Regional Heterothermy is an additional bodily mechanism used for survival. In the case of a Sea Gull the extremities can reach below -20 degrees Celsius while its internal core remains at a constant temperature. The body of the gull allows for the heat to be conserved near the core but allows the less crucial body parts to lose heat more rapidly. (Tattersall, et al., 2012)

In terms of how these methods apply to Climorphysiological architecture, it would directly be related to the active and natural systems implemented into the building. Mechanical systems, natural ventilation, and air exchange rates of the building are equivalent to the respiration rate of an animal. In winter months the exchange rate should be reduced to conserve energy taken to heat the building, while in summer months natural ventilation 
should be optimized. The energy consumption of the building ideally should be minimized when it cannot actively regenerate it. When resources are not made available to the building, the building should not continue to consume such resources at the same rate as if they were available.

\section{Chapter: Precedents}

\subsection{Building Industry Standards}

Prior to designing an innovative façade system that allows for seasonal changes the fundamentals of basic wall assembly needed to be reviewed.

Typical wall assemblies can be classified into 4 water management systems: pressureequalized rain-screen walls, drainage cavity walls, internal drainage plane walls, and facesealed barrier walls. A Face-Sealed Barrier Wall is defined as a wall that has "cladding or exterior finish, stops all water at the outside face of the wall." (Brock, 2005) See illustration 20 for an example. Internal Drainage Plane Walls are defined as a cladding that "allow for some passage of water, either through the material itself or at the joints. A secondary line of defense is required to stop any water that passes through the cladding and drain any condensed vapor." (Brock, 2005) See illustration 21 for an example. Drainage Cavity Walls are defined as a wall "consisting of a cavity and a water barrier - has openings or weep holes at the base for drainage of any water that passes through the cladding and vapor that condenses in the cavity." (Brock, 2005) See illustration 22 for an example. Pressure-Equalized Rain-Screen Walls, also known as Pressure-Moderating Rain Screens are defined as "a drainage cavity wall designed so that the air pressure of the cavity behind the cladding is similar to the exterior air pressure." (Brock, 2005) See Figure 23 for an example. The arrows show pressure and associated water vapor movement. Mass walls, 
also known as storage walls, are the most archaic way of preventing moisture from entering an enclosure. They are solid building envelopes that use their material depth to prevent the elements of coming in but retain water until evaporated. An example of a mass wall would be a mortar and stone assemblage. There are positive and negative attributes to types of wall. Face-Sealed Barrier Walls are the most ineffective method of stopping water moisture from entering the envelope assembly. If any inconsistency or tear develops on the cladding material, moisture will enter the building envelope and wreak havoc. Mold and structural damage are two of the main safety issues associated. Drainage Cavity Walls on the other hand effectively drain water moisture accumulated within the wall. This occurs as the dew point of the wall assembly is on the vapor barrier layer or towards the exterior. This drainage prevents mold from metastasizing in the wall assembly making them ideal for Canadian climates. (Brock, 2005)
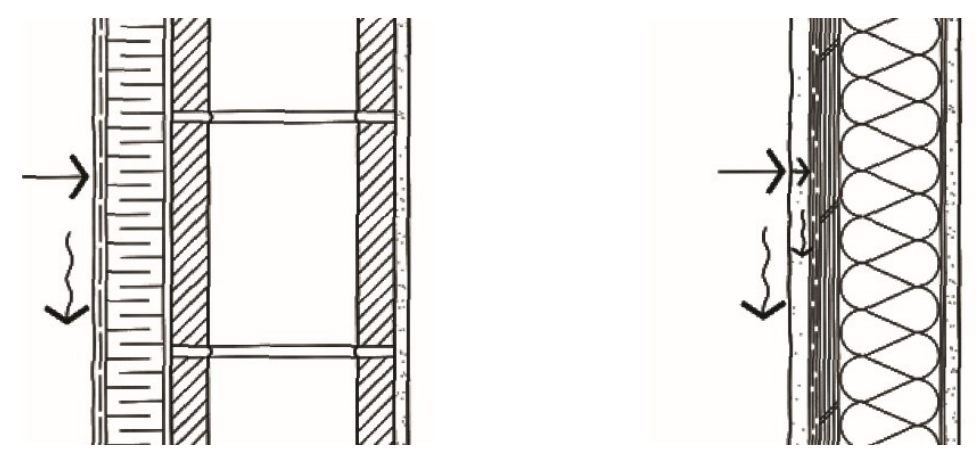

Illustration 20 Face-Sealed Barrier Wall (Brock, 2005)

Illustration 21 Internal Drainage Plane Wall (Brock, 2005) 

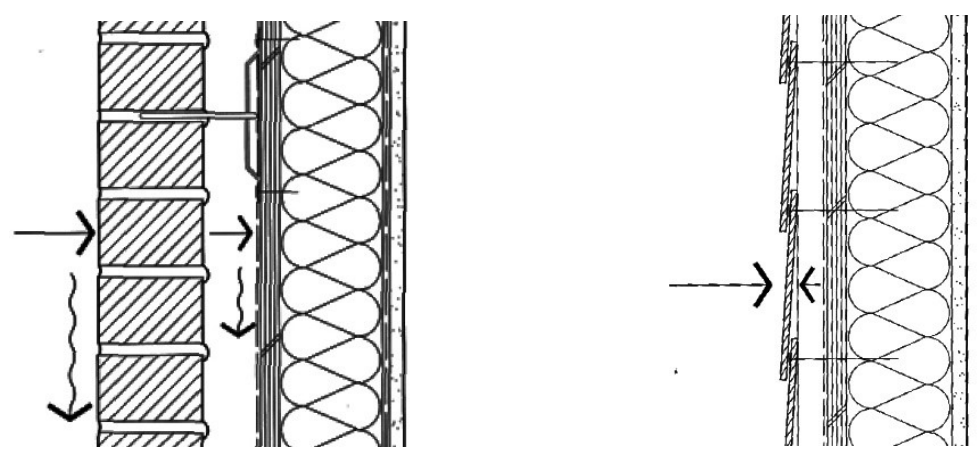

Illustration 22 Drainage Cavity Wall (Brock, 2005)

Illustration 23 Pressure-Equalized Rain-Screen Wall (Brock, 2005)

Planted wall systems would also be considered a Drainage Cavity Wall as it has a drainage plane behind the planted elements. Two types of planted wall systems exist: Green Facades and Green Walls. (Hopkins \& Goodwin, 2011) The major difference between the two are the plants grown, irrigation type, and complexity. Green Facades use climbing vines to populate the surface while Green Walls require a more vigorous growing medium and irrigation system to function.

Green Facades can be broken down into further subcategories including Trellis (A in Illustration 20), Modular Trellis Panel Systems (B in Illustration 20), and Cable \& WireOpen Net Systems (C in Illustration 20). (Hopkins \& Goodwin, 2011) All of these systems require soil at the base as a growing medium and need minimal structural support to allow the vines to grow. The benefits of these systems include seasonal fenestration shading, no irrigation system, manual watering, food growth, easy access (potted plants), and minimal maintenance. The negatives of these systems include no insulation value, and plant coverage is limited to $20 \mathrm{~m}$ in height and patterning. 
Green Walls can be broken down into further subcategories of Modular Green Walls (E in illustration 20), Vegetated Mat Wall (F in illustration 20), Hybrid Systems (D in illustration 20), Spontaneous Living Walls, and Landscape Walls. (Hopkins \& Goodwin, 2011) Modular Green Walls are defined as a green wall that "consist of panels that hold growing media to support the plant material." (Hopkins \& Goodwin, 2011) Vegetated Mat Walls are defined as a green wall "composed of two layers of synthetic fabric with pockets filled with the plants and growing media." (Hopkins \& Goodwin, 2011) Hybrid Systems are defined as green walls that have a "growing contained and placed in front of the building's spandrel panel only, providing shade to the spandrel panel and allowing light into the building." (Hopkins \& Goodwin, 2011) See illustration 24.

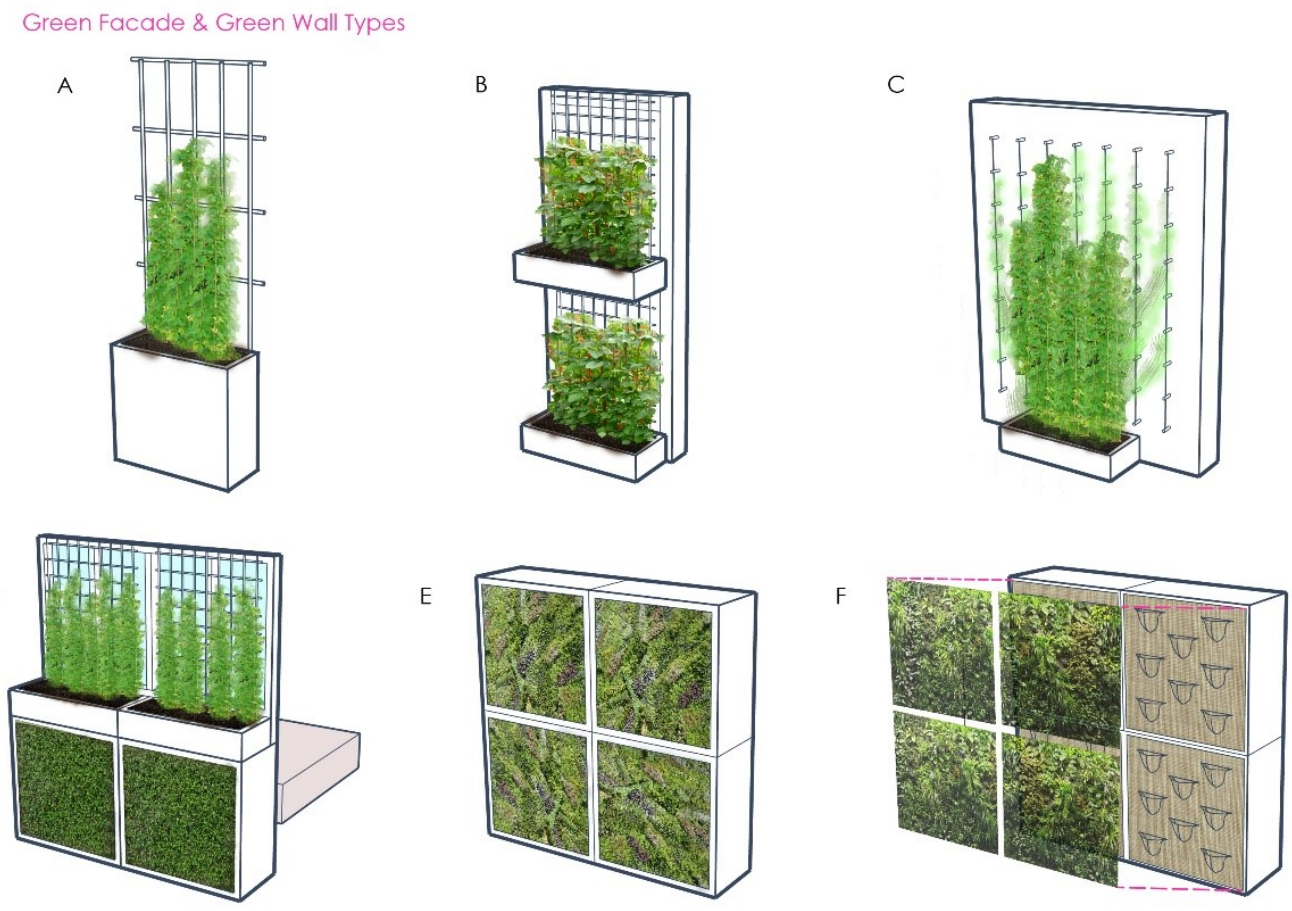

Illustration 24 Green Facades \& Green Wall Types 
The Vegetated Mat system's ability to keep plants alive with minimal maintenance was a main benefit of selecting this type of system. An irrigation fabric is used to mimic soil and debris found in nature, so is suitable for rooted plants to take to the fabric. The fabric is made of plastic so will not degrade over time. (Blanc, Vertical Garden: From Nature to the City, 2012) This is crucial to avoid having system failures within the initial stages of the green walls lifespan.

\subsection{Gardens by the Bay}

Green walls have typically been constructed from the same materials yet are found globally attempting to deal with different climatic conditions and microcosms of the given site. Seen as an icon for environmental sustainability green walls have become widely used throughout society. As Climorphysiological architecture looks to expand green walls into the Canadian climate, precedents of built green walls will be analyzed and critiqued. This critical analysis will become one of several starting points in tandem with biomimetic principles that will begin to address a wall assembly that adapts to temperate climate fluctuations. 
Gardens by the Bay located in Singapore, China offers insights to integrating green walls with biomimicry. The landscape architects Grant Associates in combinations with architecture firm Wilkinson Eyre Architects were tasked with master planning the 54 Hectares of land to create a new botanical garden. (Grant Partnership Ltd, 2014) The design teams philosophy was to create a tropical horticulture destination using technology and environmental sustainability as their main objectives. The program includes a series of indoor and exterior botanical gardens to house plants from around the world, Supertree walkways, playgrounds, information centre and seasonal displays to list a few.

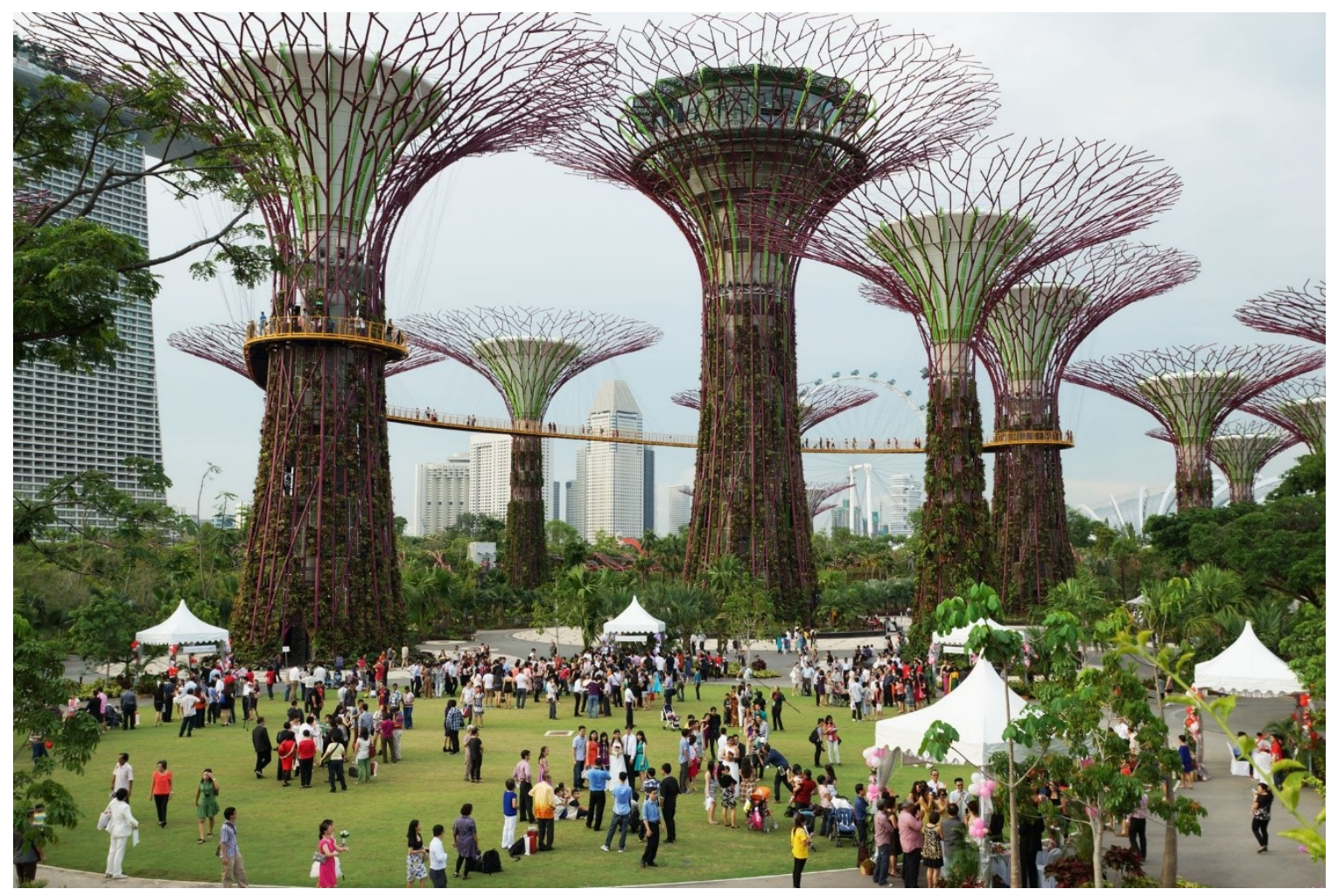

Illustration 25 Image of the Supertrees (Grant Associates, 2015) 
Completed in 2013, the Supertrees are green walls that offer particular interest. The structure is composed a series of cylindrical steel tubes that are welded to one another. The design looks much like a tree that rises and expands into a canopy overhead. The steel pieces act as the structure to hang the irrigation system, lighting, and sacks of plantings and irrigation fabric for growth. (Detail Das Architekturportal, 2012) Dependent upon the tree the park has been designed to incorporate the trees to function as solar energy collection and water collection devices.

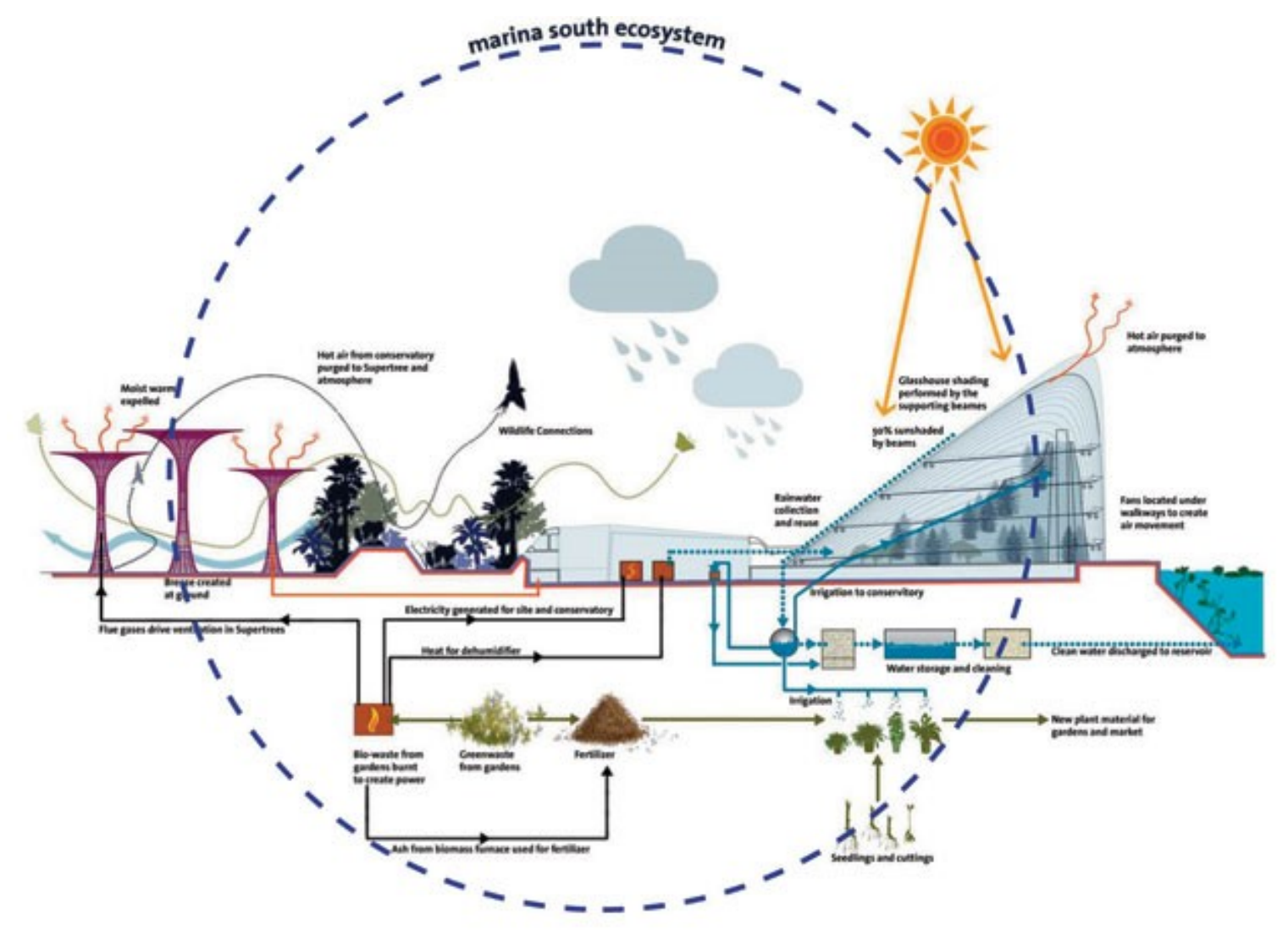

Illustration 26 Interlinking systems associated with the Supertrees 
From a biomimetic standpoint this built form strives to perform like a tree. The solar collection devices, shading devices, and the green wall planting use principles found in a tree. The structure of a tree is designed to optimize photosynthesis and provides shade for the forest floor. The canopy of a tree however does not collect water, this is done at its roots to pump the water up towards its leaves. One could argue at the scale of the Supertree gravity would be used instead of osmosis and therefore this is a reasonable biomimetic response.

The built Supertree successfully shows how green walls can provide full planting coverage and create a hollow interior for maintenance access. However there are still a series of issues that present concern. The scale of the Supertree is not at the human scale and is highly reliant upon technology for maintenance purposes. The weight of its' pieces require structural assistance and could not be fixed without proper equipment like safety harnesses and cranes. Secondly, if this approach were attempted to be implemented to a Canadian climate its' exposure to the elements and lack of an enclosed envelope would not be successful through the winter months.

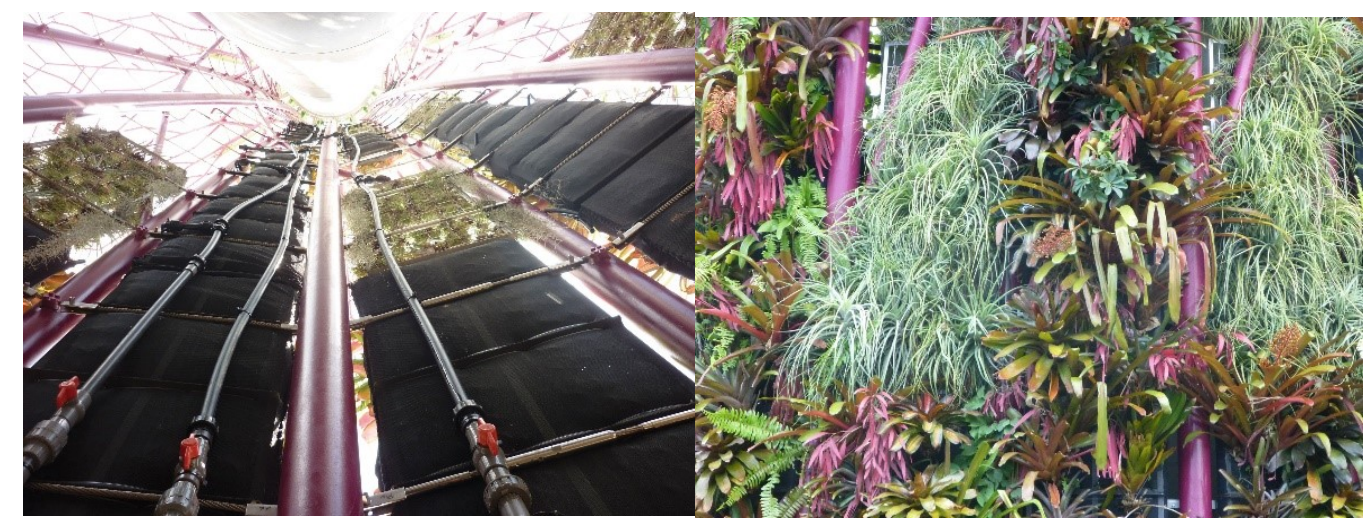

Illustration 27 Inside "Trunk" of Supertree (Grant Associates, 2015)

Illustration 28 Exterior "Trunk" of Supertree (Grant Associates, 2015) 


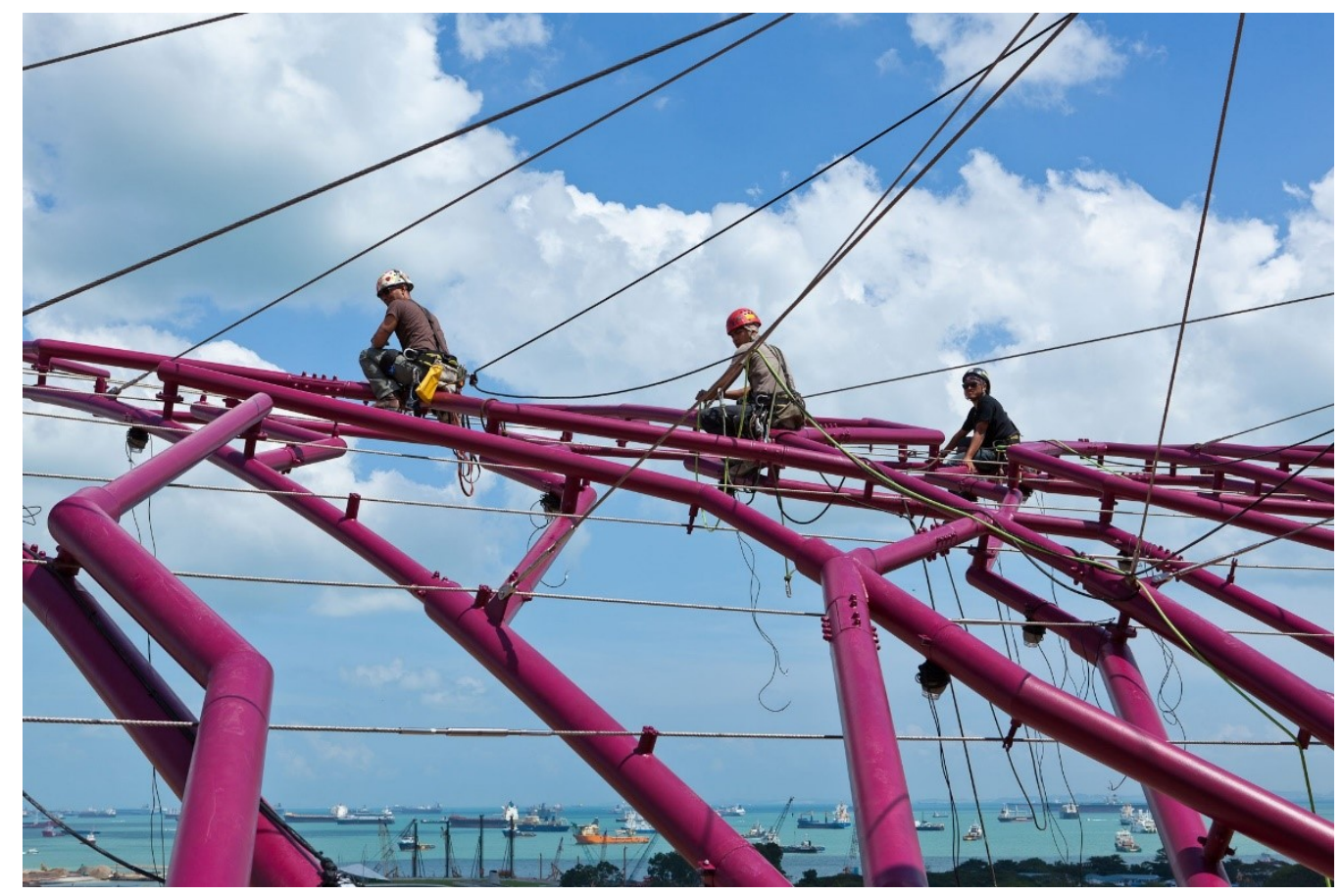

Illustration 29 Construction of Supertree revealed maintenance problems. (Grant Associates, 2015)

\subsection{The Evergreen Brickworks}

The Evergreen Brickworks completed in 2008 is the second built example of a unique green wall system. Located in the Don Valley of Toronto, Ontario, Canada the destination includes a community/environmental centre, commercial office space, educational facility, outdoor recreation, conference venue, event/wedding venue, café \& restaurant, skating rink (seasonal), playground, bike shop, exhibit display (kilns), urban agriculture (exclusive roof top, not open to general public) and weekend farmers market. (Gorgolewski, Komisar, \& Nasr, 2011) The collaborative efforts of Diamond \& Schmitt Architects, ERA Architects, Claude Cormier, DTAH, and artist Ferruccio Sardella were responsible for the buildings, 
master plan, and integrated artwork of the Brickworks. The creation of Watershed Consciousness is one artwork that was part green wall part sculpture. The main material used were CorTen steel, recycled steel, brass, copper, brass, perforated steel, plant matter, and site collected water. (Sardella, 2014) The collected water from the trough and roof in combination with a pump cycled the water through the walls network of "veins" to distribute water to the plants.

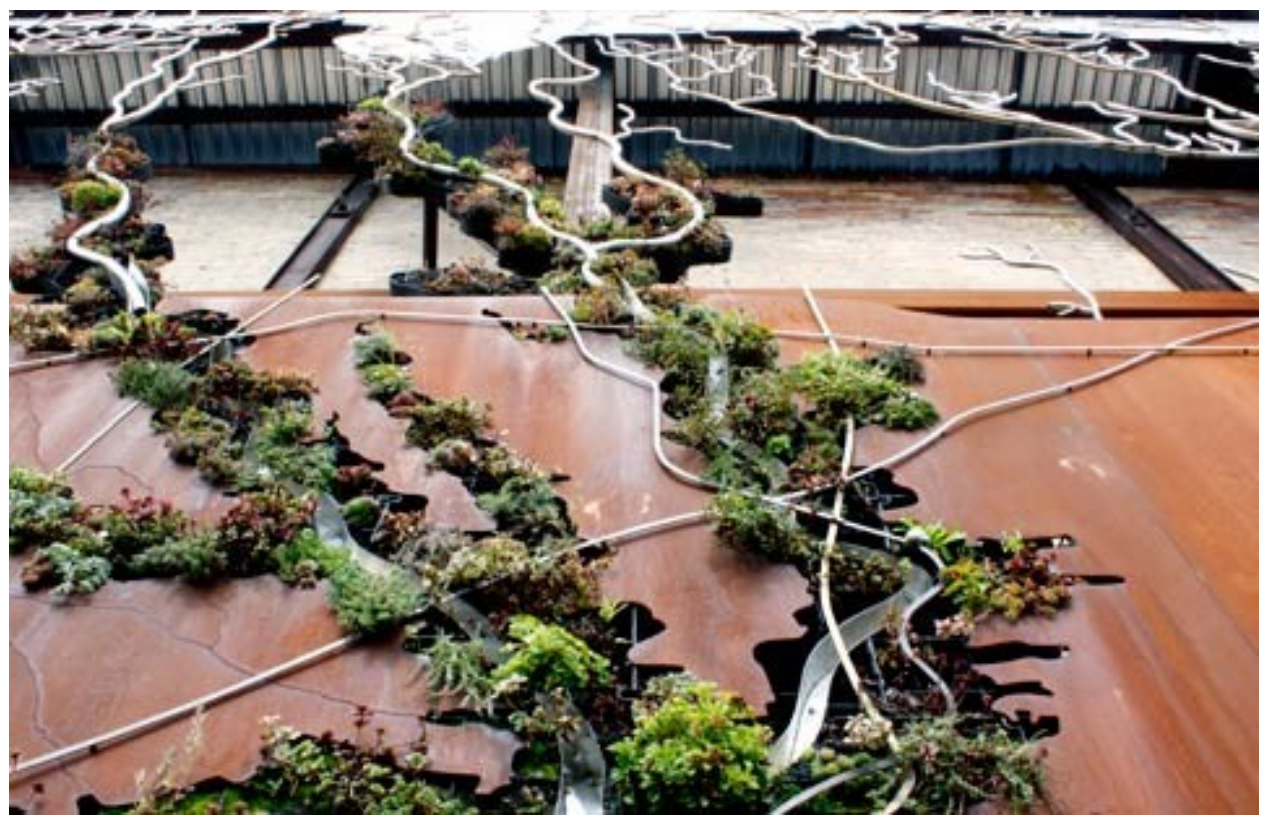

Illustration 30 Watershed Consciousness water network. (Sardella, 2015)

Sardella gives credit to the site for its conception. He explains "This installation is a site specific work that asks us to orient ourselves to the watersheds of Toronto. The organic sensibility of the ravine system that encompass the watershed is expressed in this work by green wall that interrupts CorTen steel sheets throughout the installation. Conversely, the rusted CorTen steel interprets the urban pad that surrounds the ravines at every turn. This 
reflects a negotiation that largely defines the geography and ecology of Toronto." (Sardella, 2014)

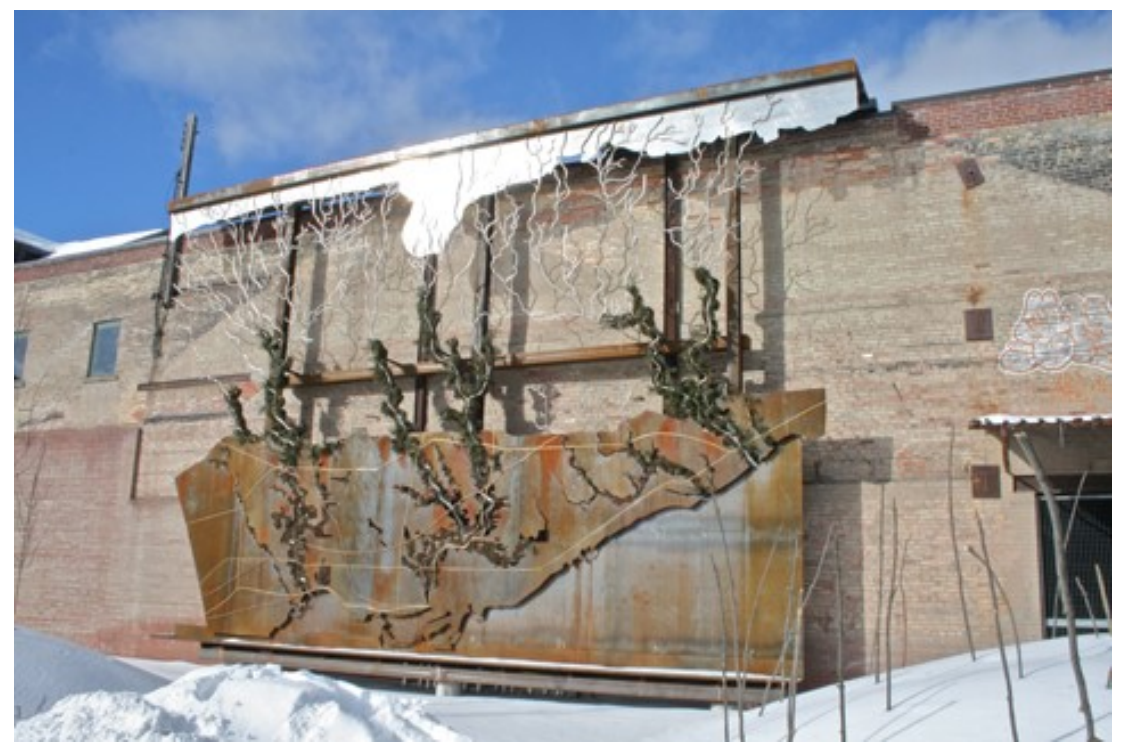

Illustration 31 Full view of Watershed Consciousness. (Sardella, 2015)

Having visited the site in all four seasons the wall is a prime example of a green wall having the capability to survive in Canadian climates. The plants specified on the wall are native to the area and have adapted a resilience to the climate shock. The pipes and pump are turned off during the winter but this is not detrimental to the installation. The "veins" of the systems are not enclosed and use gravity so water can flow down and as the snow melts the plants receive water naturally.

\subsection{Quai Branly Museum \& One Central Park}

Under the umbrella of Patrick Blanc's work both the Quai Branly Museum \& One Central Park are noteworthy. The Quai Branly Museum located in Paris, France was completed in 2005 in collaboration with Jean Nouvelle and still remains in 2015. (Blanc, Vertical Garden Patrick Blanc, 2014) The museum was one the first buildings to encapsulate itself in a green wall. Blanc's ability to select plants that will thrive in the environment after 
surgically embedded is critical to their success. Although he has a vast understanding in plant biology and how an organism can adapt to a new environment one questions how environmentally sustainable a form of green wall can be if an alien species was used. On an environmental standpoint shipping and transporting plants to a new site is both risky towards an ecosystem and is not resourceful. The ecological footprint this type of building can perhaps be more harmful to the environment than good. Additionally bringing new plants to an established ecosystem can have catastrophic and unintentional effects to neighboring plants and wildlife.

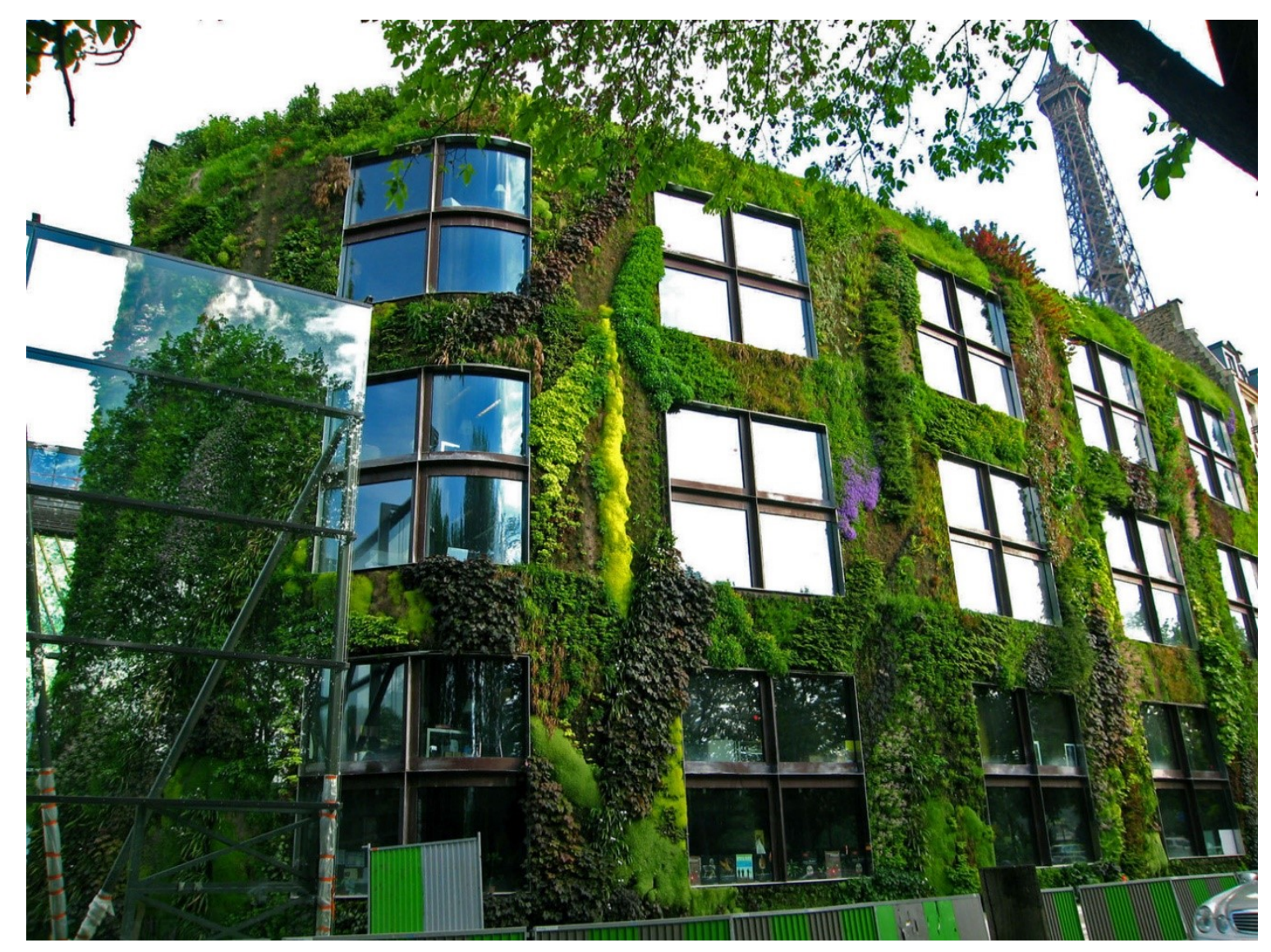

Illustration 32 Exterior of Quai Branly Museum. (Blanc, 2015) 
In his latest work One Central Park completed in 2013 and located in Sydney, Australia he tried addressing this criticism. The climate is extremely dry and placing vegetation on condominium towers becomes a challenge. At higher altitudes wind speeds are greater, therefore increasing the demands of the plants. (Blanc, Vertical Garden: From Nature to the City, 2012) The plants selected needed to be both wind and drought resistance which allowed Blanc to turn to local plants that naturally exhibited these features opposed to finding ones around the globe that may be appropriate donors to the region. Although these vegetated systems cannot do everything there is potential to offer occupants the benefits of urban agriculture or haptic engagement in future projects.

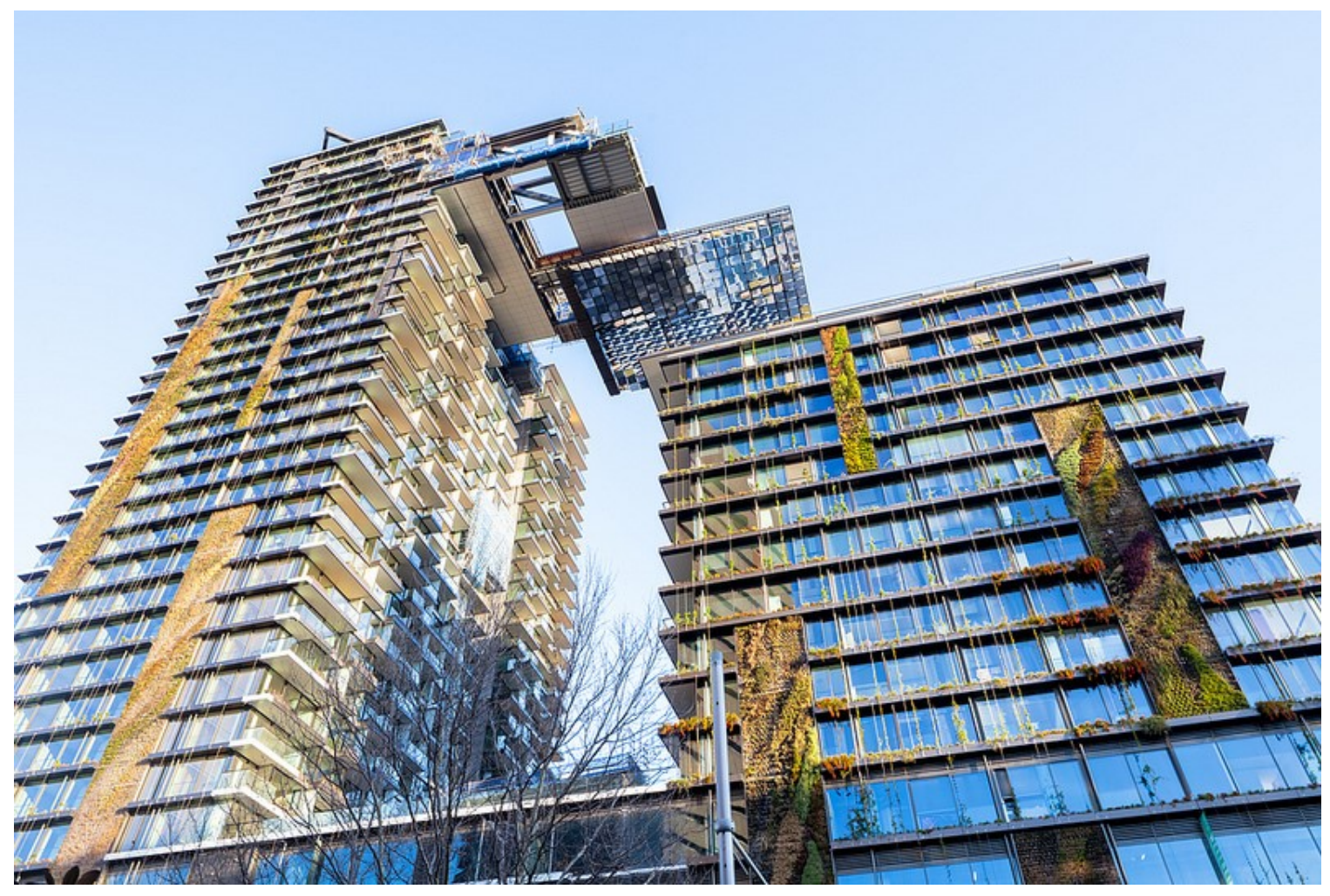

Illustration 33 One Central Park (Blanc, One Central Park, Sydney, 2015) 


\subsection{Planting Medium Systems}

Growing healthy plants require adequate amounts of sunlight (UV rays), water and nutrients. Failure to provide one of these could become detrimental to the plant. However the UV source, growing medium and nutrient supply does not necessarily need to be from traditional sources such as the sun, water and soil. The discussion of existing and alternative systems for plant growth will be analyzed. All systems explained below can use natural sunlight or artificial lighting to produce photosynthesis. However Canadian growing seasons will be a limiting factor for using certain systems listed below.

\section{Geoponics}

Geoponics is defined as "of or relating to tillage". (Merriam-Webster, 2015) Geoponic systems use soil as the growing medium. This growing system is used frequently in traditional farming but does not produce the highest yield.

The main components of the system include soil, fertilizers, growing areas, and plant species. Challenges this type of system can exhibit include the growing medium limiting how plants can be hung, resource intensive, depletes soil of nutrients after executive uses, and the majority of exterior growth is killed during winter. 


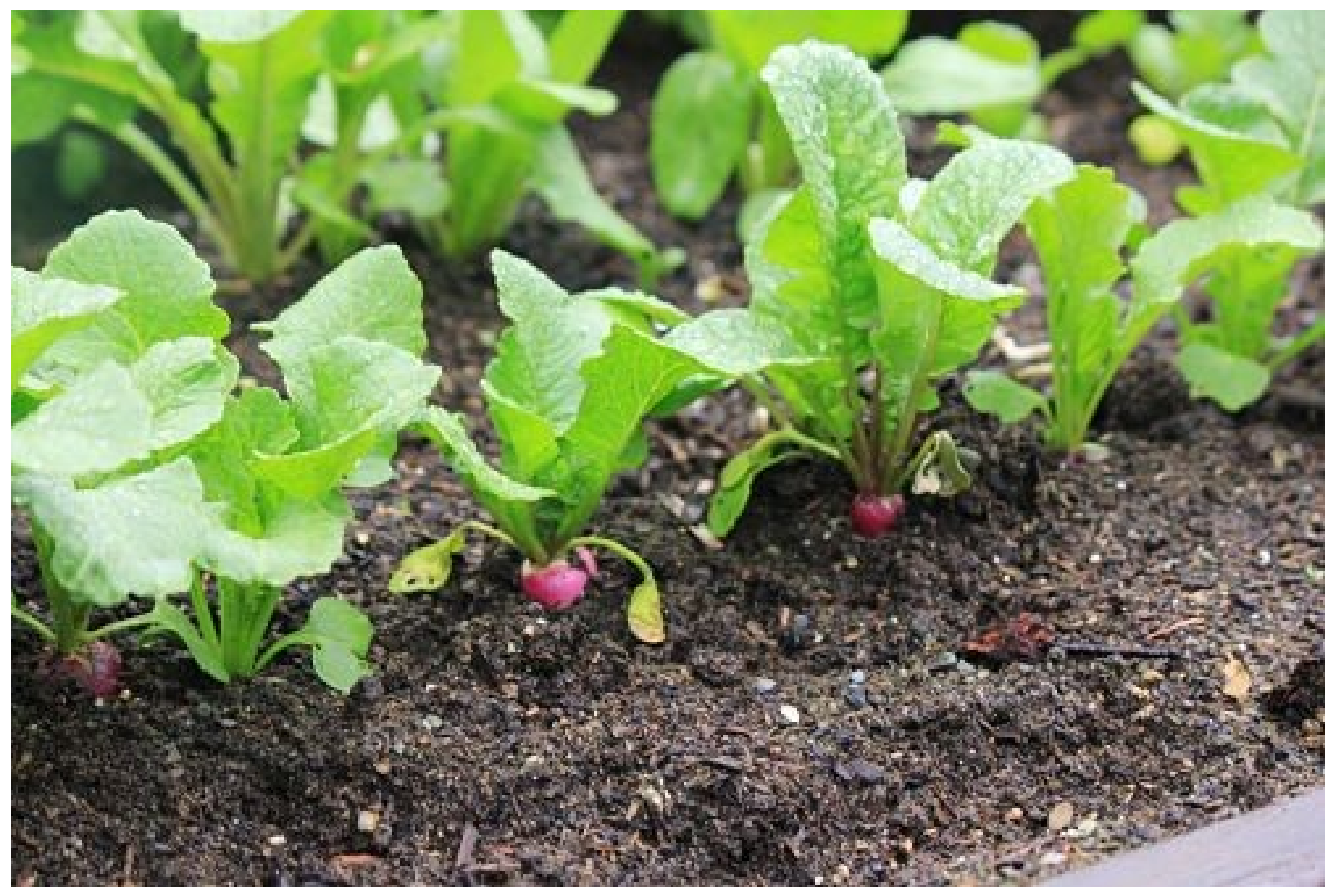

Illustration 34 Geoponic System (Butterfield, 2015)

\section{Hydroponics}

Hyrdroponic is defined as "a method of growing plants in water rather than in soil".

(Merriam-Webster, 2015) Plants using a hydroponic system grow in a nutrient rich water based solution opposed to soil.

The main components for this system are a sufficient water supply, plant fertilizers, plant species, and water proof growing containers. Plants using this system typically are embedded in the water. The challenges associated with this system include exterior growth 
killed during winter months, mold accumulation due to lack of water pressure, resource intensive, and winter drainage is needed to avoid pipes bursting.

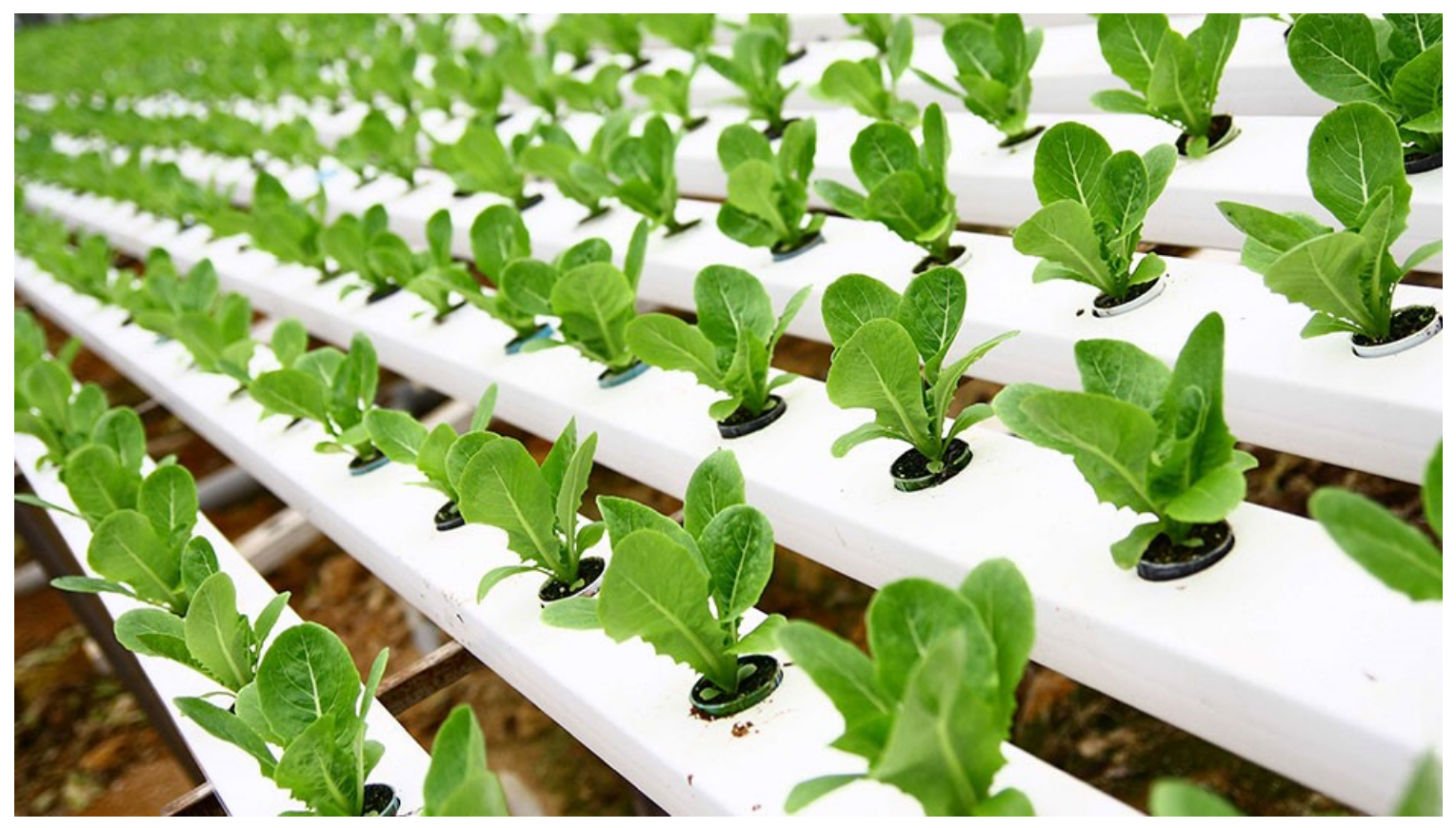

Illustration 35 Hydroponic System (Hydroponic Supplies Warehouse, 2015)

\section{Aeroponics}

Aeroponics is defined as "the process of growing plants in an air or mist environment without the use of soil or an aggregate medium (known as geoponics). The word "aeroponic" is derived from the Greek meanings of aero- (air) and ponos (labour)". (Google Definitions, 2015) This system uses no growing medium but instead suspends plants while water either mists or trickles over the roots. These systems are typically put on timers for periodic watering. Since the entire system does not require a growing medium nor substantial amounts of water, this is the most efficient system in terms of resource to produce ratio.

Aeroponic systems are comprised of an irrigation/misting system, planting containers, a pump, and plant species. This system is the most resource efficient as water is not 
continually being sprayed or cycled unless necessary. The associated challenges this system encounters are roots clogging water flow causing parched plants or overflow, exterior growth killed during winter, mold accumulation due to lack of water pressure, and winter water draining to avoid pipe bursts.

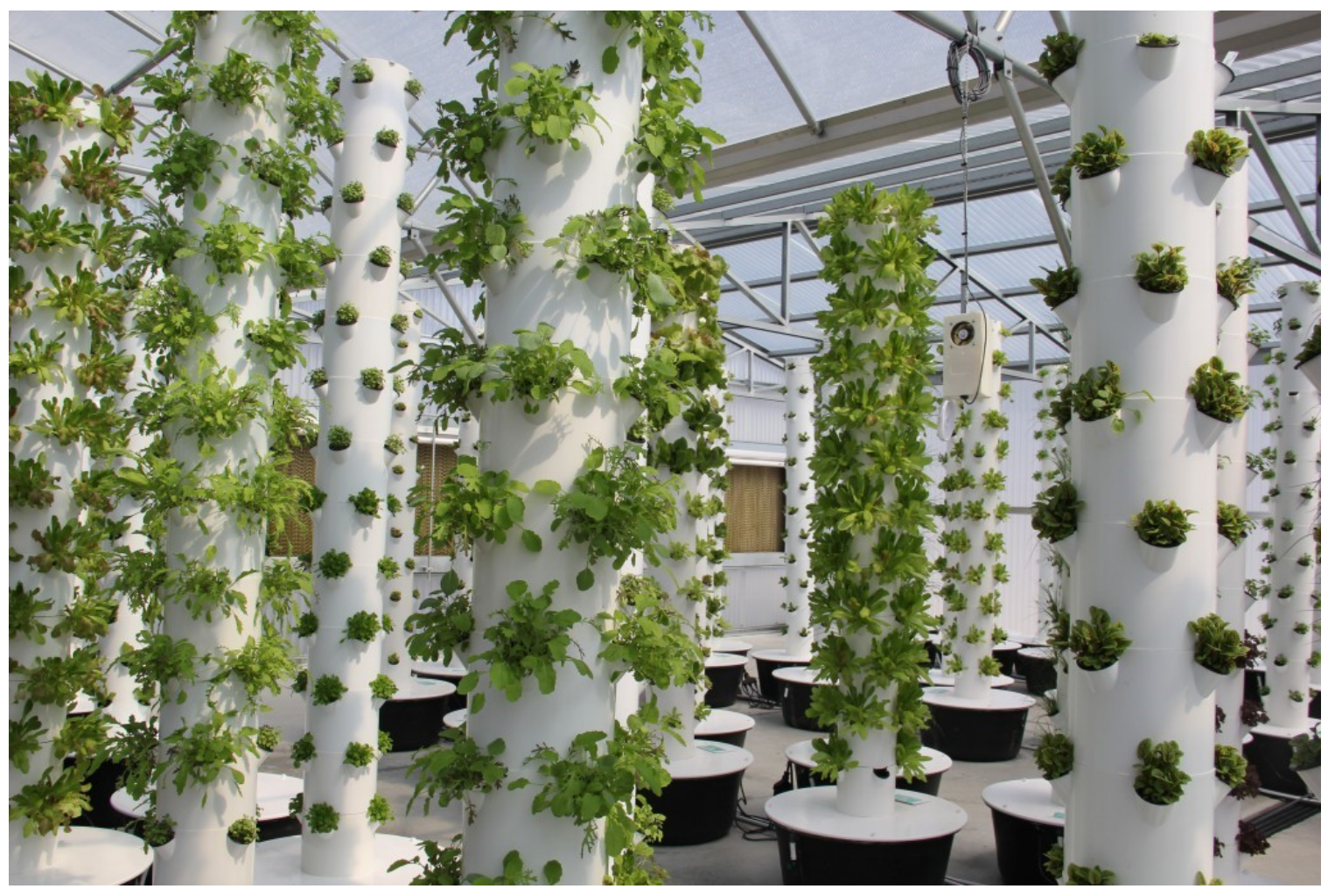

Illustration 36 Aeroponic System (Grow Make Give, 2013)

\section{Aquaponics}

Aquaponics is defined as "a system of aquaculture in which the waste produced by farmed fish or other aquatic animals' supplies nutrients for plants grown hydroponically, which in turn purify the water." (Google Definitions, 2015) The system pumps the water through a series of tubes that use sediment from the aquarium to nourish the plants.

The main components of an Aquaponics system include an irrigation/ misting system, planting containers, a pump, plant species, aquarium, and aquatic life. This system requires more maintenance then the other systems as animals must be fed routinely and there health 
must be monitored frequently. Associated problems that occur with this system include roots clogging water flow causing parched planting and spills, exterior growth killed during winter, aquatic animals need sufficient protection during winter, mold accumulation due to lack of water pressure, and winter water draining to avoid pipe bursts.

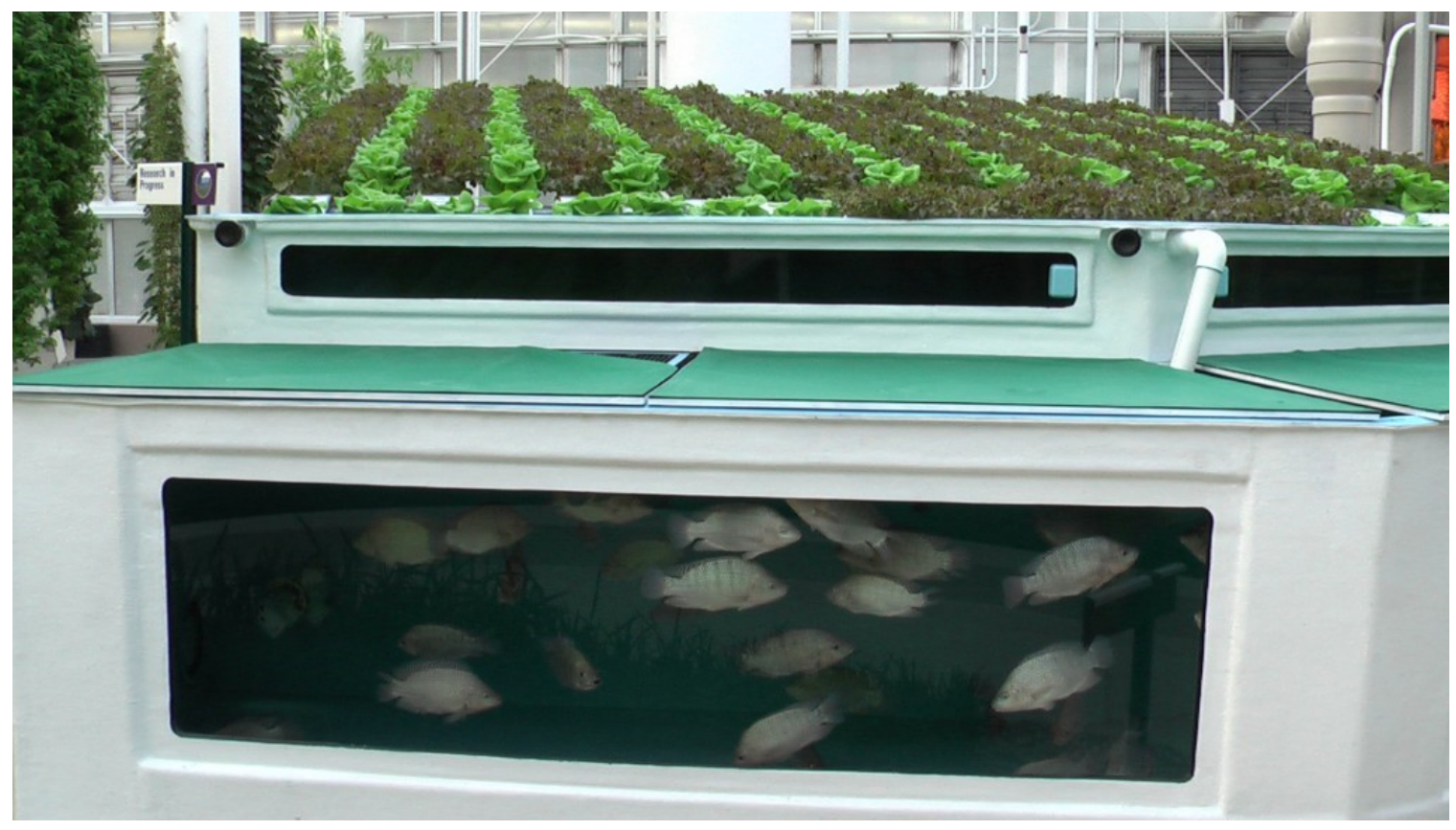

Illustration 37 Aquaponic System (Mikel, 2015)

\subsection{Developing Program}

Plant growth has typically been done in interior and exterior conditions that engage with nature or replicate it. In Canadian climates the growing seasons range from April to October of each year. Winter allows the soil to take a break before starting the cycle of growth in spring. Interior green rooms are used to replicate the summer conditions to allow plant production to occur even during winter using natural or artificial lighting. One engages with natures obstacles, while the other replicates an ideal summer condition. In 
regards to yield, taste, and production a company in the Netherlands is taking the idea of a green room to a new extreme.

PPU (Plant Production Units) were coined by a company called PlantLab. In nature the sun emits white light (full spectrum), however plants do not absorb green wavelengths. Plants absorb the remaining spectrum while green wavelengths are reflected off, this is why we see plants as green. Therefore the scientists at PlantLab have customized the growing environment to the ranges of light absorbed and utilized by the plant. This reduces each plant down to a simplified equation to maximize produce yield. Factors including air temperature, root temperature, relative humidity, light rays, water, fertilizers, and air flow are all incorporated in their patented equations. (PlantLab, 2015)

\section{Program \\ EXPERIMENTAL \& RECREATIONAL FACILITY}

Interior

- Administration/Office Space (3+)

- Large Flex Space/Rental Space

- Workshop \& Studio Spaces (2+)

- Interior Green House (2+)

- PPU (Plant Production Unit) $(2+)$

- Labratory \& Testing Facillty

- Gardening Shed

- Bathrooms

- MEP faciluties

Exterior

- Labratory \& Testing Facillty (external access)

- Green Roof Garden \& Patio

- Resting Spaces (pedestrian path \& waterfront)
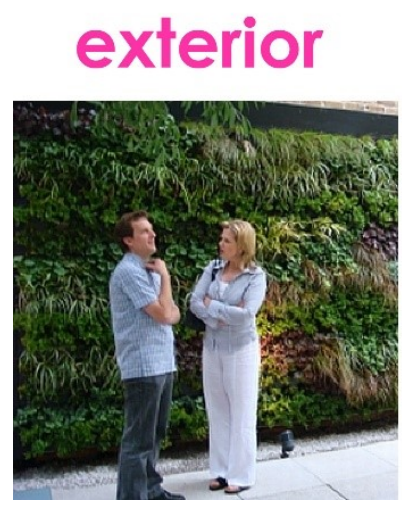

interior

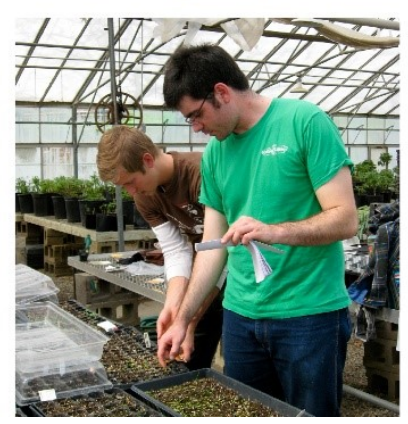

+ customized

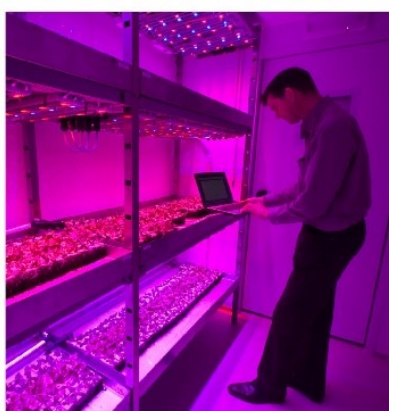

Illustration 38 Programmatic equation for experimental building 
In the case of Latent Project it strives to provide Carleton University, The Experimental Farm, and Tree Arboretum a location to engage with the climate and proposed Dow's Lake site. The site's seasonal interaction with the freezing and thawing of Dow's Lake and its' proximity to the pedestrian paths following the Rideau River instruct the future building design to incorporate a portion for recreational use. The publicness of the site enforces any construction to have the ability to camouflage with its settings and welcome the public.

\section{Chapter: Weather}

\subsection{Weather \& Climorphysiological Architecture}

The stance that Climorphysiological architecture takes when dealing with weather is to look at what the site has to offer from weather, building science and programmatic perspectives. Any element that touches upon the site should be utilized and optimized in the most effective way possible. The architecture that stems from this form of thinking will ideally evolve over time to acclimatize and familiarize itself with the environment.

Tim Ingold's book, Being Alive, expresses the environment as a thing that is every changing and continually becoming something new. His hypothesis argues that the world is a meshwork of points in constant interaction with one another opposed to a network with locked in interactions. (Ingold, 2011)

Ingold brings insight to the failures of the western scientific world. He explains that often science is designed to categorize objects so they can be more easily understood. These categories are manmade, but most importantly are linked with man's visual observations

to discern where such an object belongs. However perception is a participatory way of categorizing the immaterial and material, and thus can also be interpreted as being bias. 
(Ingold, 2011) Ingold explains that such clear divisions between what is earth and what is sky need to be re-examined through an understanding of openness. The world does not close itself off with definitive boundaries so neither should man. In architectural terms this theory strives to re-establish a dialogue with the meshwork of the world.

In Canada four main seasons are experienced but are often thought about by society as mini charactertures in a sense. Spring being a time of blooming flowers and rain, summer as sunshine and heat, autumn for the harvest and changing leaves, and winter for its ice and snow. These charactertures are the main starting points for developing a Canadian architecture that is true to its' region but needs to embrace consistent metamorphosis. In actuality although the seasons continually cycle, the light and weather properties of the given site will be in constant fluctuation and maturation. Although the occupant may revisit a building deemed as climorphysiological, the state of change the building will be under taking will be an entirely new experience. The story the building will be telling in relationship to weather will be linked with its past while continuing to form new experiences with the ever changing conditions of the earth and sky.

He quotes in the chapter Sky, Earth, \& the Weather "This sphere is where all the lofty action is: where the sun shines, the winds blow, the snow falls and storms rage. It is a sphere in which powerful persons seek not to stamp their will upon the earth but to take flight with the birds, soar with the wind and converse with the stars. Their ambitions, we could say, are more celestial than territorial.” (Ingold, 2011)

Climorphysiological architecture tasks designers and builders alike to look beyond scientific networks into the world of meshworks. Through this type of architecture the discipline would have the ability to transcend function, form, and materiality and move 
into notions of societal significance, beauty, delight, and spirit. This dialogue between weather and architecture has the ability to weave the environment, material, building industry and its related "points" into a meshwork that speaks of great volume to pop culture and generations to come.
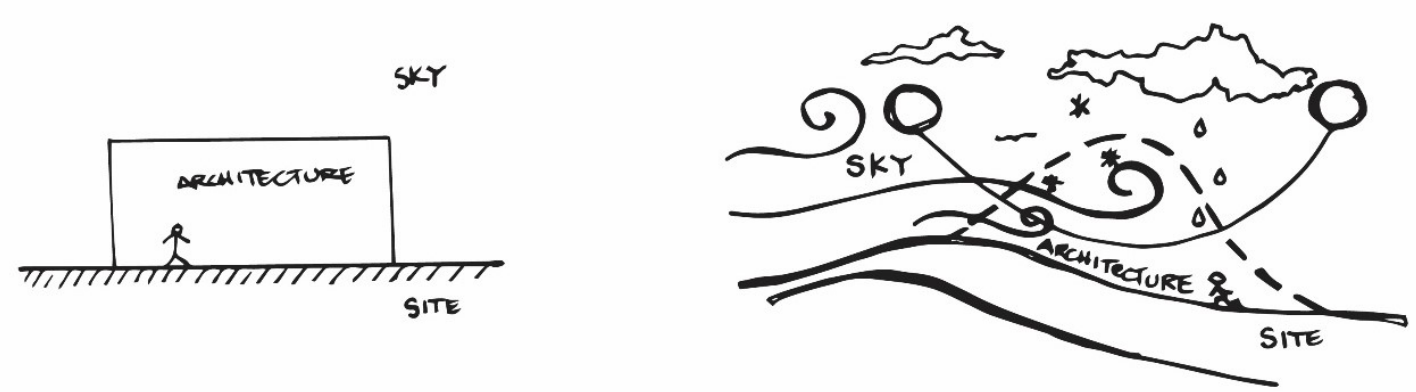

Illustration 39 The left drawing is a traditional view on architecture as a barrier between the sky and site. Climorphysiological Architecture's view of integrating weather as a shaping and developmental principle in architecture. Principles illustrated in Ingold's drawing Illustration 1 have been applied to illustration 39.

The material and immaterial objects of the world are continually changing. This is an eternal evolution and is a consistently changing meshwork where all found within the sky, earth \& weather are interwoven. Kenneth Frampton explains in his 6 Points Towards Critical Regionalism that architecture of resilience will be one that has the ability to remain societally significant. (Frampton, 1983) Ingold's similarly explains the greater amount of points this meshwork is interwoven with, the greater the hold it will take on society. (Ingold, 2011) Climorphysiological architecture creates a link between architecture, weather, climate, environment, culture, regionalism, wildlife, biomimetics, materiality, and the built world to become an activist of societal concern.

As weather patterns fluctuate seasonally the architect and inhabitants will learn to embrace these changes. The blizzards, the thunder storms, and the heat waves that used to make 
civilization cringe will ideally become the source of joy and wonder as these hindrances will be turned into something innovative.

The Canadian landscape ranges dramatically from coast to coast, as does it vary from its borders of the south up to the artic. Natures wildlife and plant life that originate within the microclimates of the country vary in order to adapt to environment.

In the book 41 to 66: Regional Responses to Canadian Architecture it describes the architecture that has been born out of the individual provinces and territories. Fabrication methods, materials and massing established by early settlers and Native Americans revealed a historical narrative born out of the climatically specific region. (McMinn \& Polo, 2005) The materials and methods of construction were found within the natural landscape.

In the case of Ontario early settlers built barns that slopped snow off of the roves and was made of the lumber found in the region. (McMinn \& Polo, 2005) However these traditions have not evolved for the last 200 years to incorporate new technological advances in construction method and material making, nor do they engage with the elements to their full potential.

The architecture that has been built upon these traditions does not begin to tackle a narrative to describe a contemporary form of Canadian architecture however and needs significant updating. These climate sensitive weather traits in the new form of Canadian architecture 
should strive to work with the natural landscape of the site as much as possible and with resources to be utilized further.

\subsection{Macroclimate Conditions}

Although we now have an understanding that the environment is a meshwork and cannot be so rigidly categorized it is still necessary to look at the weather statistics collected on the site. The site selected in Ottawa, Ontario, Canada has specific weather measurements and microclimatic conditions that needed to be understood to design the Latent project. Macroclimate conditions included precipitation, temperature, and seasonal statistics. Each category gave the project a series of other conditions and an understanding of what to expect on the site in regards to its limitations and potentials.

\subsection{Angle of Repose for Snow}

The angle of repose is a critical consideration when attempting to capture snow. It is defined as the resting position (angle) degree that a molecule reaches to stabilize itself. The angle of repose is often referred to when describing an avalanche as it is the angle the snow will settle at. As snow piles upon one another the molecules begin to stack. If the stacked molecules surpass the angle of repose they will shear off and fall to stabilize themselves. Each grain has its own specific angle of repose based upon the size and shape its molecular breakdown. (Ball, 2004)

The angle of repose becomes critical for capturing snow and designing its associated details. Angles found within the building should not exceed 63 degrees on the snow will 
shear off and fall. (Armstrong, 2015) Please see Appendix A for the documentation regarding the angle of repose for snow type.

\subsection{Precipitation Records, Prominent Wind Direction, \& Sun Angles}

Ottawa, Ontario weather database has the statistics of the region that have transpired over the last 60 years. This collection includes average and maximum precipitation values annually, month, and daily. These statistics have been reproduced in Appendix B for further viewing and referencing. Structurally speaking the new wall assembly should prepare for the worst case scenario in regards to weight and snow accumulation height for improved insulation values. Prominent wind directions should be taken into account to relieve humidity during summer months, and to protect against winter winds. The sun angles of the region are consistent annual records that should be utilized in the design to provide a heat source during winter and shading in summer months.

As Canada is a fresh water country the implications of acidic or salt water destruction to the building exterior was not an issue needing to be addressed in the design. Had it been a salt water region, how salinized rain water or debris would affect joints and hardware on any mechanized dynamic façade would needed to be taken into account.

The Latent project seeks to combine the predicted weather patterns and biomimetic principles to create a building envelope customized to the proposed site on the shores of Dow's Lake in Ottawa, Ontario, Canada.

\section{Chapter: Design Proposition}

\subsection{Building Envelope: Pine Facade}

The building envelope underwent a series of iterations considering overall purpose, materiality selection, structure, and biomimetic principles to achieve the final outcome. 
Presented on December 9, 2014 the Pine Façade incorporated the principles of an igloo, green wall, and the pine tree to develop a building façade that continually changes according to the season. Two types of the Pine façade were introduced both serving to function with separate plant types and mechanisms in mind.

\section{PINE FACADE}

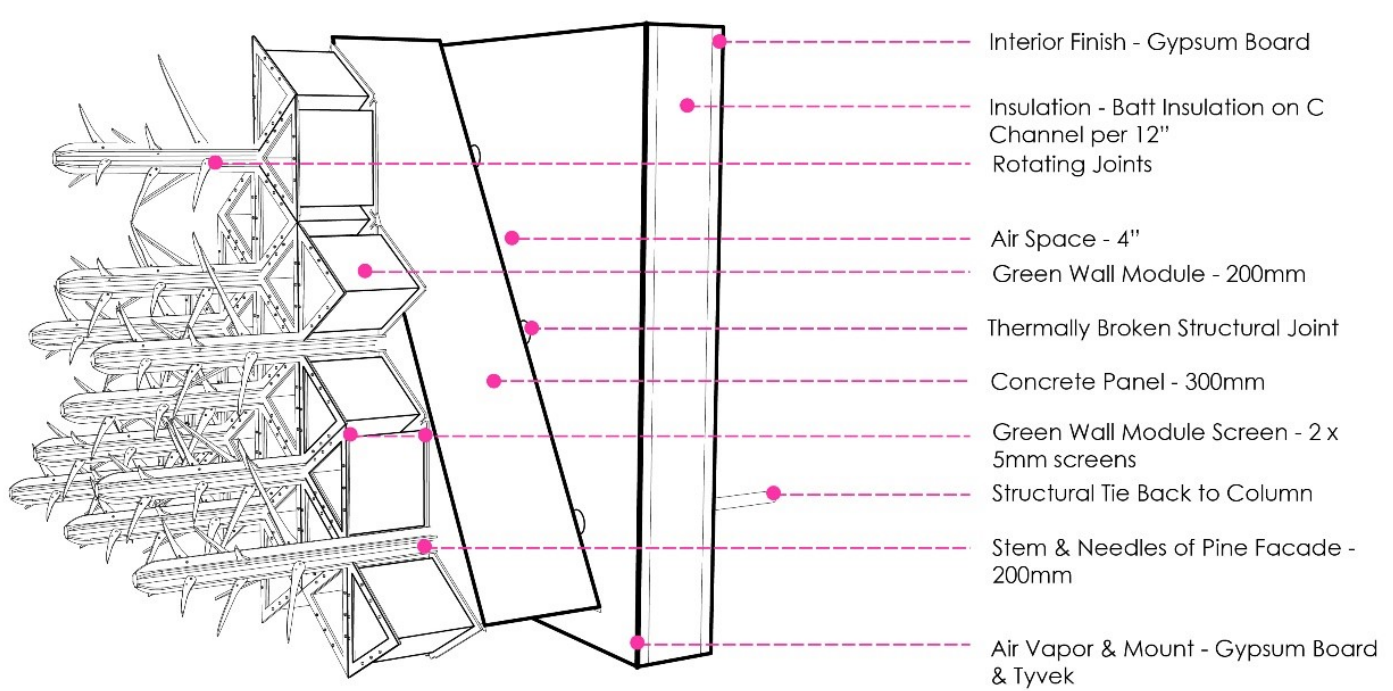

\section{Illustration 40 Pine Facade components}

The static Pine Façade would not open or close but would act as a trellis system for climbing plants from spring to fall. In winter months the vines would be exposed on the trellis system but would be skeletal in comparison to the lush growth in the warmer seasons. The dynamic Pine Facade would open and close depending upon the season and fenestration response. In winter months the Pine façade would open to collect snow and ice as an additional layer of insulation for the building envelope. During spring to autumn 
experimental interchangeable green wall modules could be tested by students or professionals from Carleton University, Experimental Farm, or the Tree Arboretum.

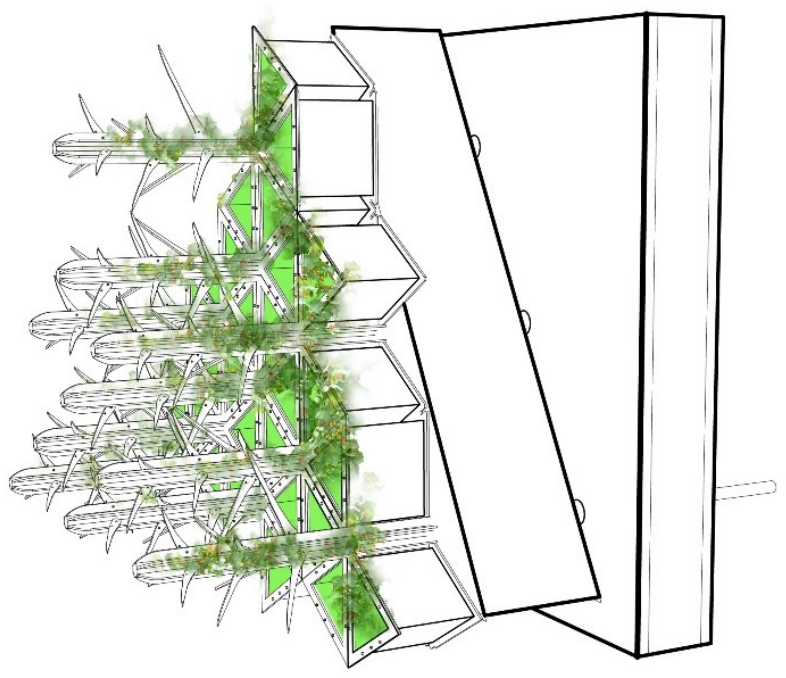

Dynamic Pine Facade - Closes in summer months to maximize sun

hitting green wall behind

Static Pine Facade - Acts as a Trellis system for climbing plants

\section{Illustration 41 Pine Facade in spring}

Wall Assembley
PINE FACADE - SUMMER

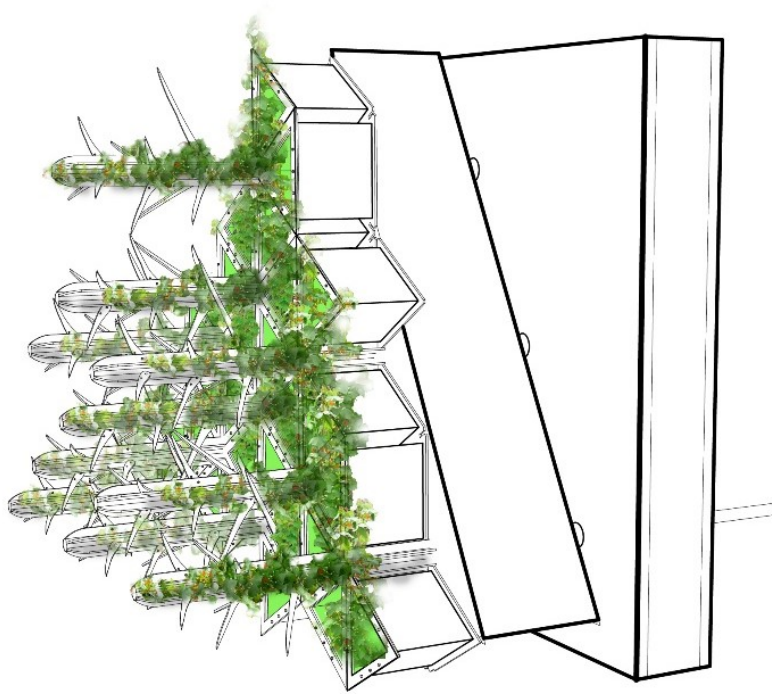

Dynamic Pine Facade - Closes in summer months to maximize sun hitting green wall behind

Static Pine Facade - Acts as a Trellis system for climbing plants

Illustration 42 Pine Facade in summer 


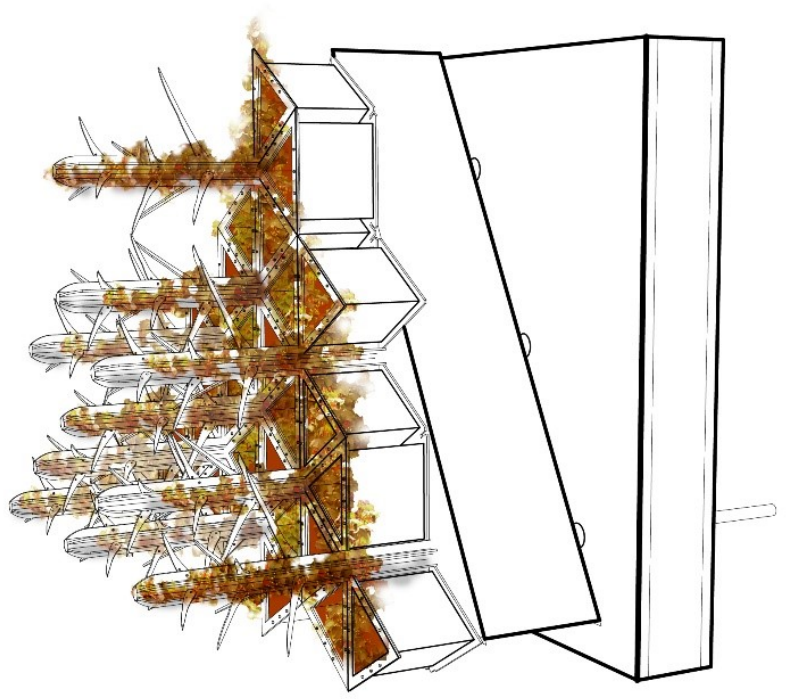

Illustration 43 Pine Facade in autumn

PINE FACADE - WINTER

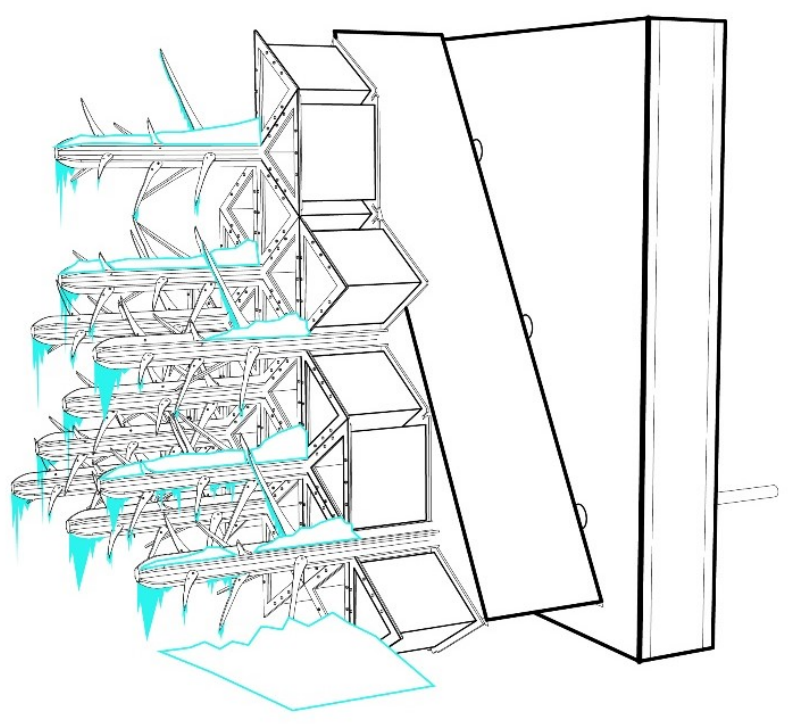

Pine Facade

- Accumulates snow and ice during

winter months

- The greater the snow fall, the more the snow insulation building envelope receives

- Helps protects plants that can remain alive during winter months

\section{Illustration 44 Pine Facade in winter}


The December critique gave way to what the project needed to develop in order to progress forward. The final façade system needed to address how the backup wall structure and insulation could be further integrated instead of using a standardized envelope condition, how a pine cone closes and opens as inspiration for Pine Façade mechanization and how needles can close in on itself, and how to increase needle population along a surface for more consistent snow accumulation on the surface of the panel..

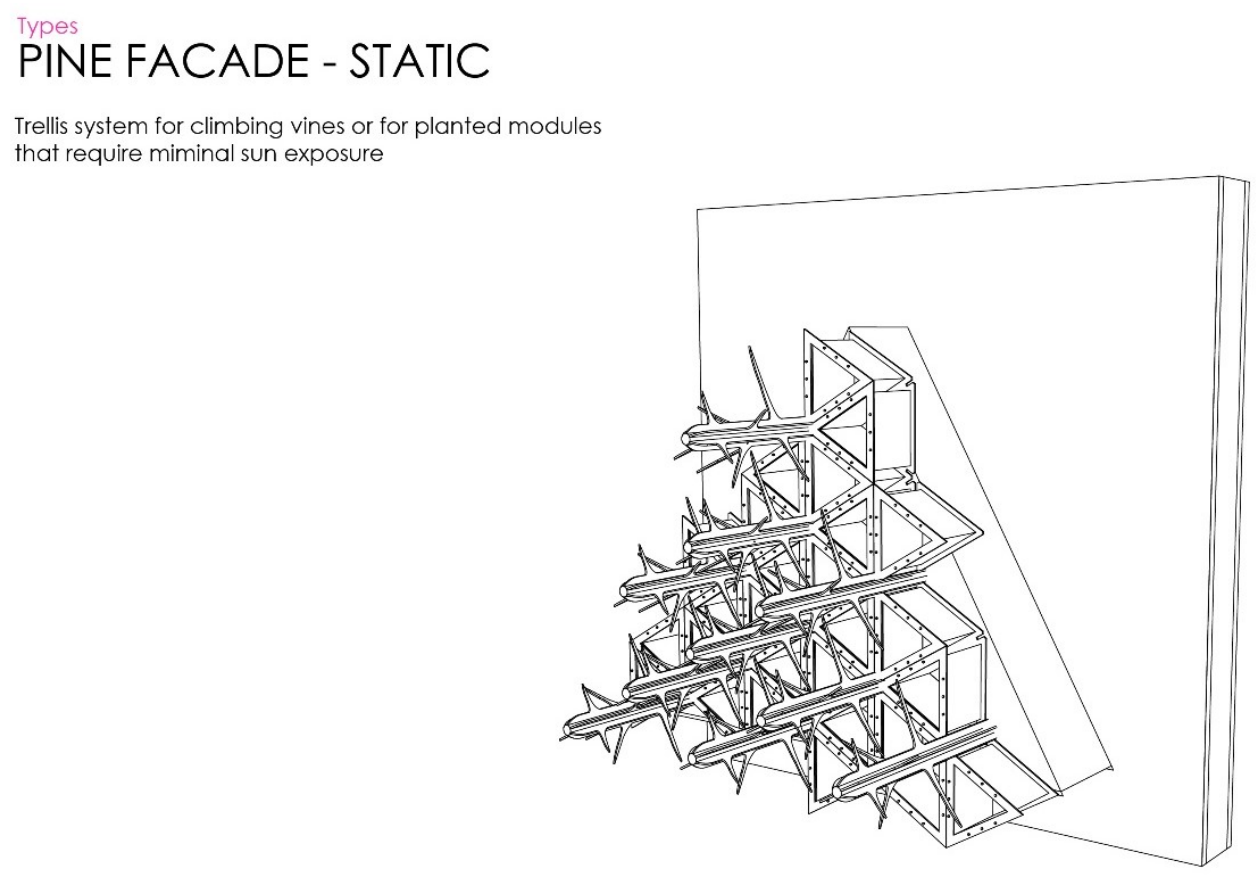

Illustration 45 Static Pine Facade 


\section{PINE FACADE - DYNAMIC CLOSED}

Needles are closed during spring and summer months to maximize sun exposure.

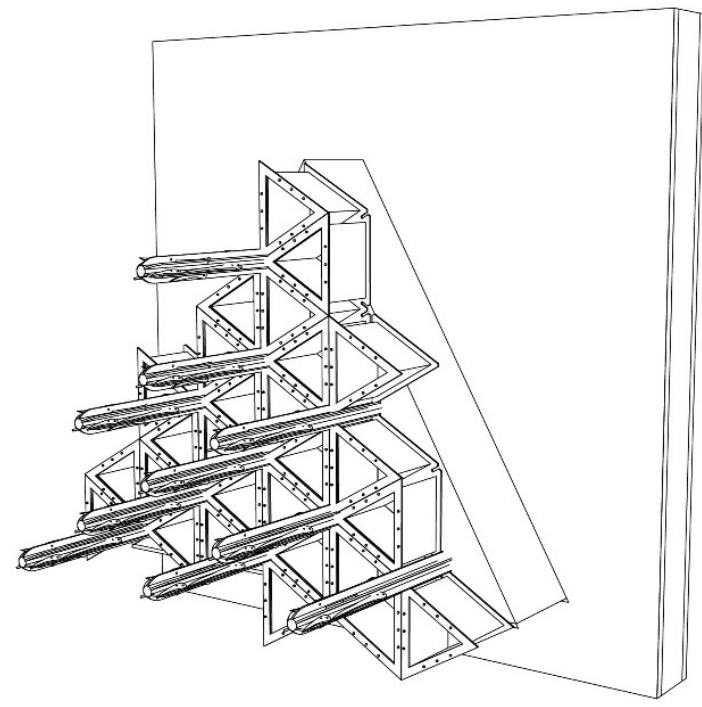

Illustration 46 Dynamic Pine Facade in closed state

\section{PINE FACADE - DYNAMIC OPEN}

"Pine Facade" used to collect falling snow during winter months

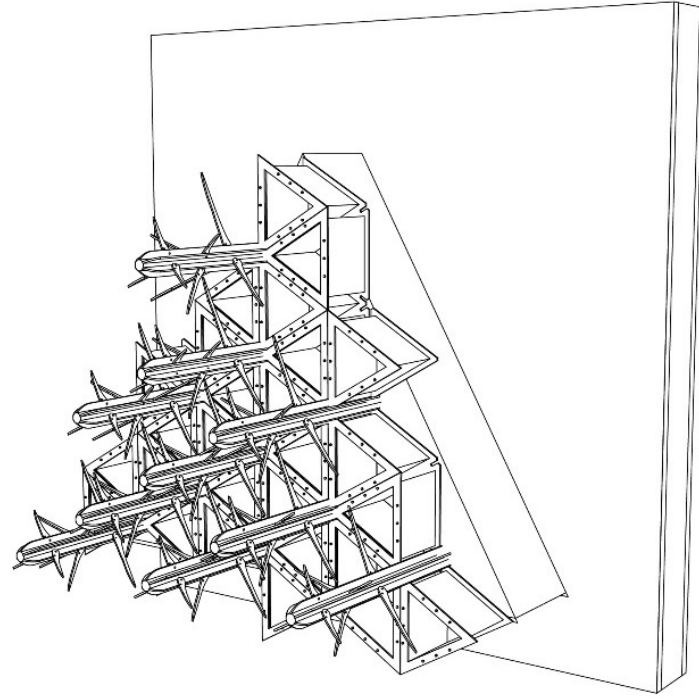

Illustration 47 Dynamic Pine Facade in open state 
During the second iteration the design progressed to use less mechanical ways of thinking and related back to natural processes. The second major iteration made stem profiles that compacted into one another that used attached acetate to increase the population of "needles" to improve snow capture. This solution was still highly mechanized and required further simplifying. Additionally each of the acetate "needles" had no support to them so although wind would filter through moving the acetate its capabilities of holding the snow were not as efficient as possible.

\section{WINA Assembley FACADE - ITERATION 2}

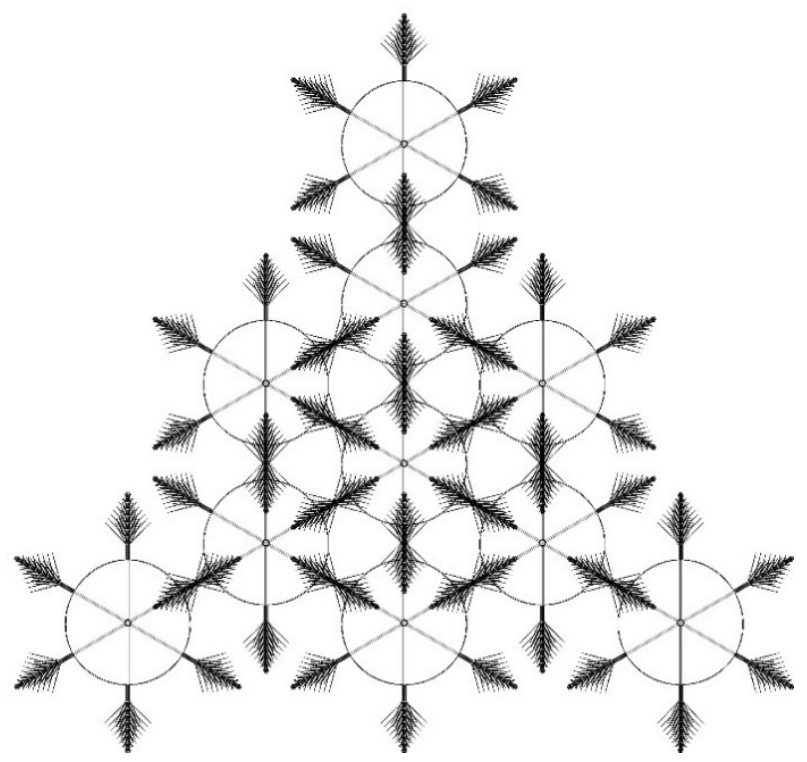

Illustration 48 summer elevation of the snow capturing devices of the Pine Façade (Iteration 2). 


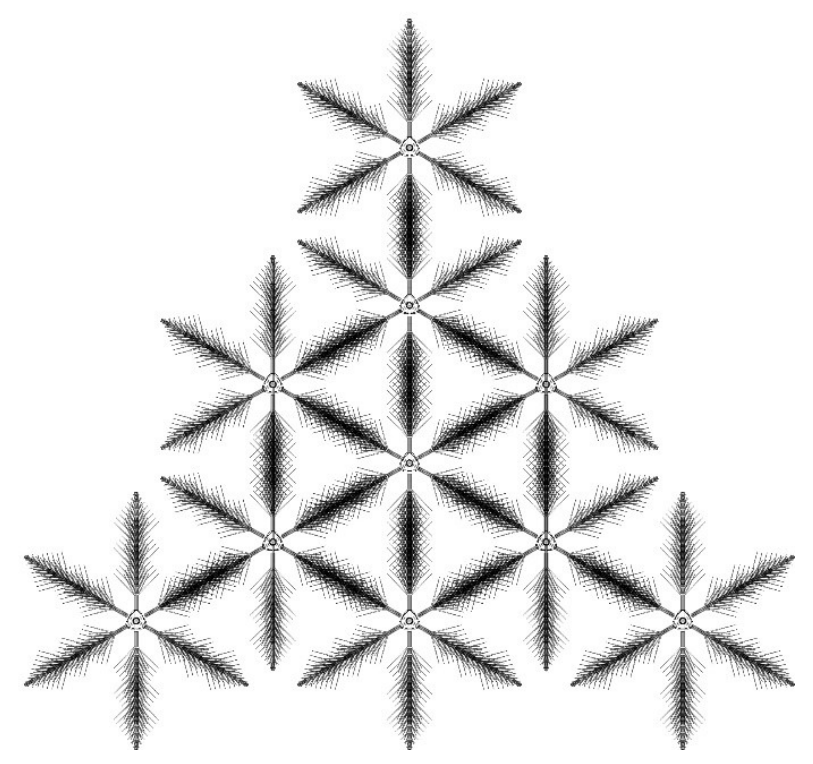

Illustration 49 shows the elevation of the snow capturing devices of the Pine Façade (Iteration 2) during winter months.

Working with this framework the materials LiTraCon and Aerogel were investigated to try to create a panel that would be structurally rigid, transparent, and insulated for aesthetic and performative reasons. The interior of the building was designed to be lit with translucent light filtering through the LiTraCon during the day, while at night interior lights create a glow seen from the exterior. Seasonal plant growth and snow accumulation should be seen from the interior of the building further linking occupants and the architecture back to the site. 
The third major iteration used a translucent LiTraCon Panel and the Dichroic Glazing System. The LitraCon is the structurally rigid portion that takes the weight of the steel "stems" and latex panels. In summer months the steel rod frame and latex panels would withdraw into the LiTraCon Panel to avoid plant growth that could destroy the mechanism. While in late autumn the mechanism would disband from behind the cavity in the LiTraCon Panel to prepare for winter snow collection to act as an additional layer of insulation. In winter months the frame stretches the latex to close the stoma while in early spring the steel rod frame compresses to open the cuts within the latex allowing water to drain and trickle down the facade. This uses similar principles of the stoma seen in pine needles to conserve water. Additionally the LiTaCon on the exterior surface will be sandblasted to texturize the exterior face of the panel in order to grip particulates of dirt, snow, or ice. This uses the same principle as the ridges surrounding the stoma found on the pine needle to conserve water.

A trellis system made of threaded rods and steel attachment pieces was placed at the end of each of the steel "stems". Although the wall assembly accounted for snow accumulation and vine growth to occur on the same plane it relied too heavily on the force of the disbanding mechanism to overpower seasonal vine growth. The final iteration needed to take into account where plant growth and the disbanding mechanism would not hinder one another's functional objective. 


\section{PINE FACADE - ITERATION 3}

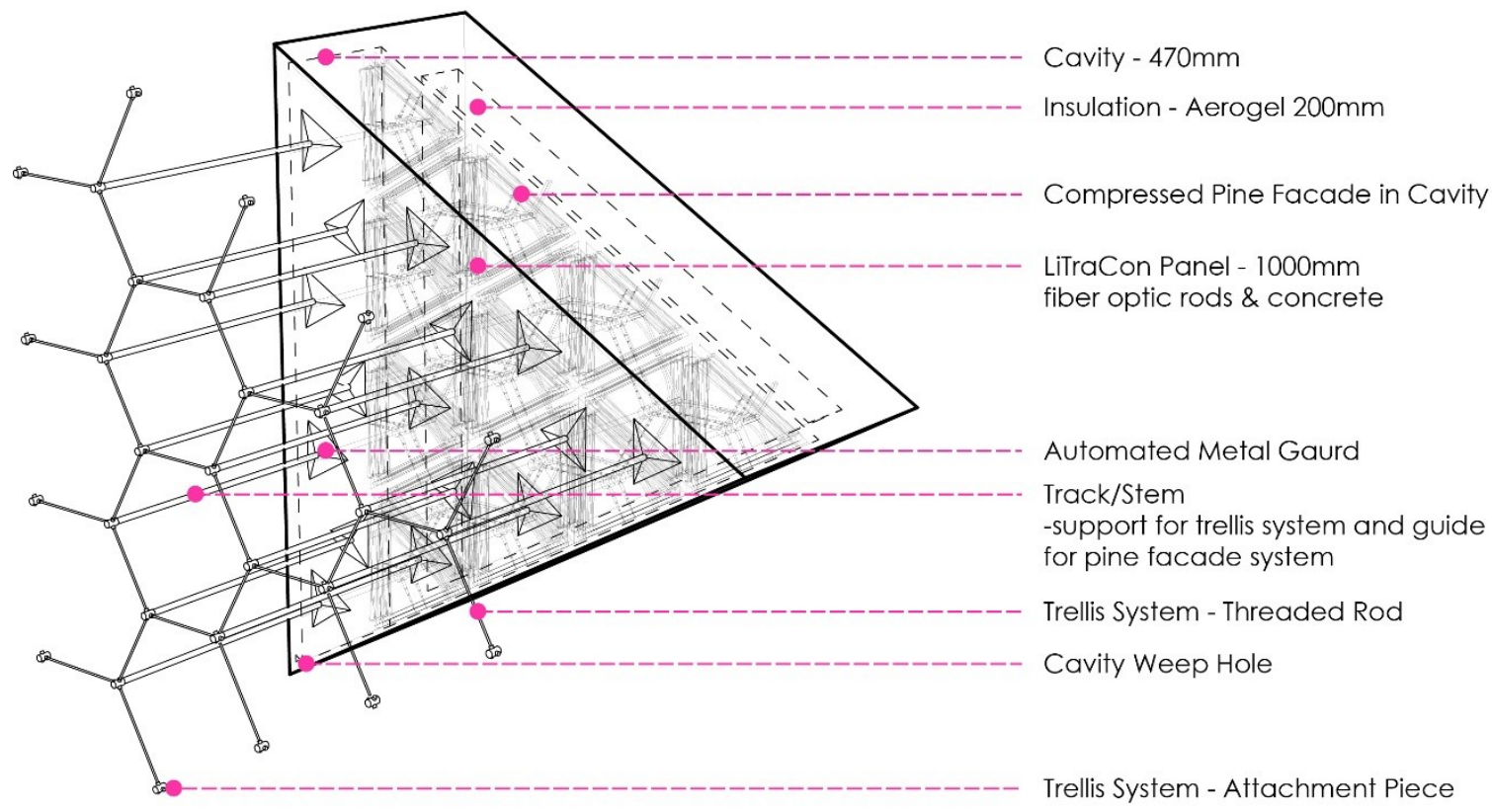

\section{Illustration 50 Shows the Components in Iteration 3}




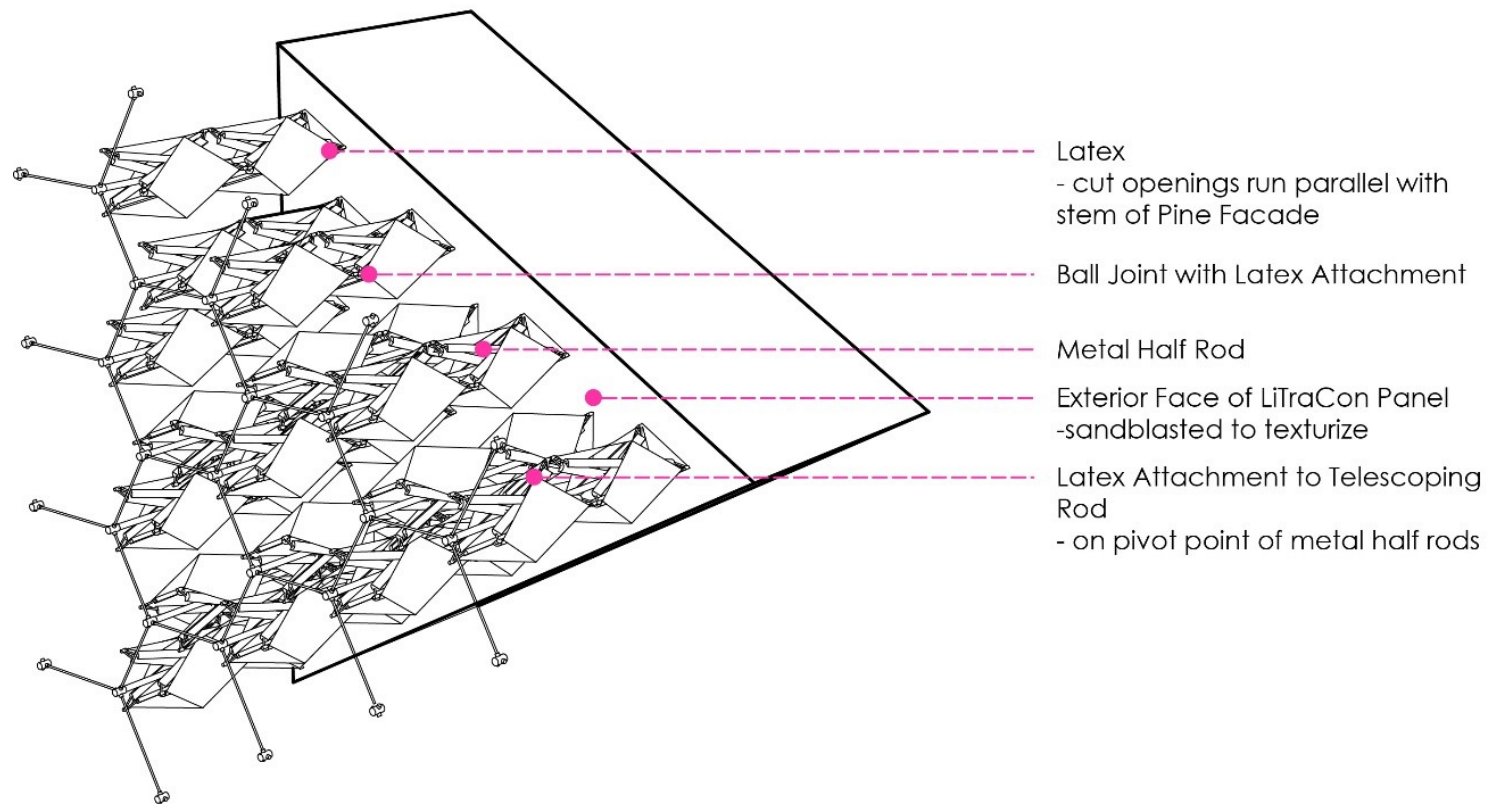

Illustration 51 Shows the Components in Iteration 3

Wall Assembley

PINE FACADE - ITERATION 3

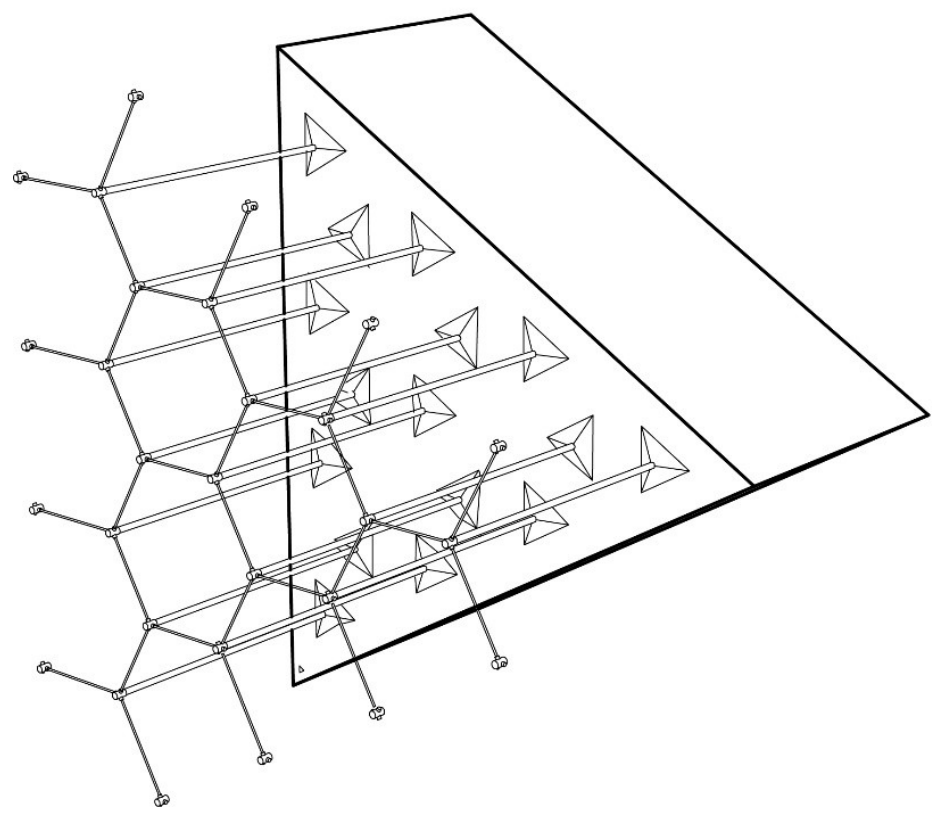

Stage 1 Summer

- Trellis System used for climbing vines

- Pine Facade is compressed into the wall during growing seasons

Illustration 52 Shows Stage 1 


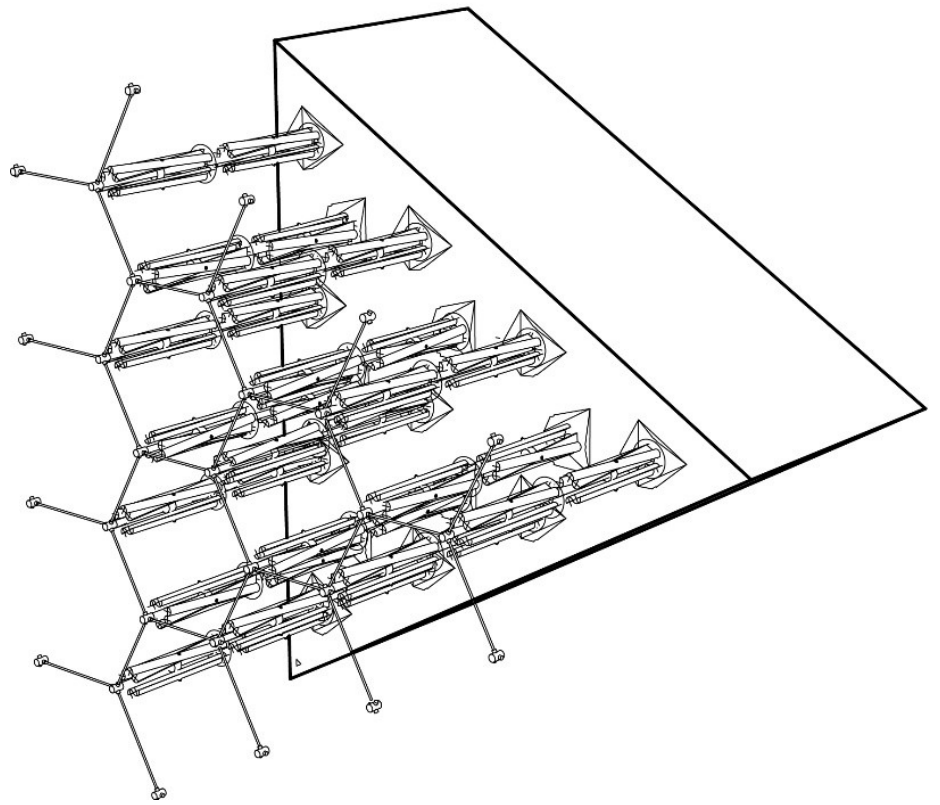

Illustration 53 Shows Stage 2

Wall Assembley

PINE FACADE - ITERATION 3

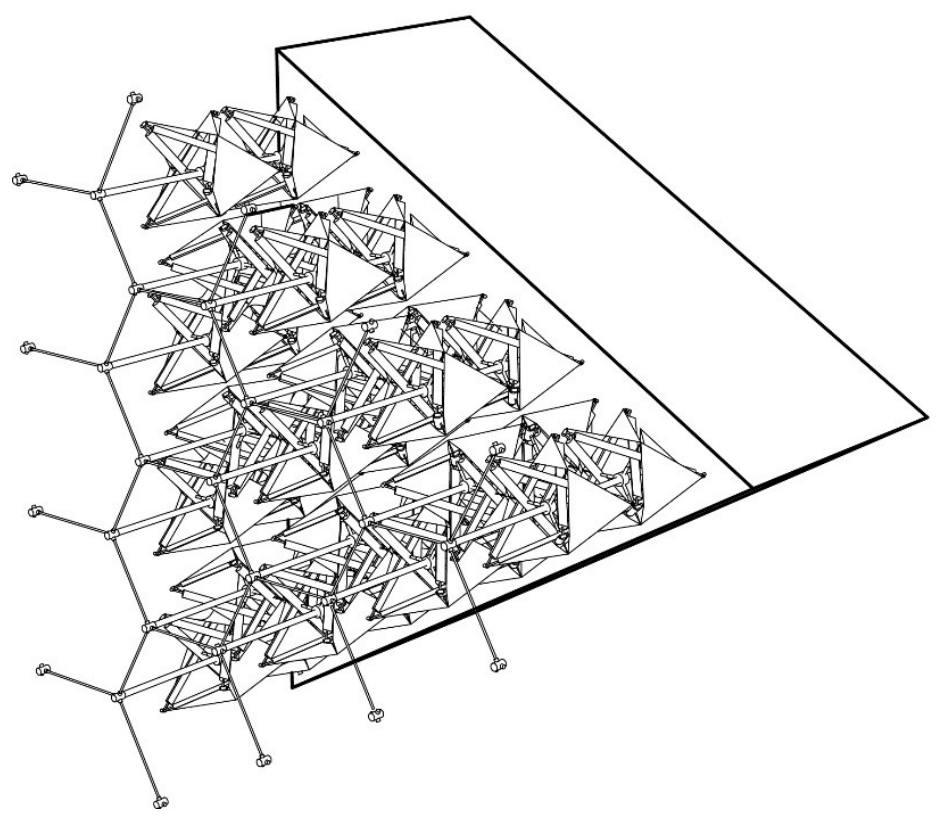

Illustration 54 Shows Stage 3
Stage 2 Late Autumn

- Leaves change colour and drop for winter

- Pine Facade system disbands from inside of wall to prepare for winter snow and ice accumulation
Stage 3 Homeostatic

- Frame at 90 degrees of one another

-Stoma not pulled closed or pulled open 


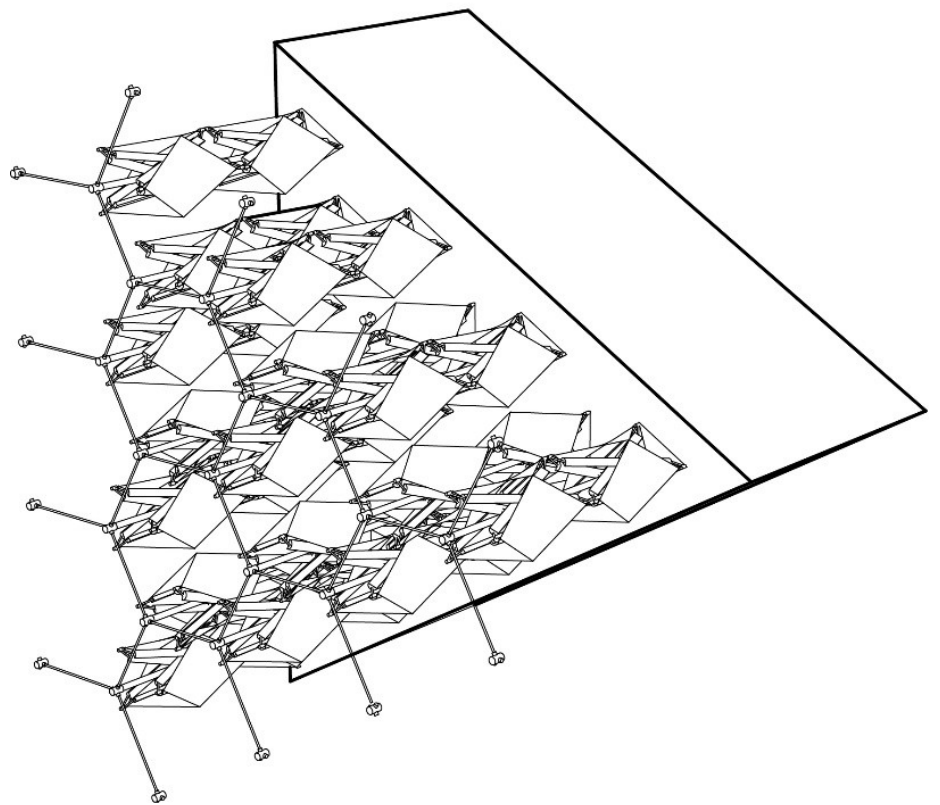

Illustration 55 Shows Stage 4

Wall Assembley

\section{PINE FACADE - ITERATION 3}

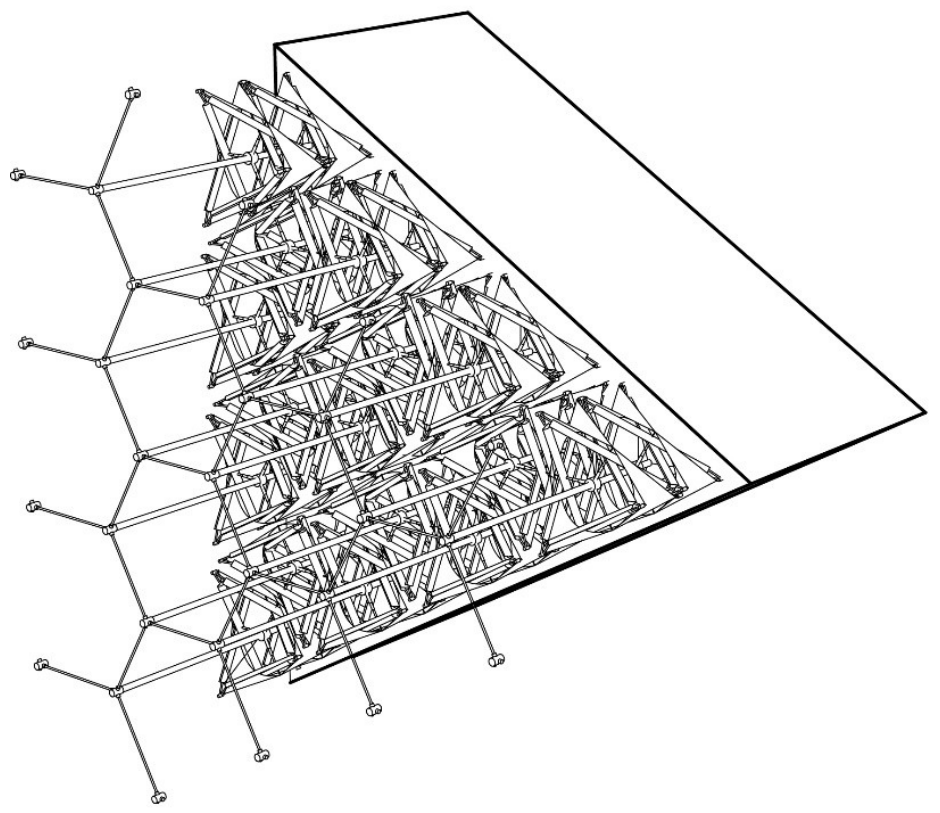

Illustration 56 Shows Stage 5
Stage 4 Winter

- Stem of vine remaining on Trellis System collects snow

- Frame expands forwards to pull Latex. Cuts within Latex (Stoma) are pulled closed

- Snow and ice accumulate on Latex surfaces and within frame and stem assembly

Stage 5 Late Winter/Early Spring - Snow and ice begin to melt as temperatures rise

- Frame compresses toward the wall pulling stoma in Latex open

- Stoma allow water to melt and trickle down the surface of the facade

- Water used for sping vine growth

- Dry Pine Facade compresses back into wall cavity for growing season 
The last iteration of the Pine Façade took the same mechanisms from the previous iteration and moved the trellis system to a distance where the snow capturing devices and plant growth would not harm one another and could become occupied by inhabitants. This design move eliminated the need to retract the snow capturing device back into the LiTraCon panel and reduced the mechanization movements from five steps (stretch latex, compress latex, homeostatic state, stretch frame, and compress frame) down to two (stretch latex and compress latex)

The last design iteration focused on the trellis systems as a means for getting full vine coverage along the building façade. Although modules were not used the trellis system itself could be used to hang planting modules in the future.

\section{Wall Assembley
PINE FACADE - ITERATION 4}

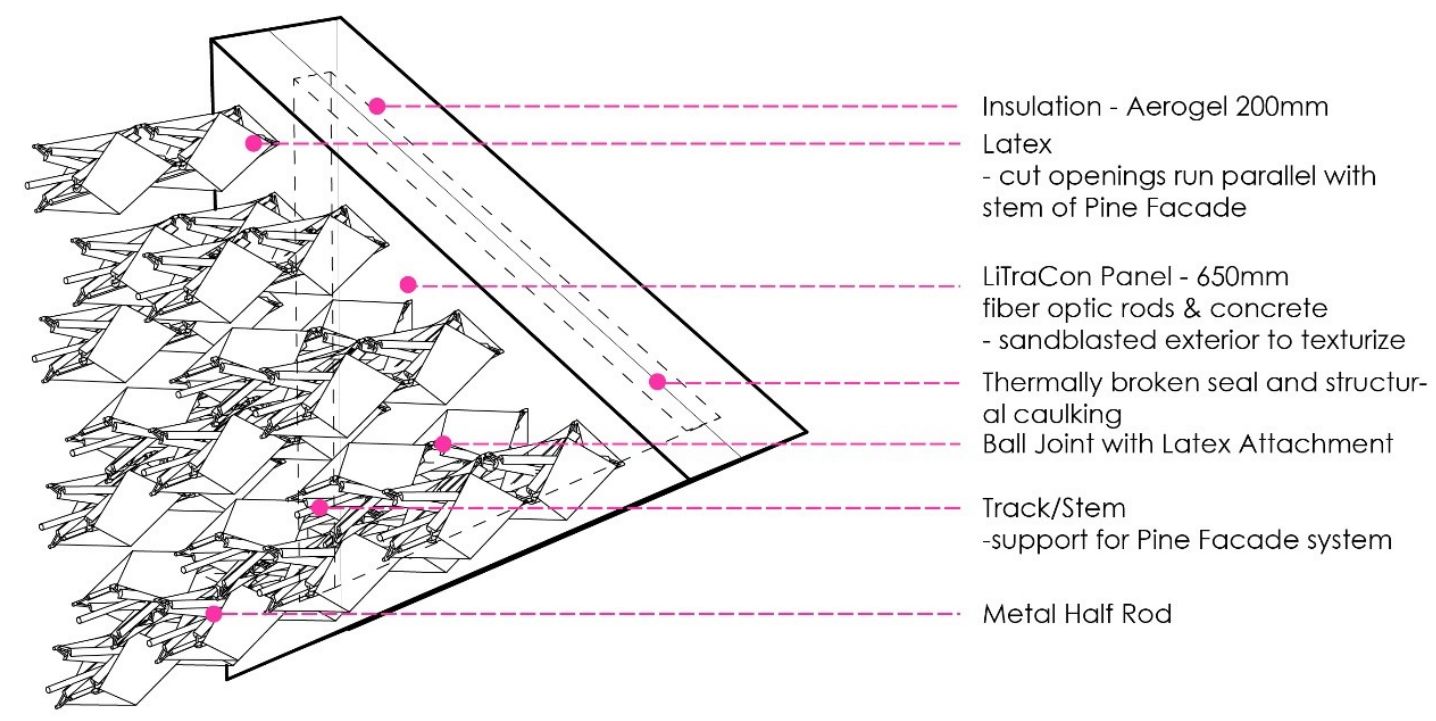

\section{Illustration 57 Shows Components of Iteration 4}




\section{PINE FACADE - ITERATION 4}

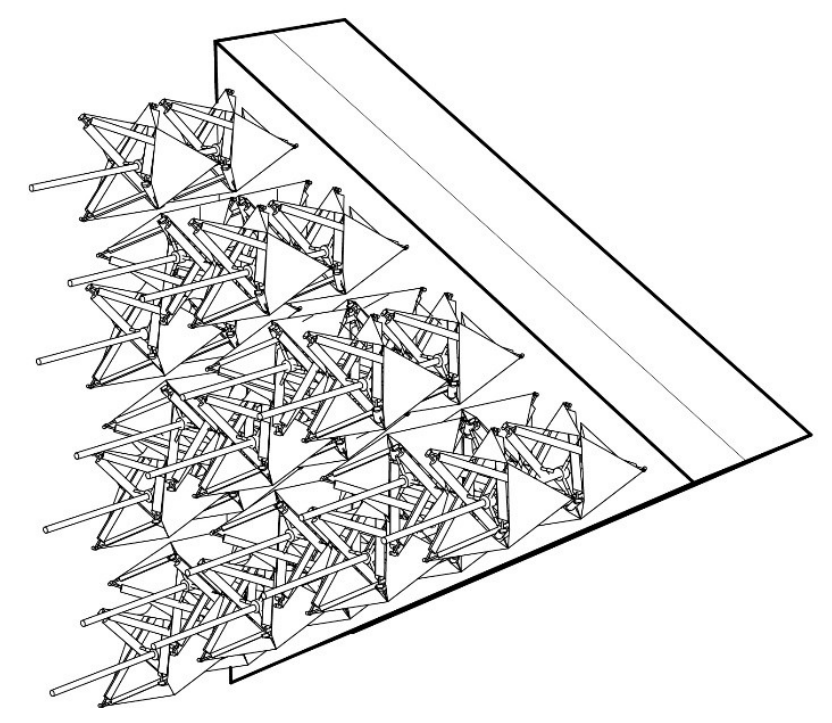

Illustration 58 Stage 1

malasementer

\section{PINE FACADE - ITERATION 4}

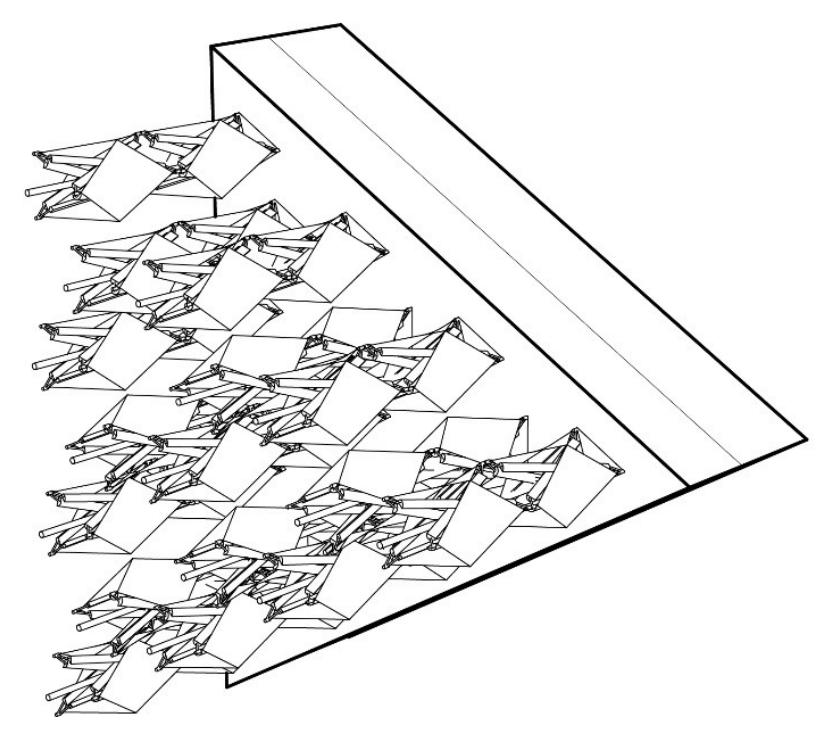

Stage 1 Summer, Spring, \& Autumn

- Pine Facade frame compresses and stoma on Latex are stretched open

- Water moves through stoma openings and is collected at the base of the wall for Trellis System plants
Stage 2 Late Autumn \& Winter

- Pine Facade frame compresses in the opposite direction and stoma on Latex are stretched closed

- Snow and ice accumulate on Latex surfaces and within frame and stem assembly

\section{Illustration 59 Stage 2}




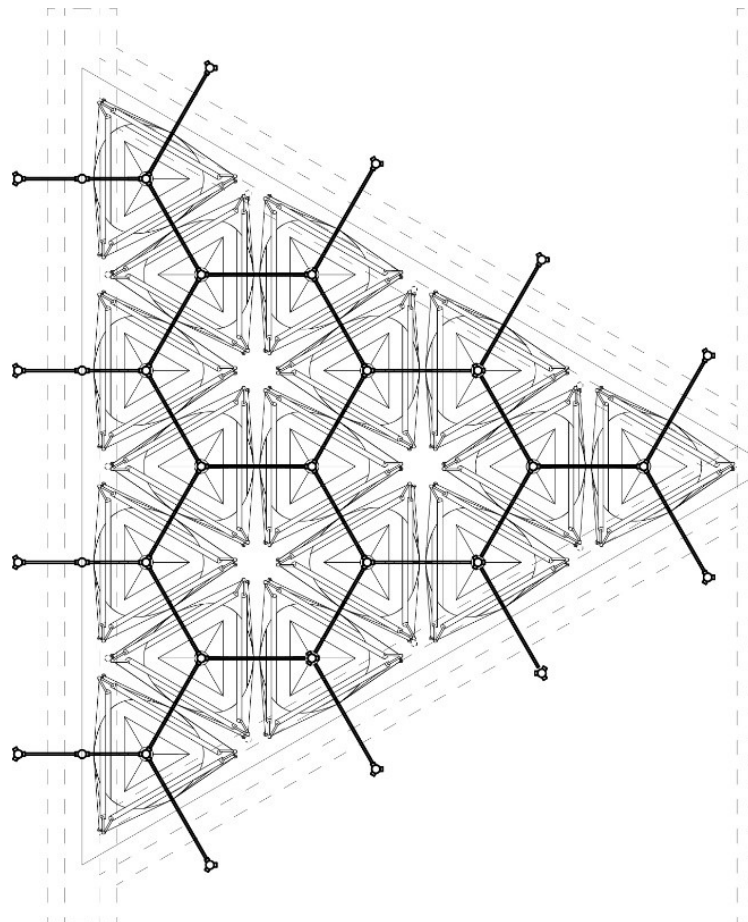

Illustration 60 Elevation A of Iteration 4 during summer

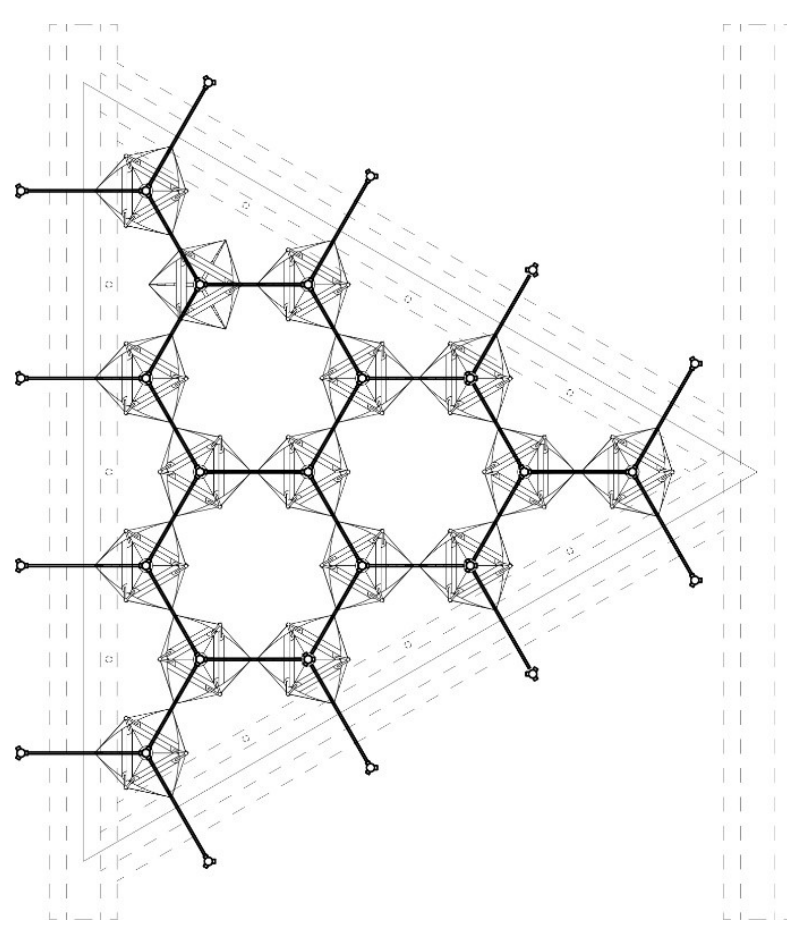

Illustration 61 Elevation A of Iteration 4 during winter 

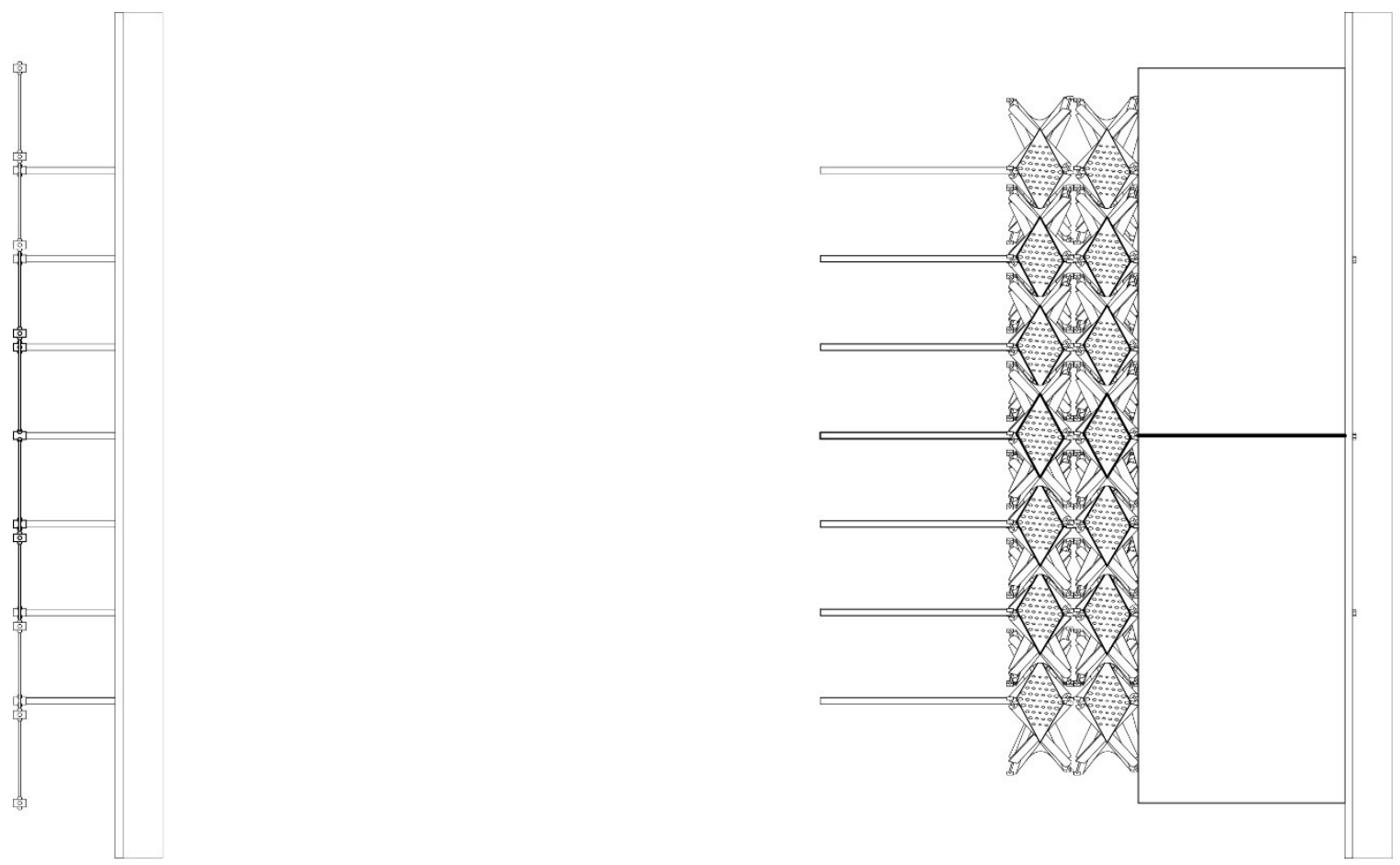

Illustration 62 Elevation B of Iteration 4 during summer
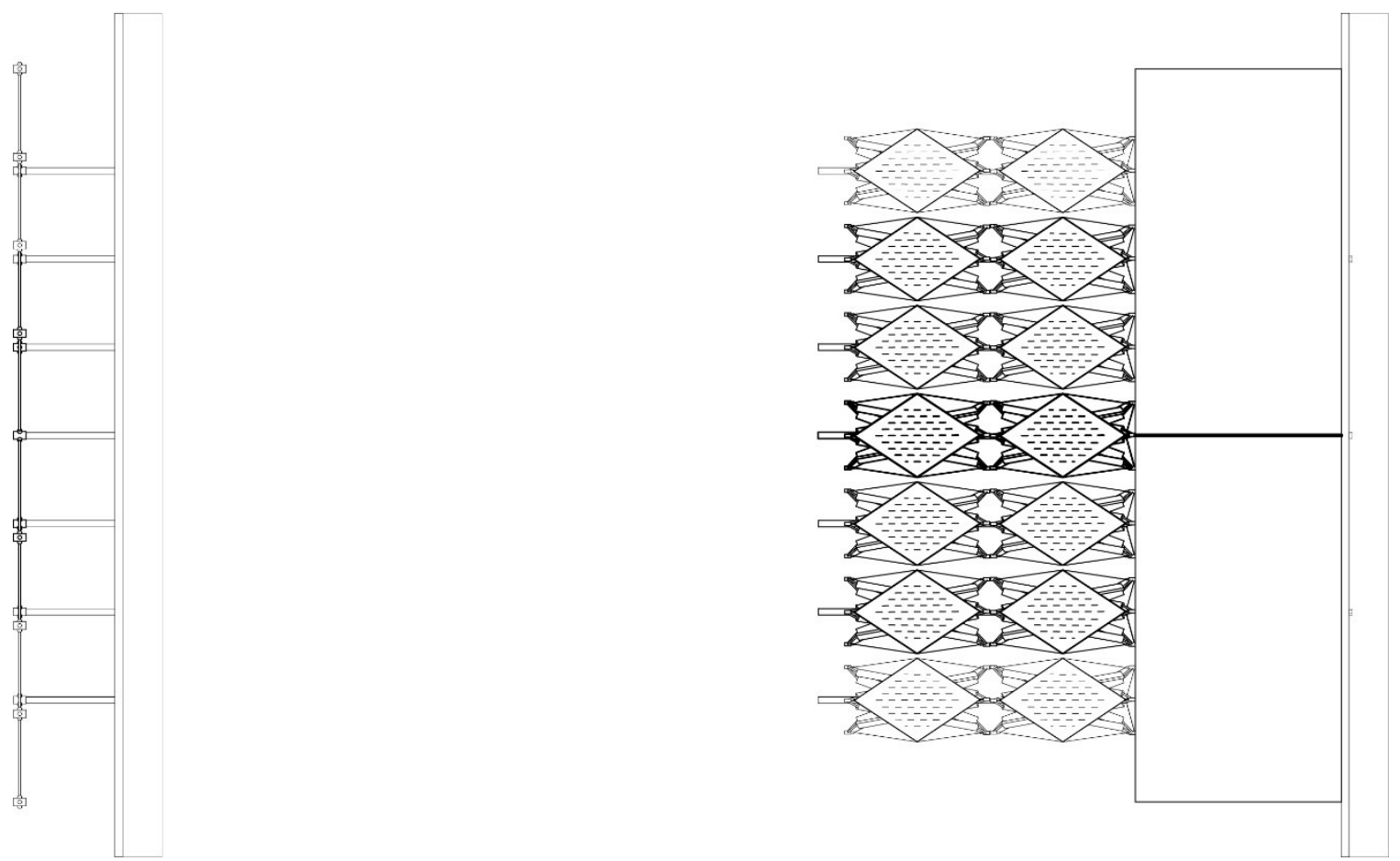

Illustration 63 Elevation B of Iteration 4 during winter 

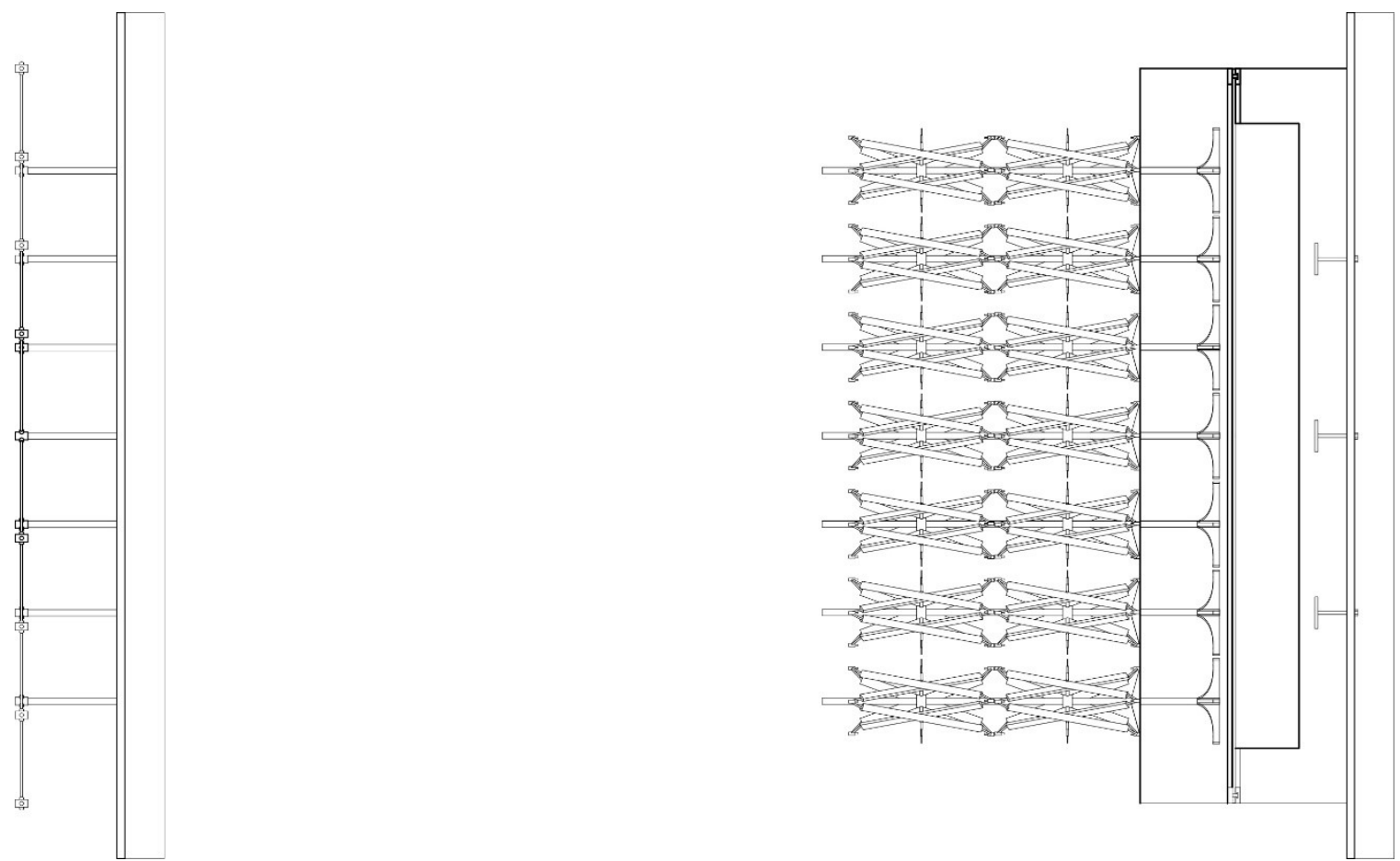

Illustration 64 Section of Iteration 4 during winter

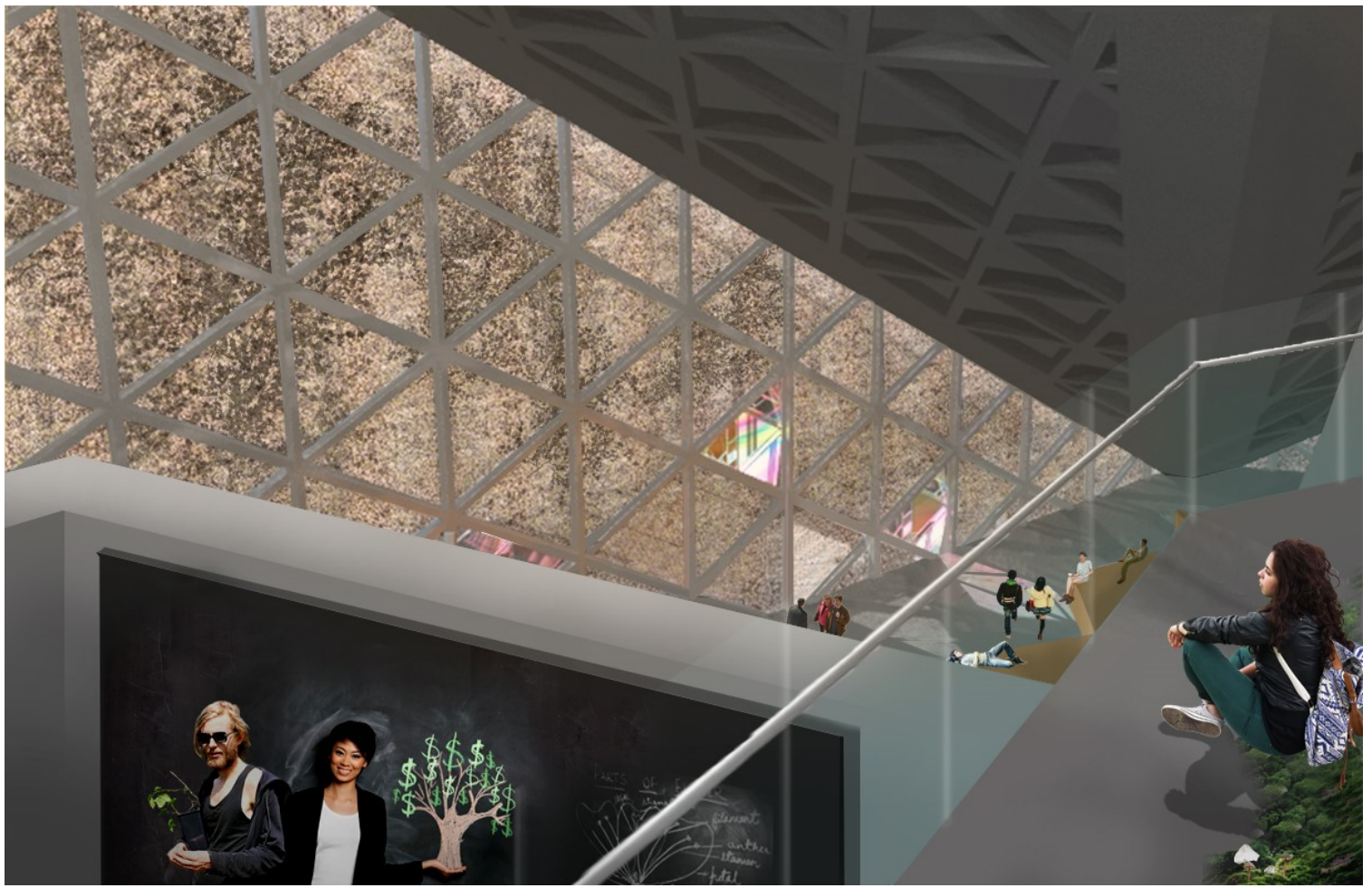

Illustration 65 Interior rendering during the summer showing silhouettes of vines cast on LiTraCon panels 


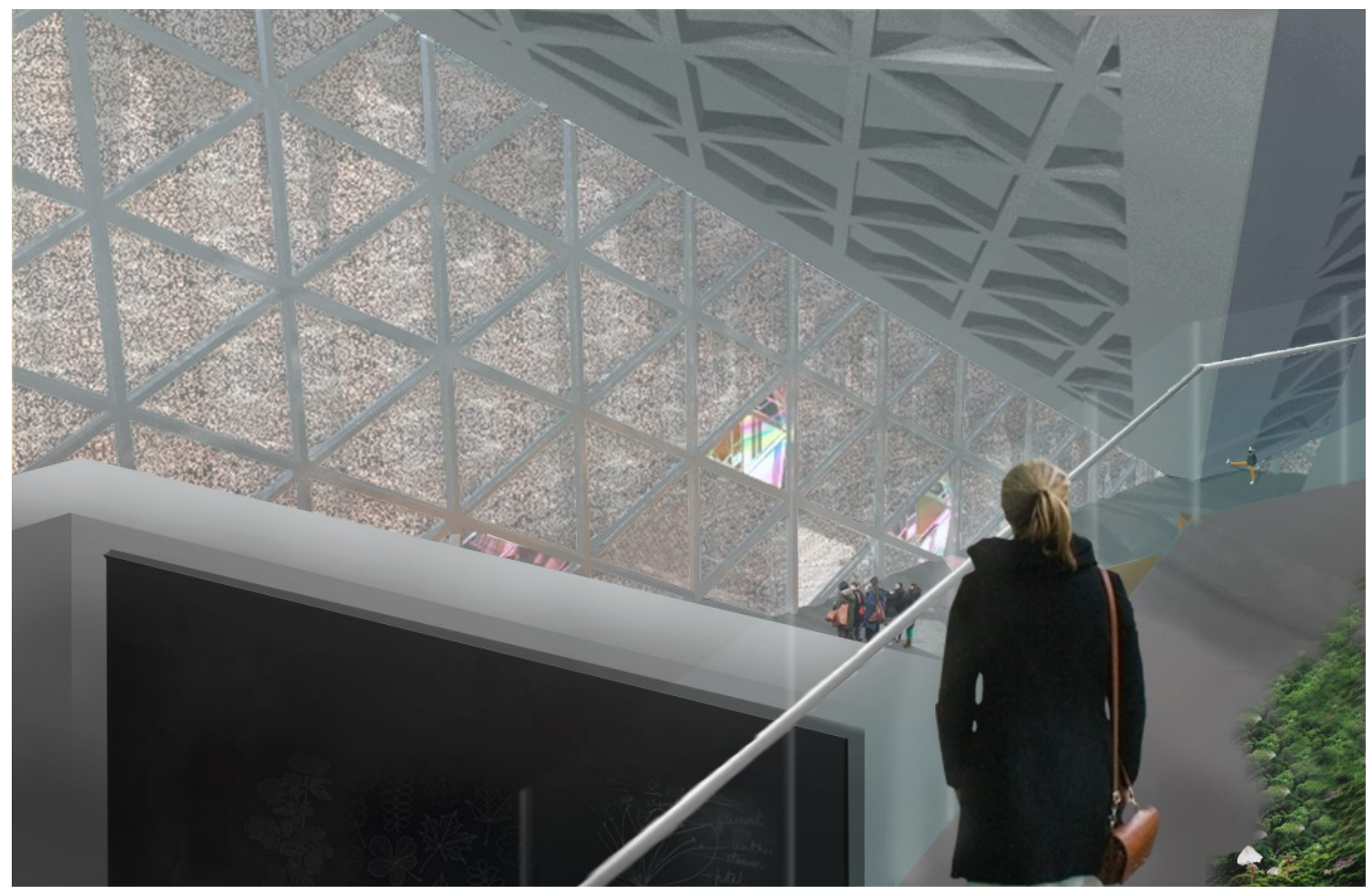

Illustration 66 Interior rendering during the winter showing snow accumulation and icicle silhouettes cast on LiTraCon panels

\subsection{Building Proposal: Latent Project}

The Latent Project's massing was directly formed by the sites alternating seasonal wind directions, site topography, site footprint, sun analysis, and reiterative development with the building envelope and its desired objectives. As seen in nature both plants and animals 
have behavioral, morphological, physiological adaptation mechanisms to resist cold climates and these principles were directly applied to the building.

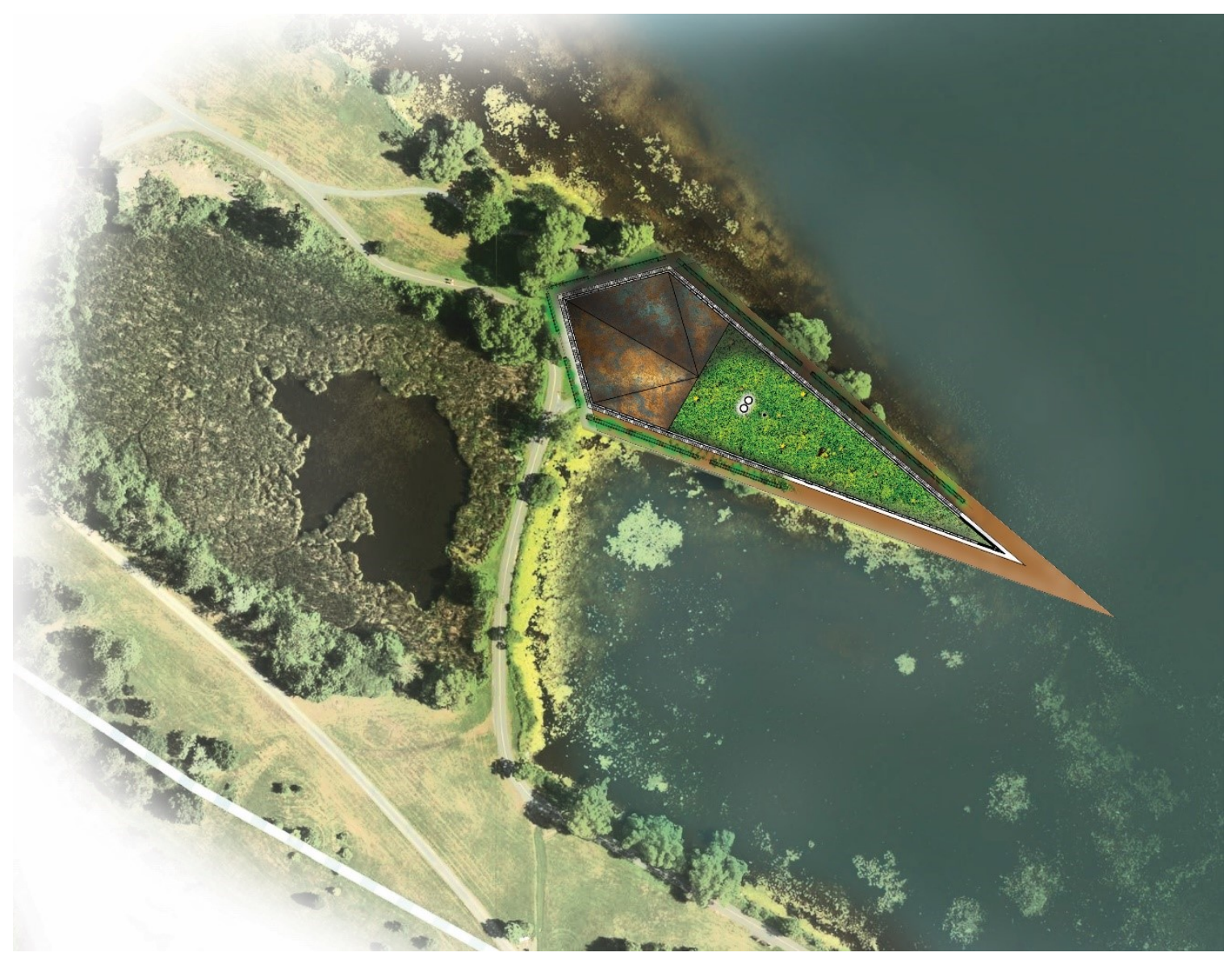

Illustration 67 Shows site plan on Dow's Lake

The walls or major planes of the building were situated in consideration of the contextual environmental factors. The south eastern and north eastern facades' of the building tilted inwards towards the sites pier to simplify the mass and replicate the site's footprint while allowing it to be sheltered from winter winds. The western portions of the building however act as the major planes to collect snow for insulative purposes in winter months but become seasonal entrances in warmer months. The dichroic glazing system open periodically to allow for cross ventilation to occur in warmer months and creates portions of the window that reflects the light differently depending upon the time of year and time 
of day. Entrances on the north, south, and east sides are pushed inwards to create a protected covering for occupants during times of poor weather but these doors should remain open in warmer months.

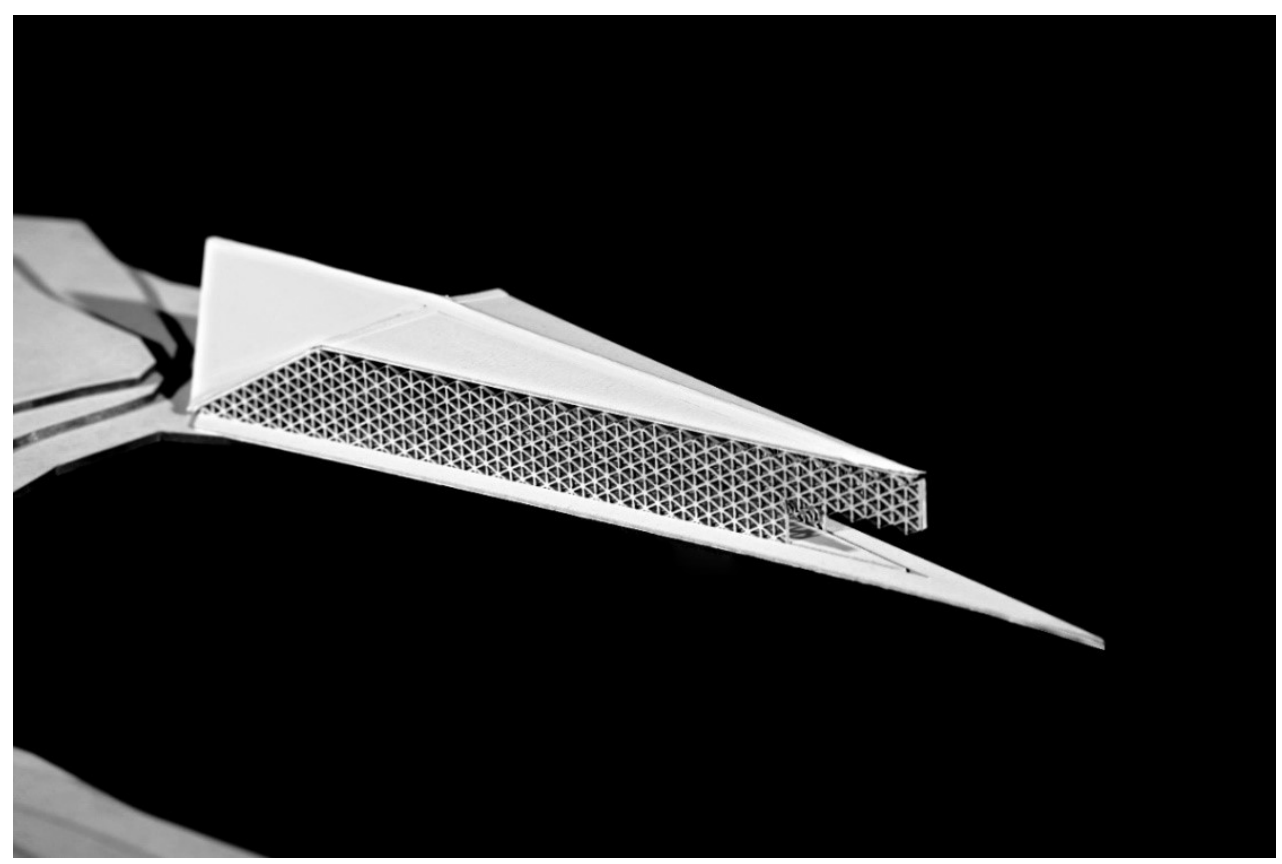

Illustration 68 Schematic massing model

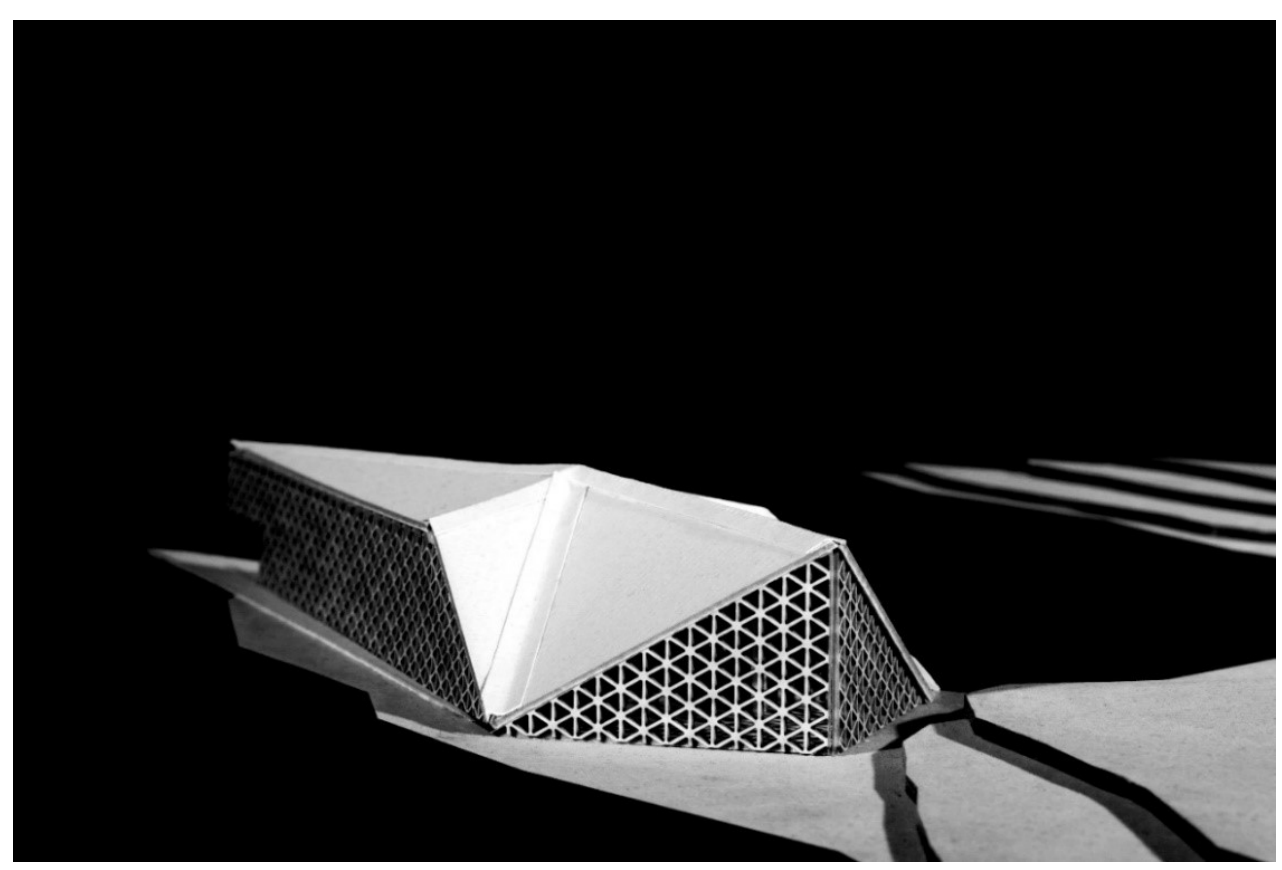

Illustration 69 Schematic massing model 


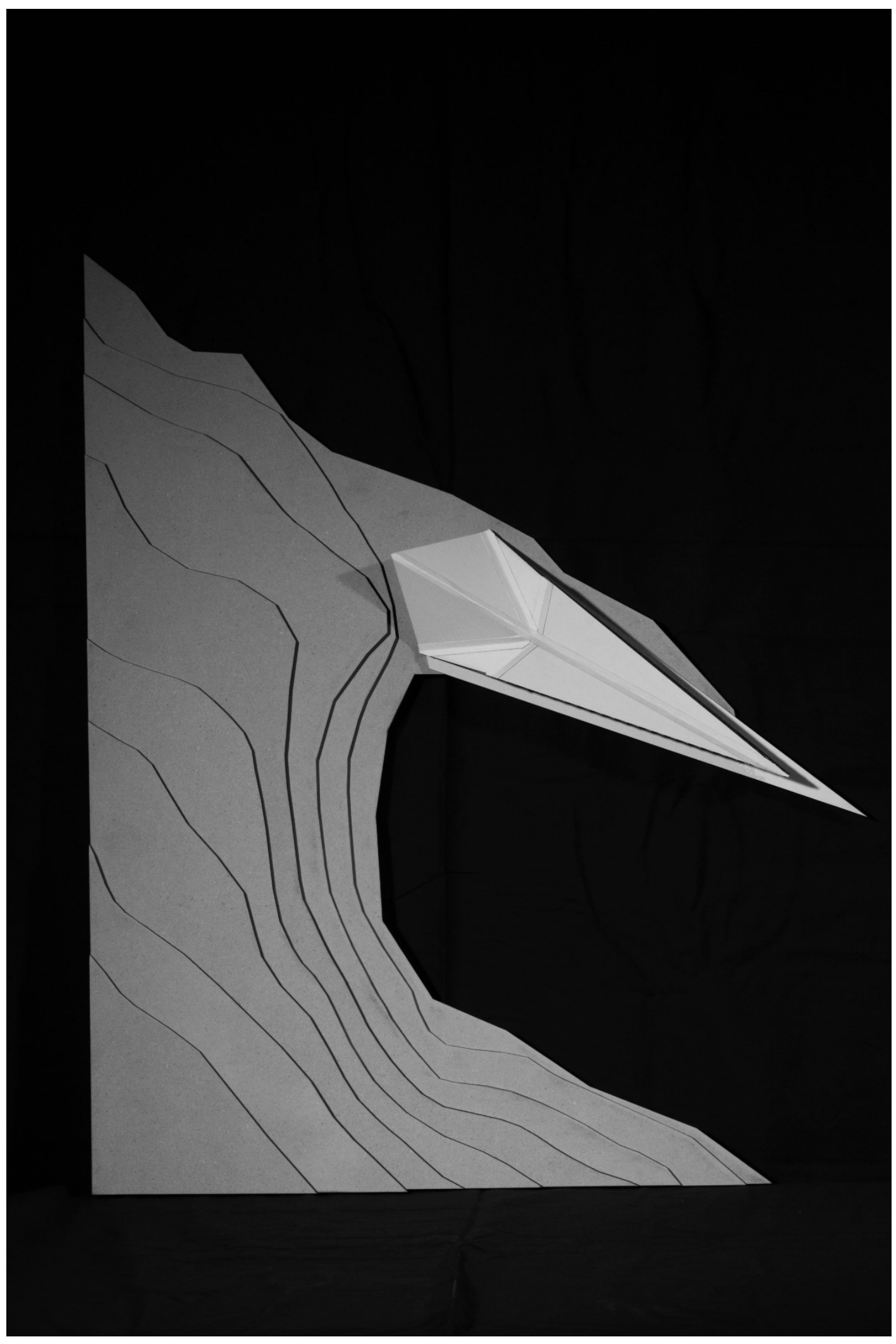

Illustration 70 Schematic massing model plan view 
The building purposely becomes more opaque towards the west of the building for performance and programmatic purposes. The west portion is more solid as it requires less natural light for the offices, PPU's, workshops, bathrooms, and viewing platforms. The east side of the building on the other hand requires a great deal amount of light for the green house and is entirely glazed in this section. Individual windows are removed from the otherwise translucent walls towards the west to give views to interior spaces suspended from the tree columns.

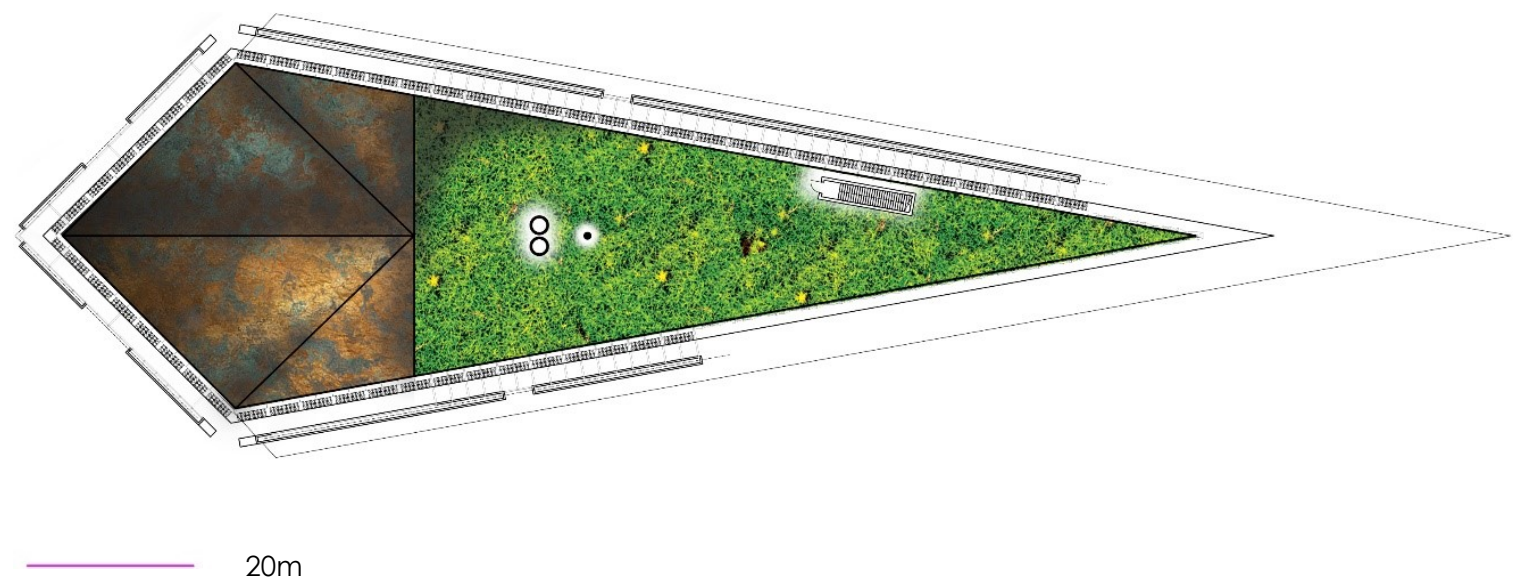

\section{Illustration 71 Roof Plan}

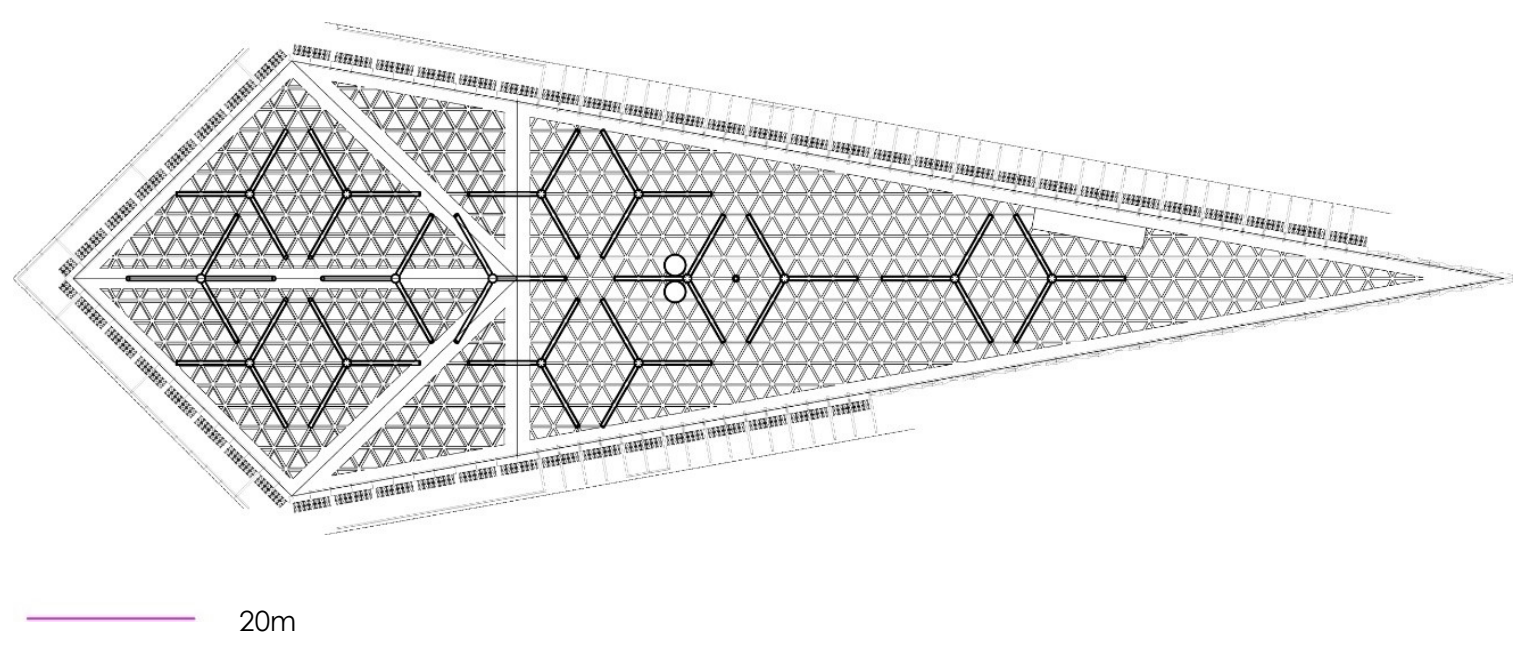

Illustration 72 Reflected Ceiling Plan showing tree column and branch location relative to roof waffle slab 


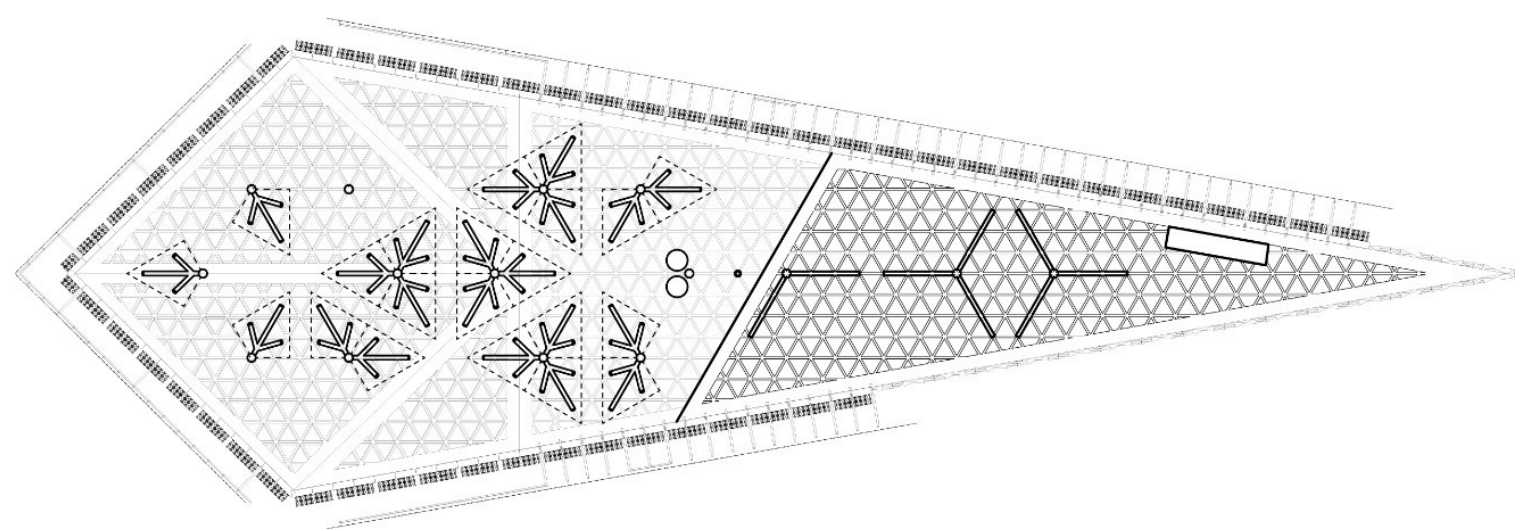

$20 \mathrm{~m}$

Illustration 73 Reflected Ceiling Plan showing tree column and branch location supporting floor slabs

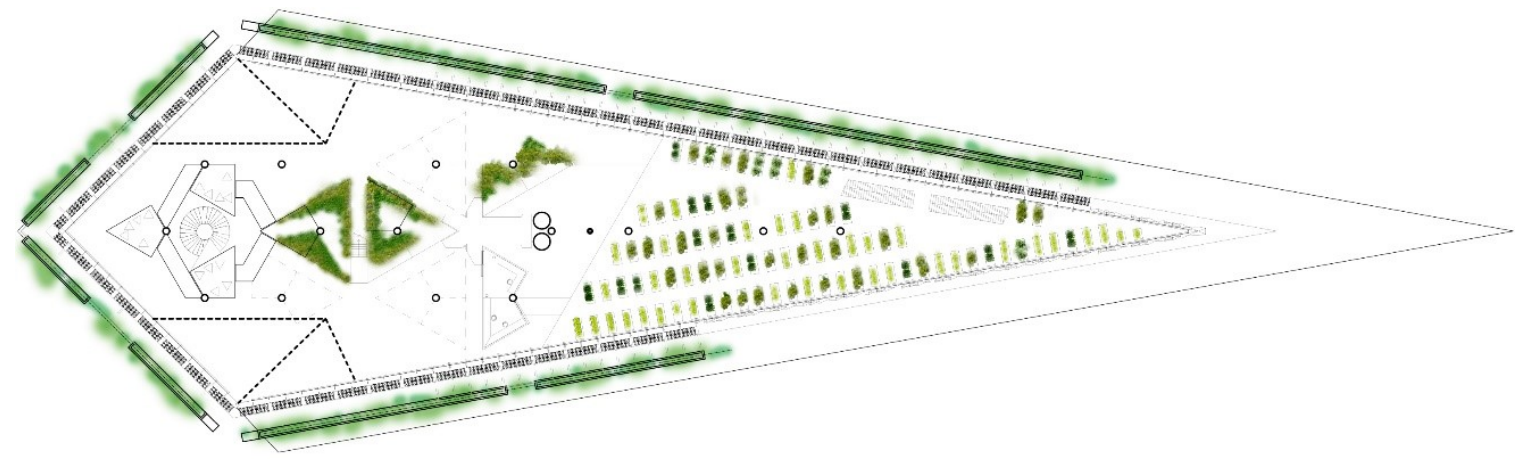

$20 \mathrm{~m}$

\section{Illustration 74 third floor plan}

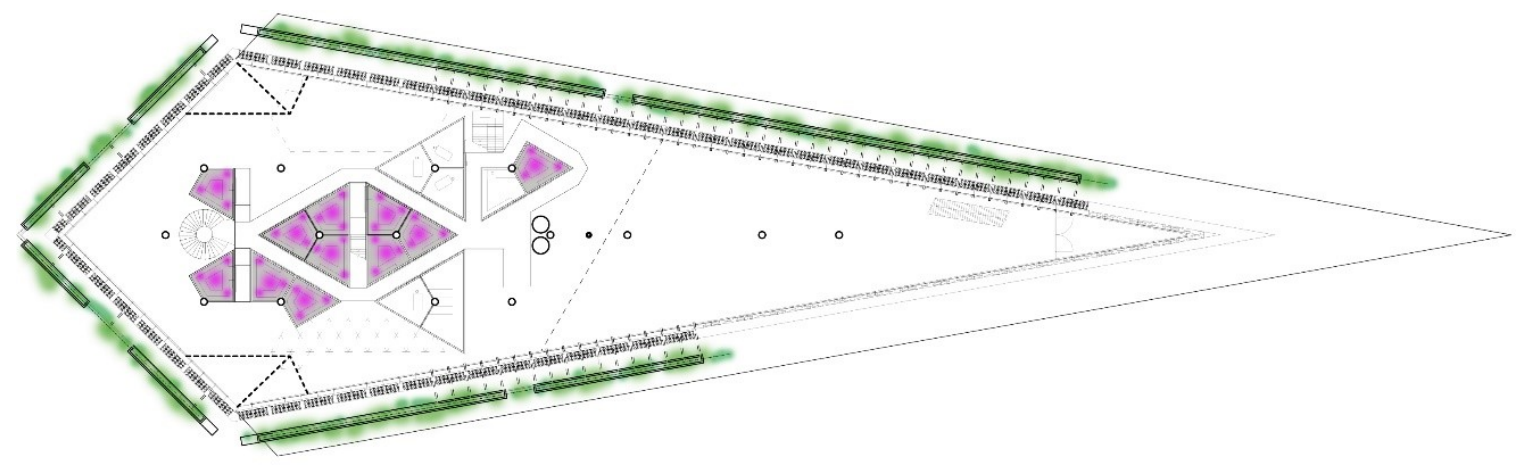

$20 m$

Illustration 75 second floor plan 


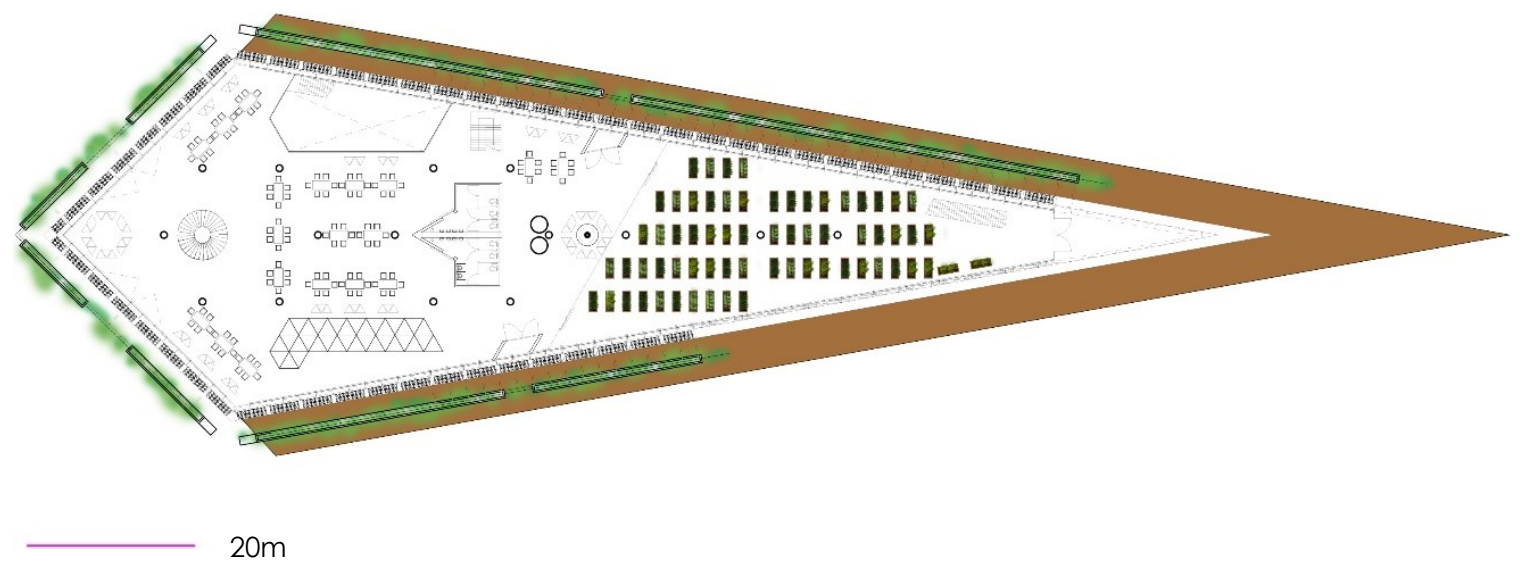

Illustration 76 ground floor plan

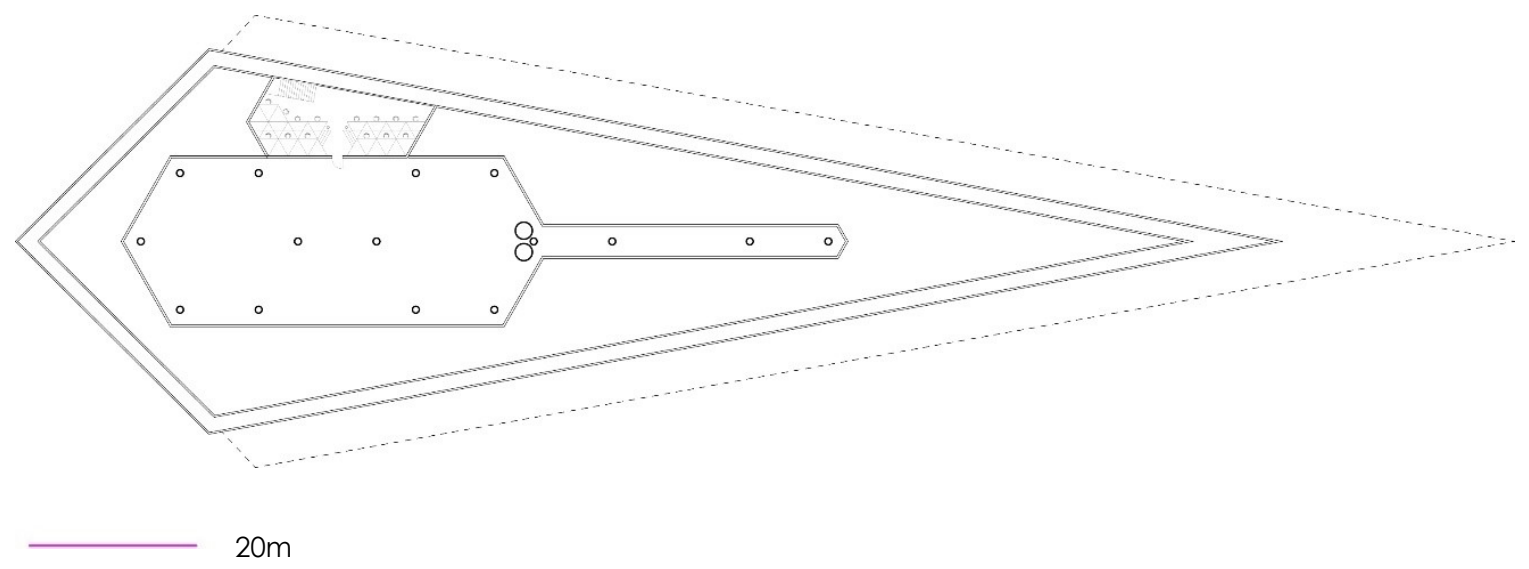

Illustration 77 basement floor plan

The roof planes have seasonal purposes. The flat eastern roof acts as an accessible roof for seasonal growing, while in winter months the parapet helps collect windblown snow. The pitched western roves act to collect snow on a macroscale.

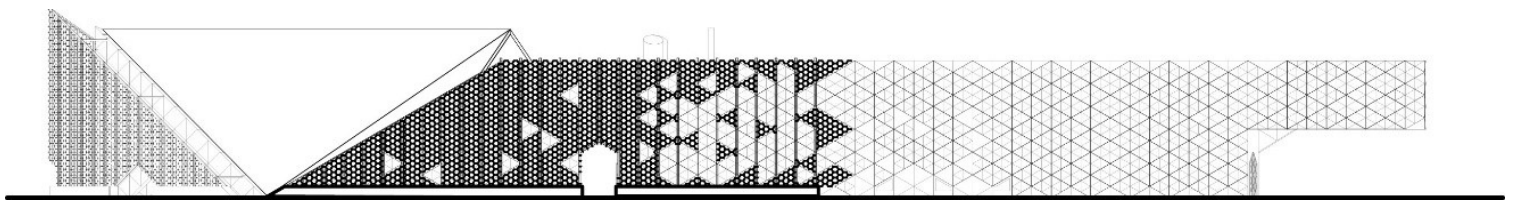

Illustration 78 South facade 


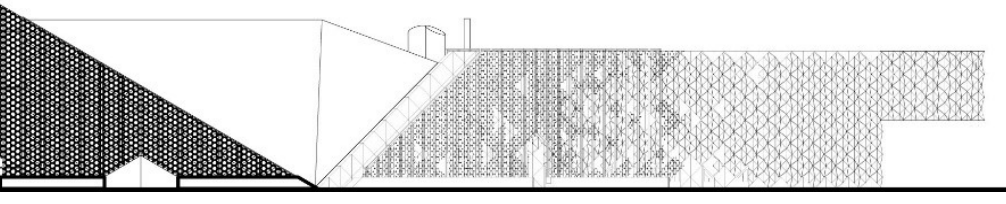

\section{Illustration 79 South west facade}

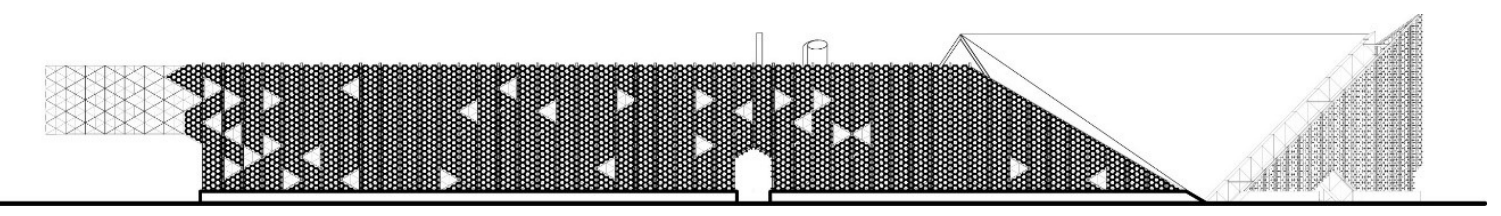

Illustration 80 North façade

The boardwalk surrounding the northeastern and southeastern facades accommodate seasonal uses of Dow's lake. The pier of the dock allows an area that cantilevers over the ice for skaters during the winter and an area to touch the water in summer months. The southern dock creates an area for summer boaters to dock alongside the building in the bay and watch wildlife. Recessed seating areas are located along the northeastern and southeastern facades. The trellis system is placed at the center of the dock to create a portion of the envelope that is both enclosed but open to the elements. This area allows for internal gatherings to occur and for sun bathers to use the back of the planter box as support when lying against it. 


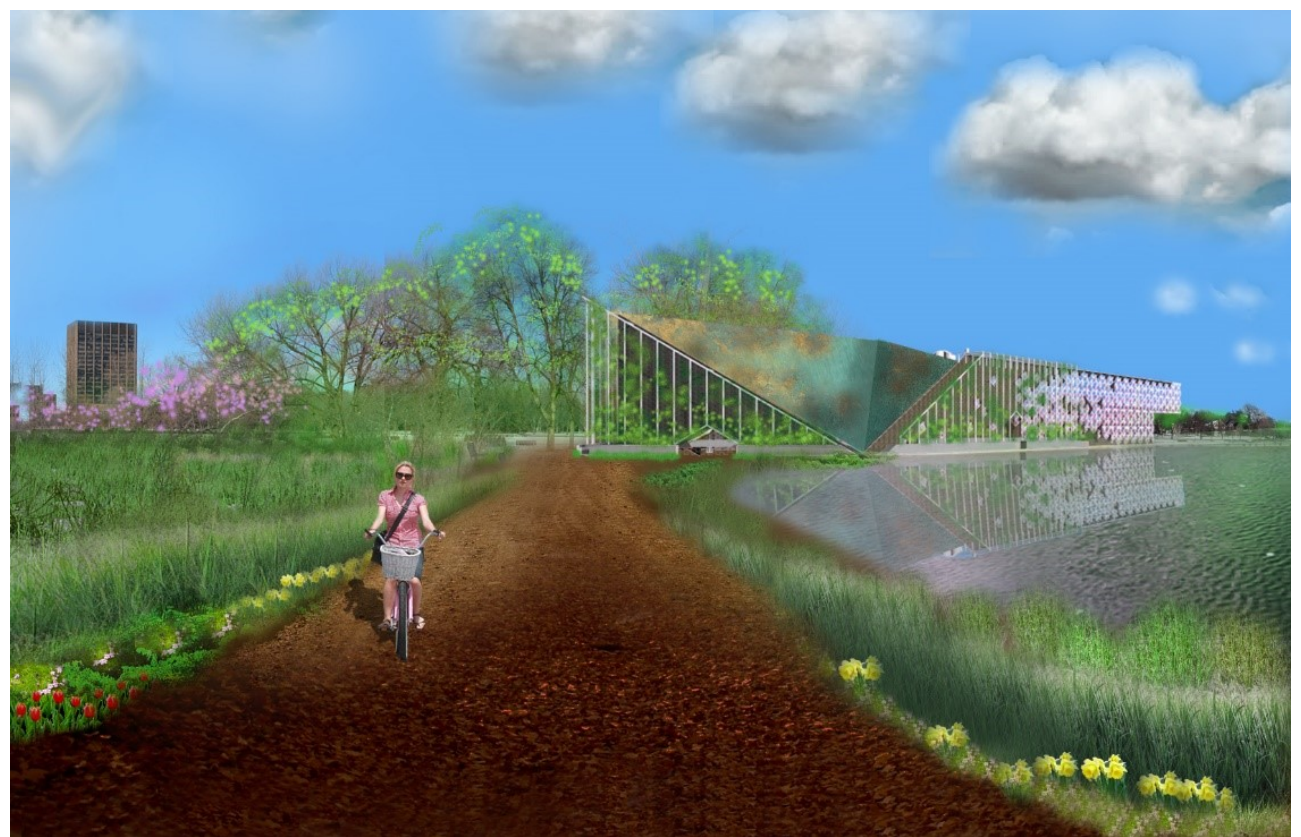

Illustration 81 Rendering of Latent Project in spring

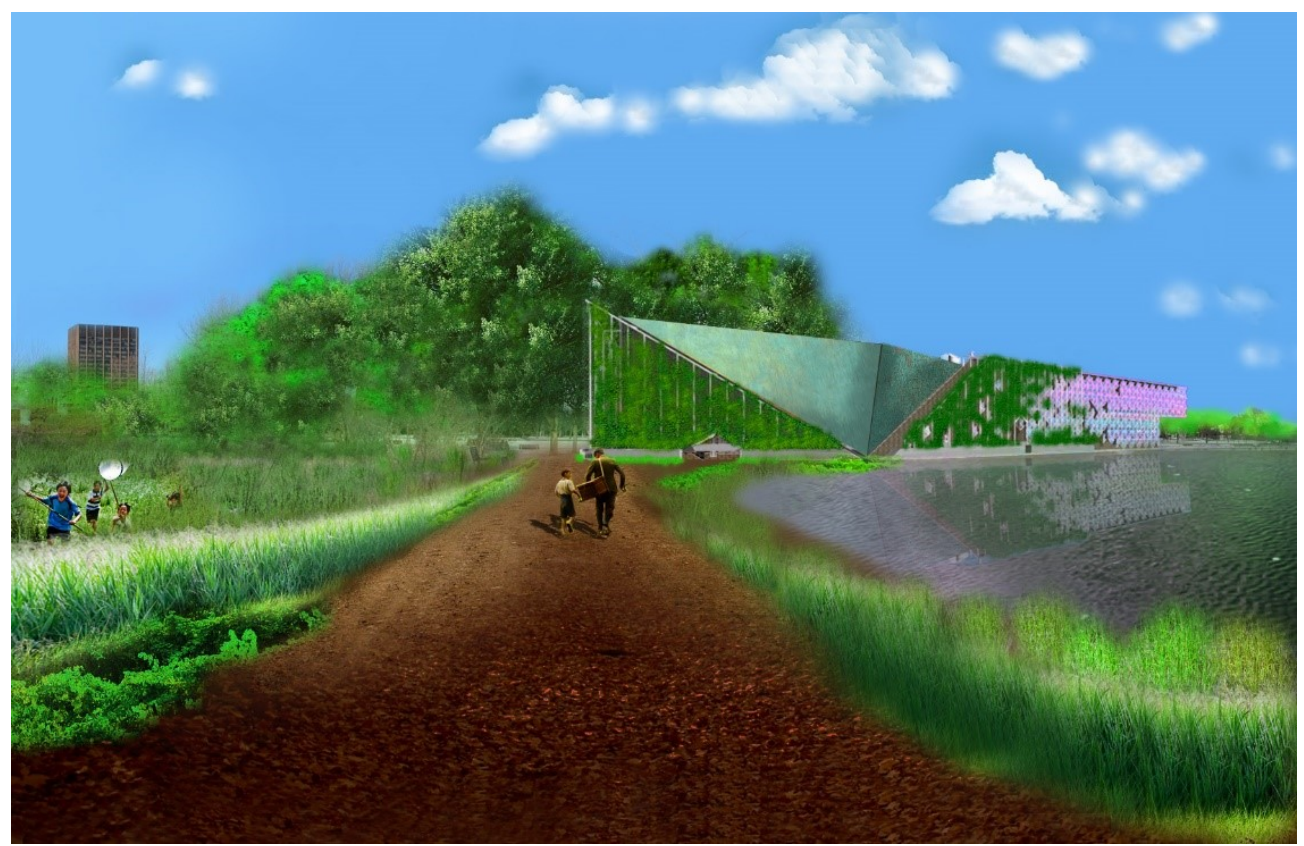

Illustration 82 Rendering of Latent Project in summer 


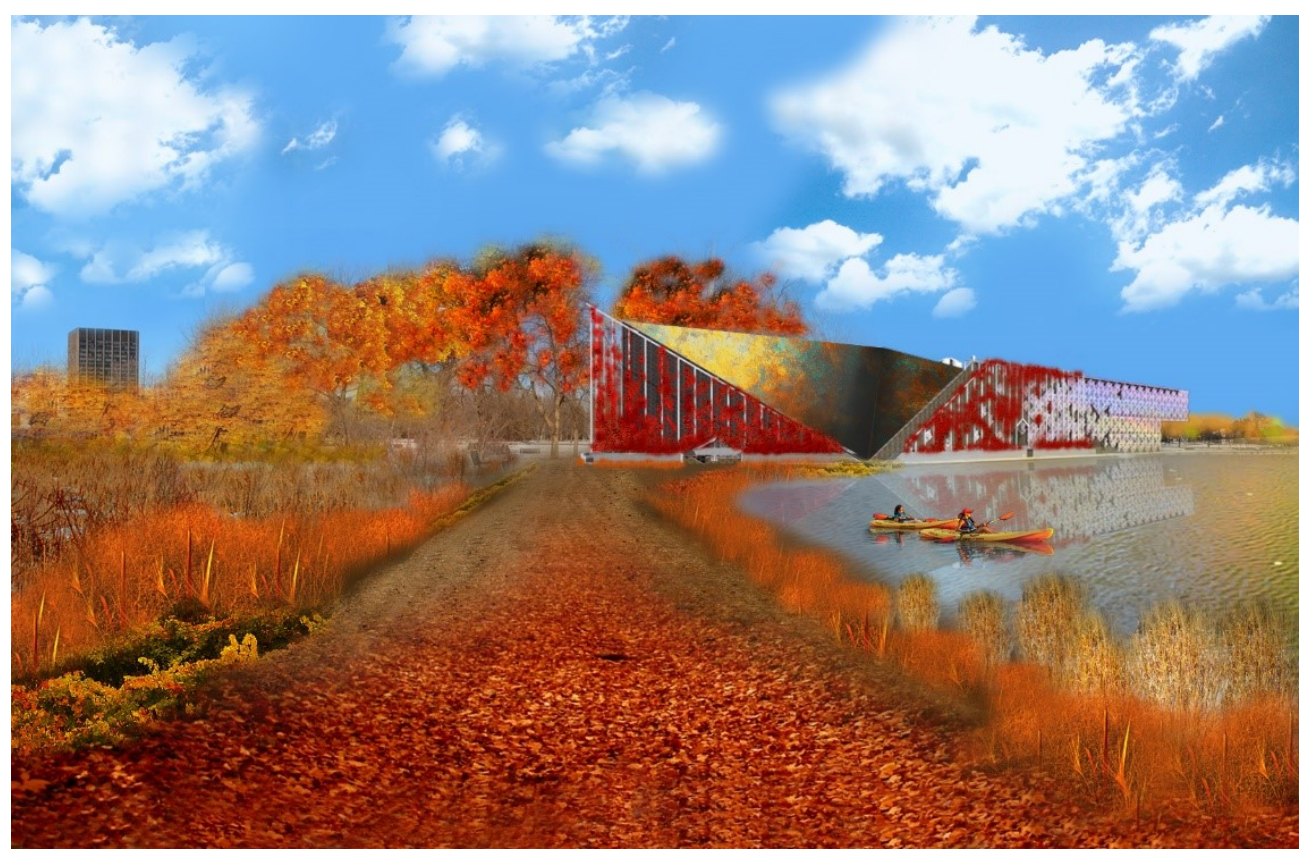

Illustration 83 Rendering of Latent Project in early autumn

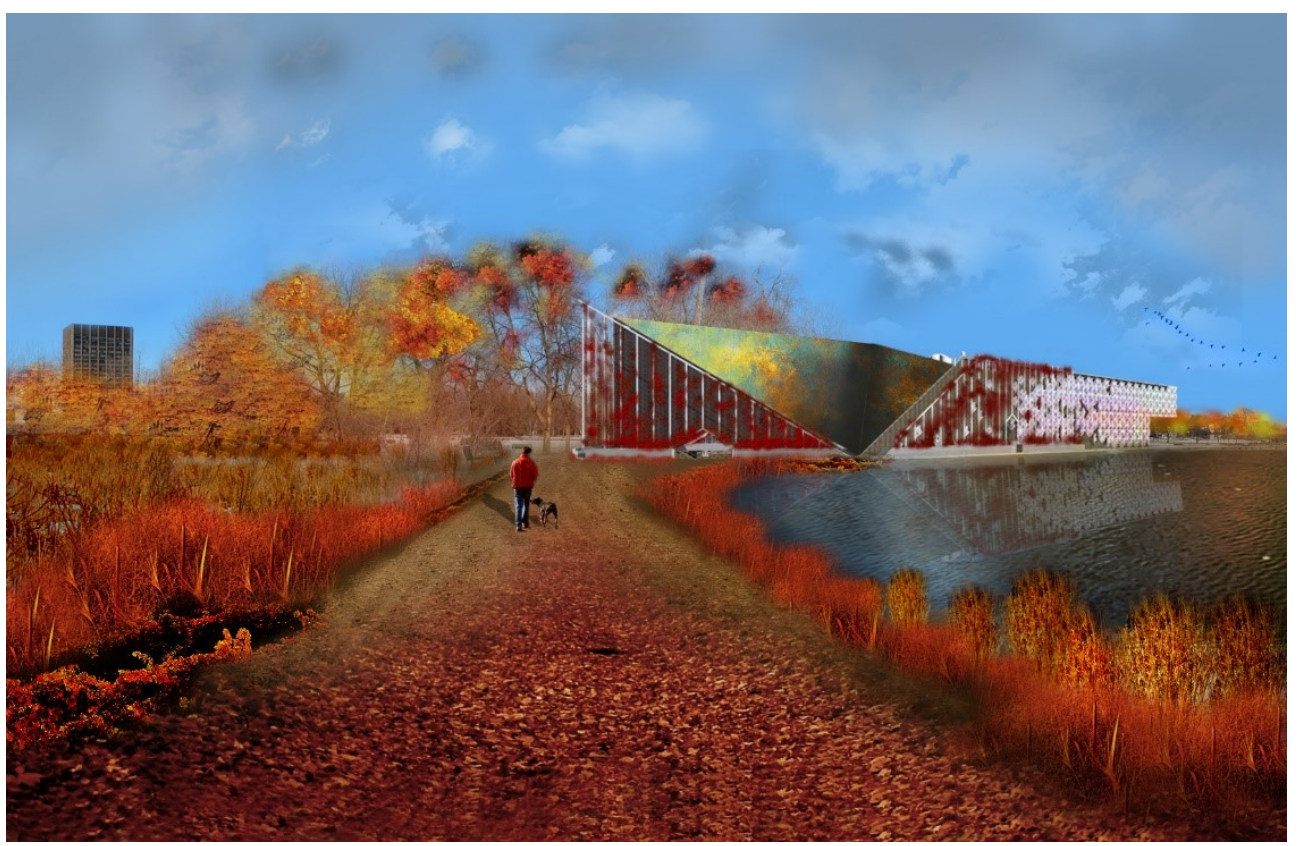

Illustration 84 Rendering of Latent Project in late autumn 


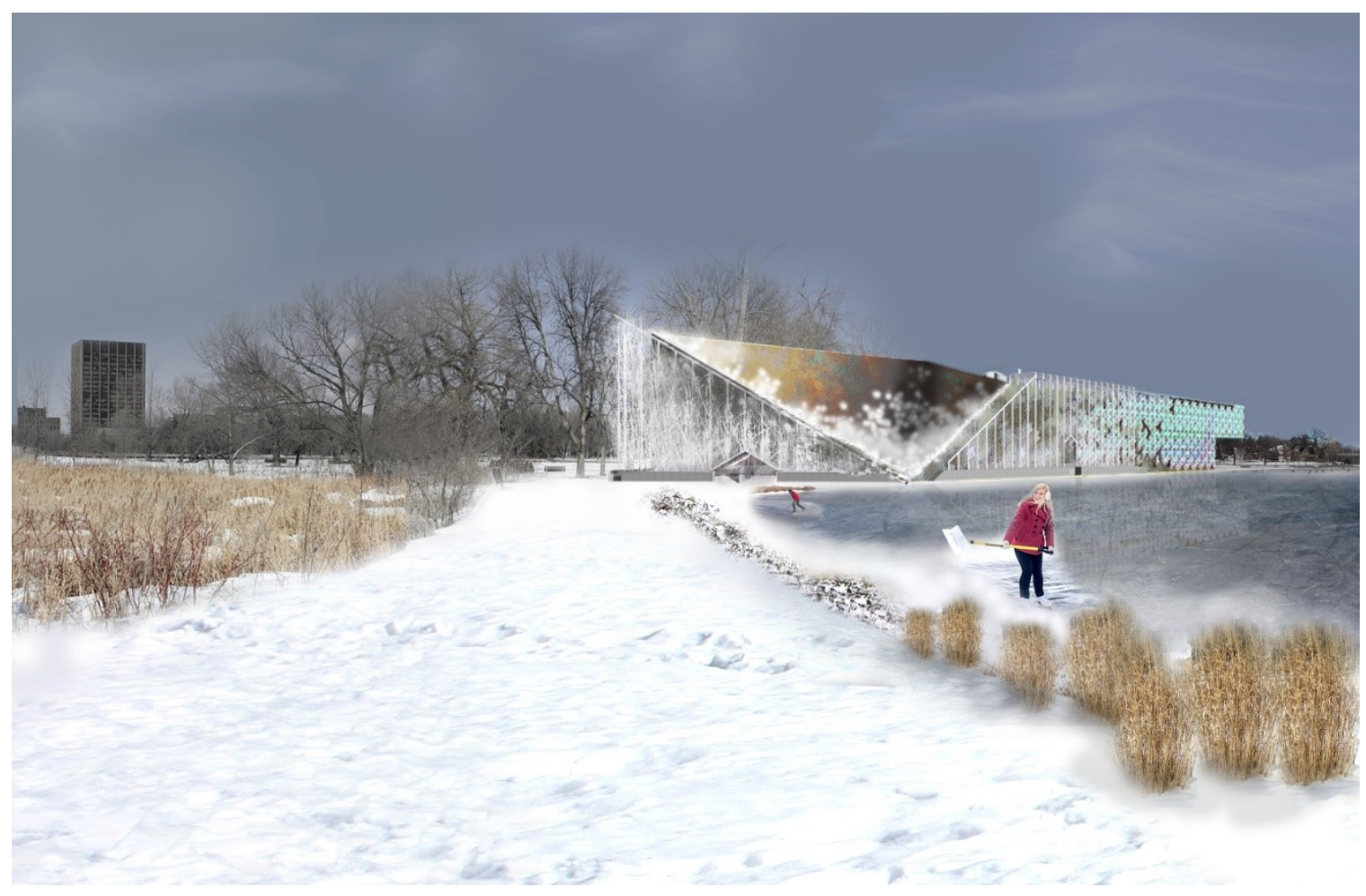

Illustration 85 Rendering of Latent Project in winter

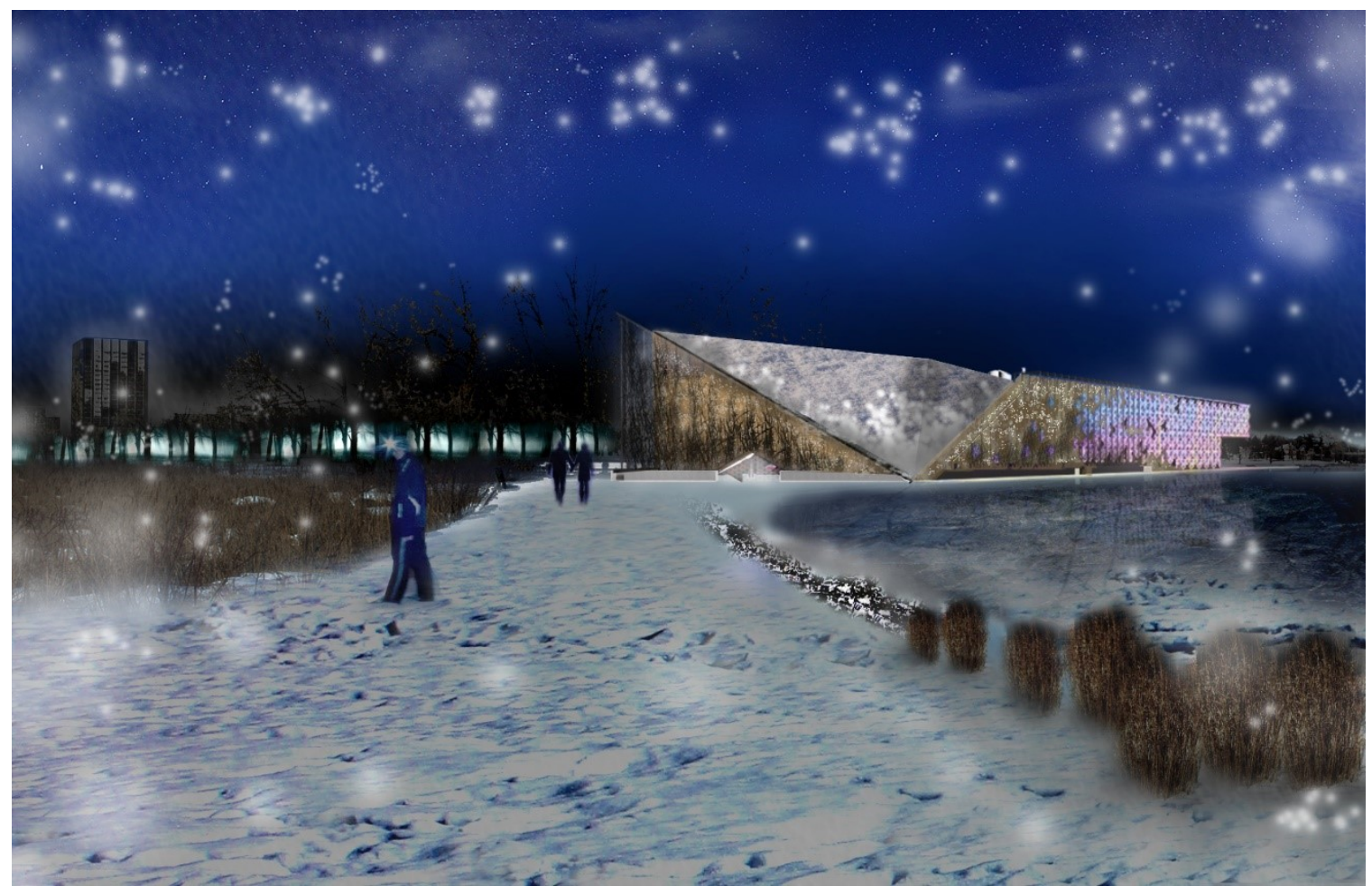

Illustration 86 Rendering of Latent Project during early evening 


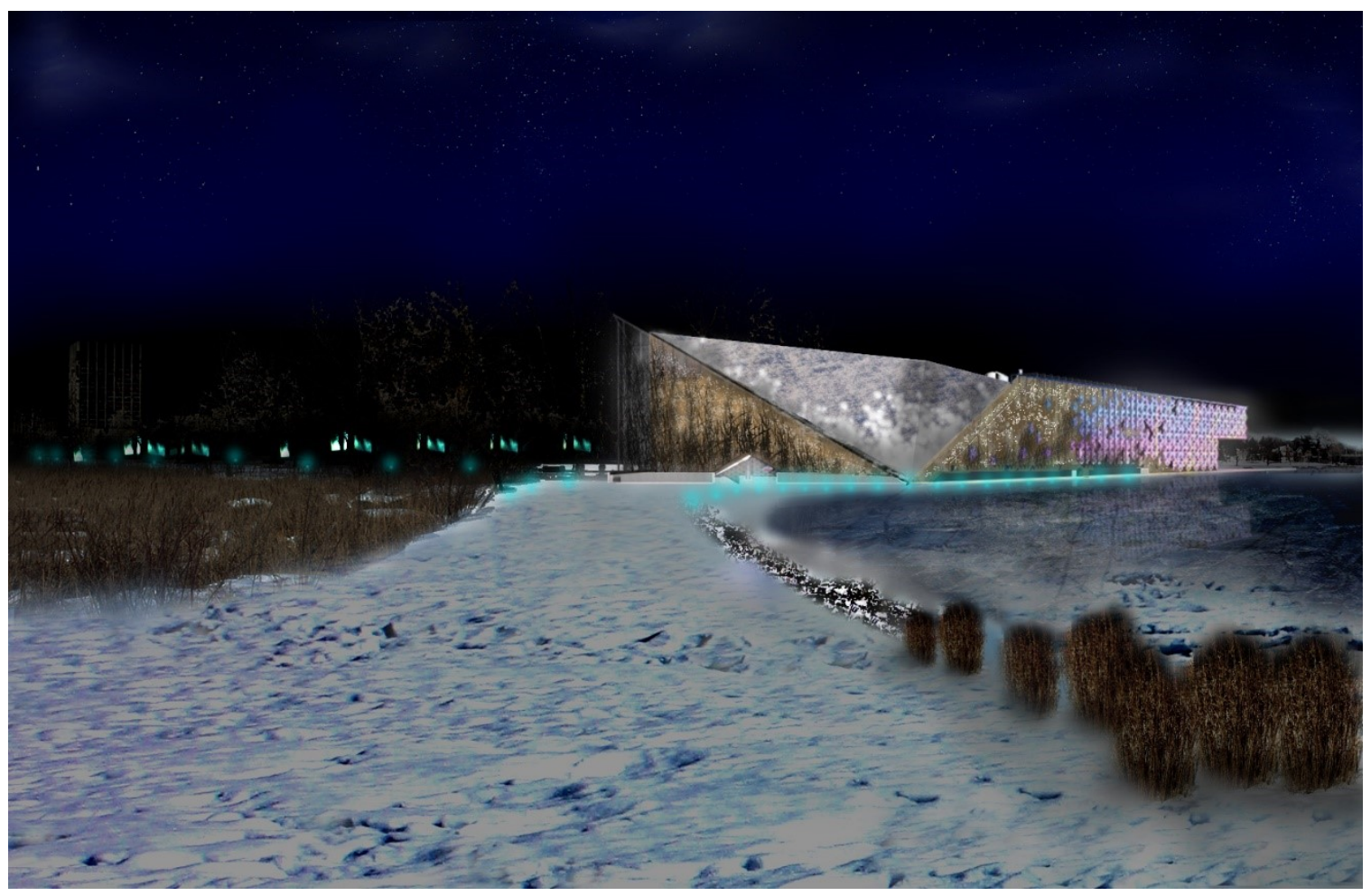

Illustration 87 Rendering of Latent Project in the middle of the night

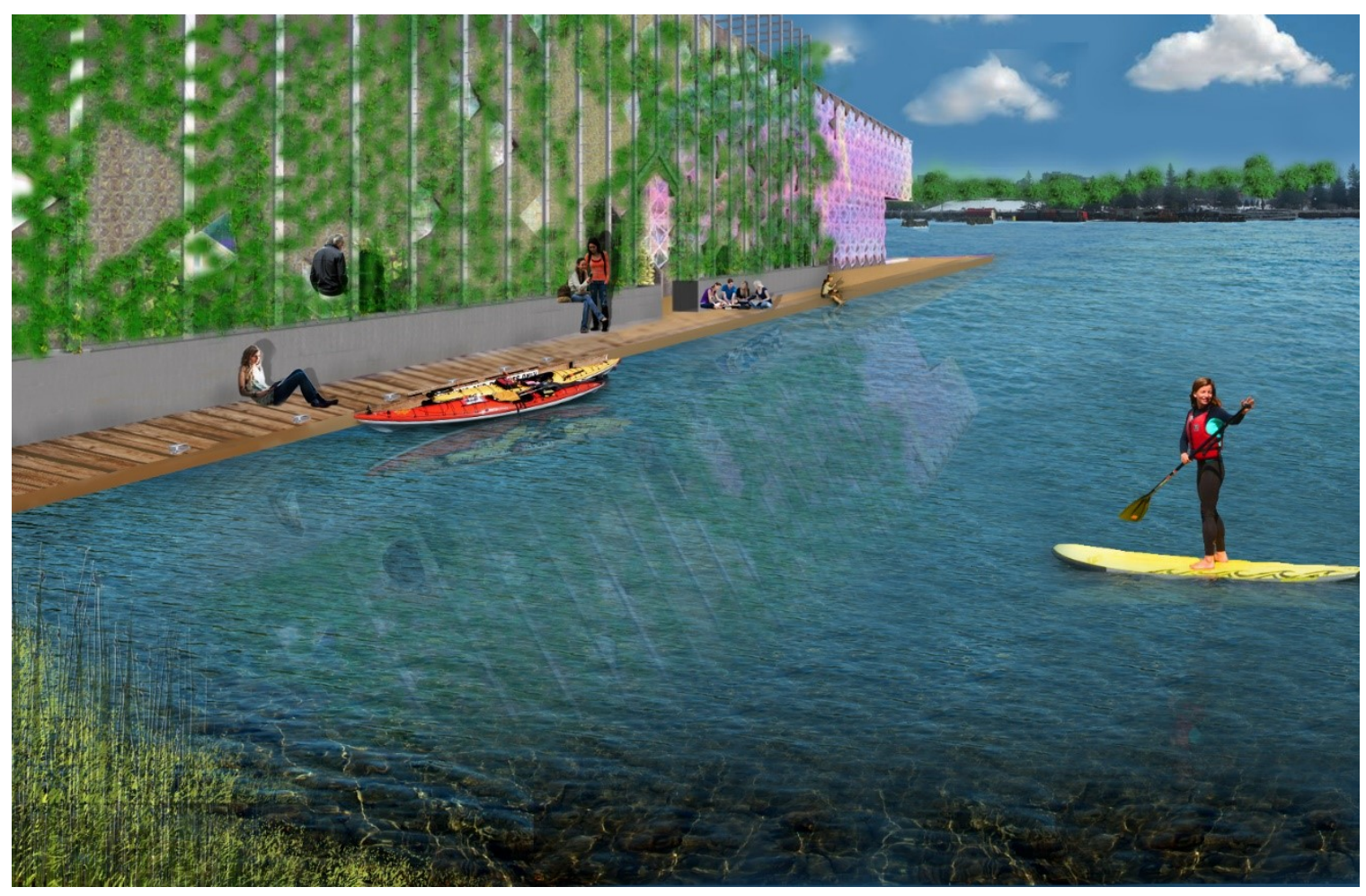

Illustration 88 Rendering of Latent Project dock during summer 


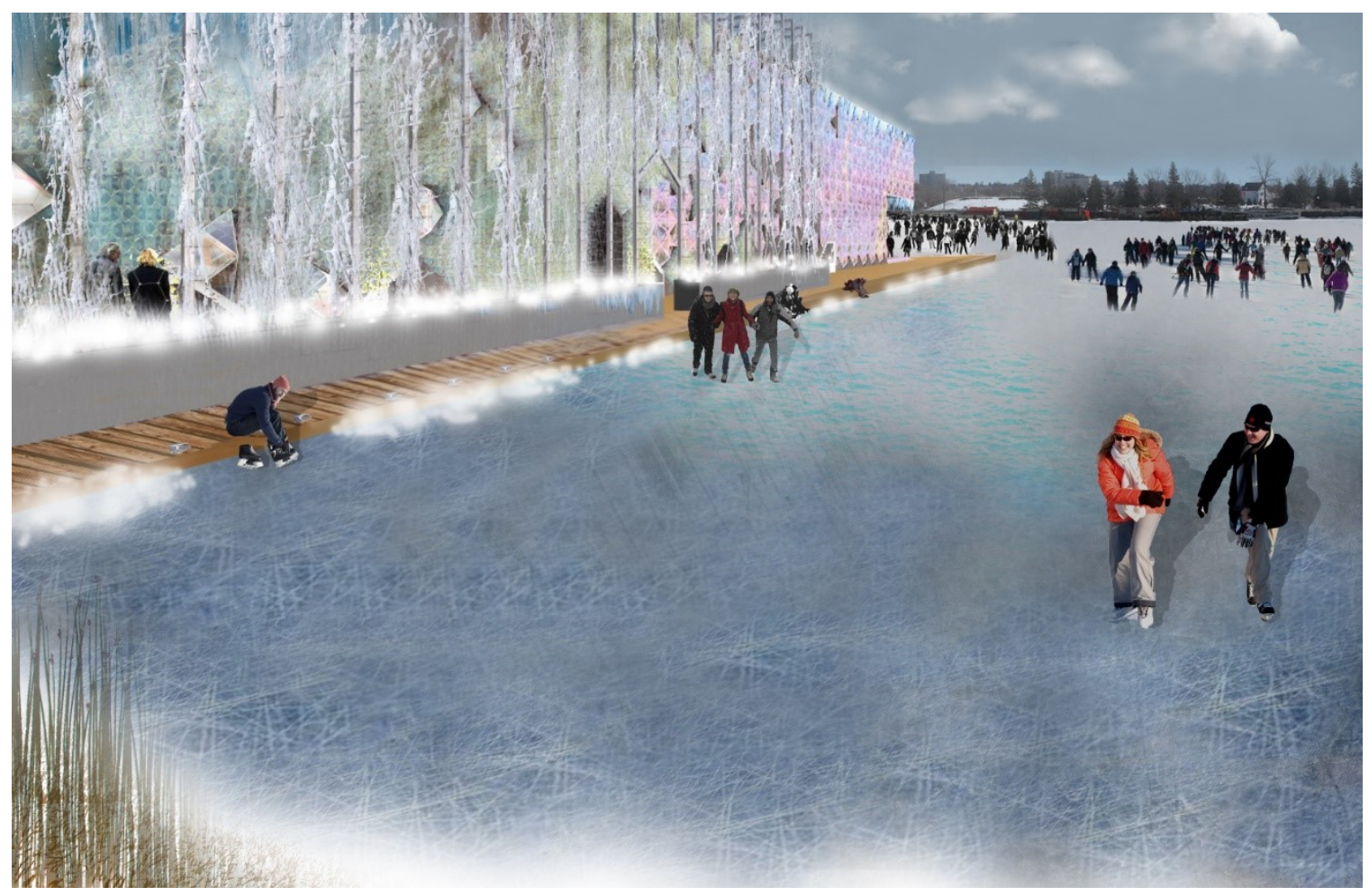

Illustration 89 Rendering of Latent Project dock during winter

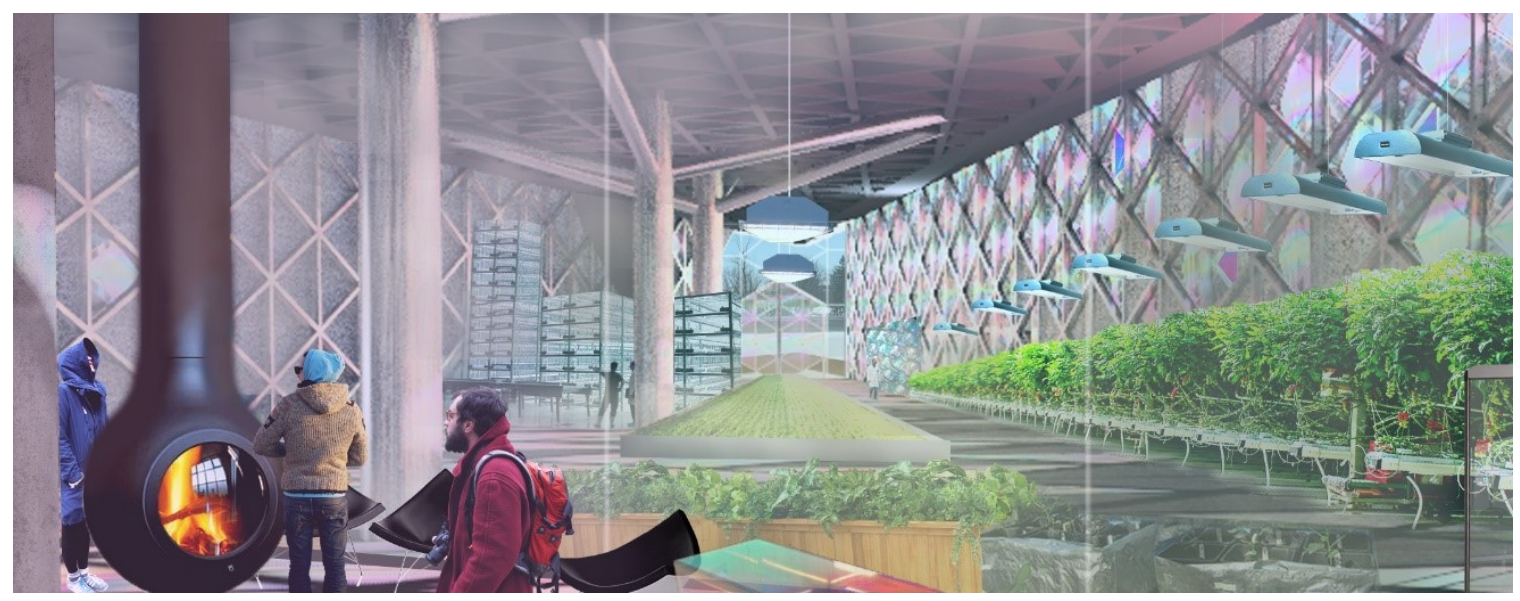

Illustration 90 Interior rendering showing central fire place and growing space on the ground floor

Geothermal energy was selected as a method to heat the building due to the sites proximity to the water table. The steel tree columns are hollow to allow for mechanical, electrical, and plumbing to run up to the supported floor platforms. 
A fire place is centrally located in the building for winter heating in addition to heat gathered by the geothermal system. The central location of the fire pit was strategized for radial heat distribution.

The Pine Façade system in warm months is used to help retain and capture water for the building and the trellis system. A grate located at the base of the wall permits water to filter through and be stored at the base of the building. This reservoir will help water plants in the rare case of summer drought.

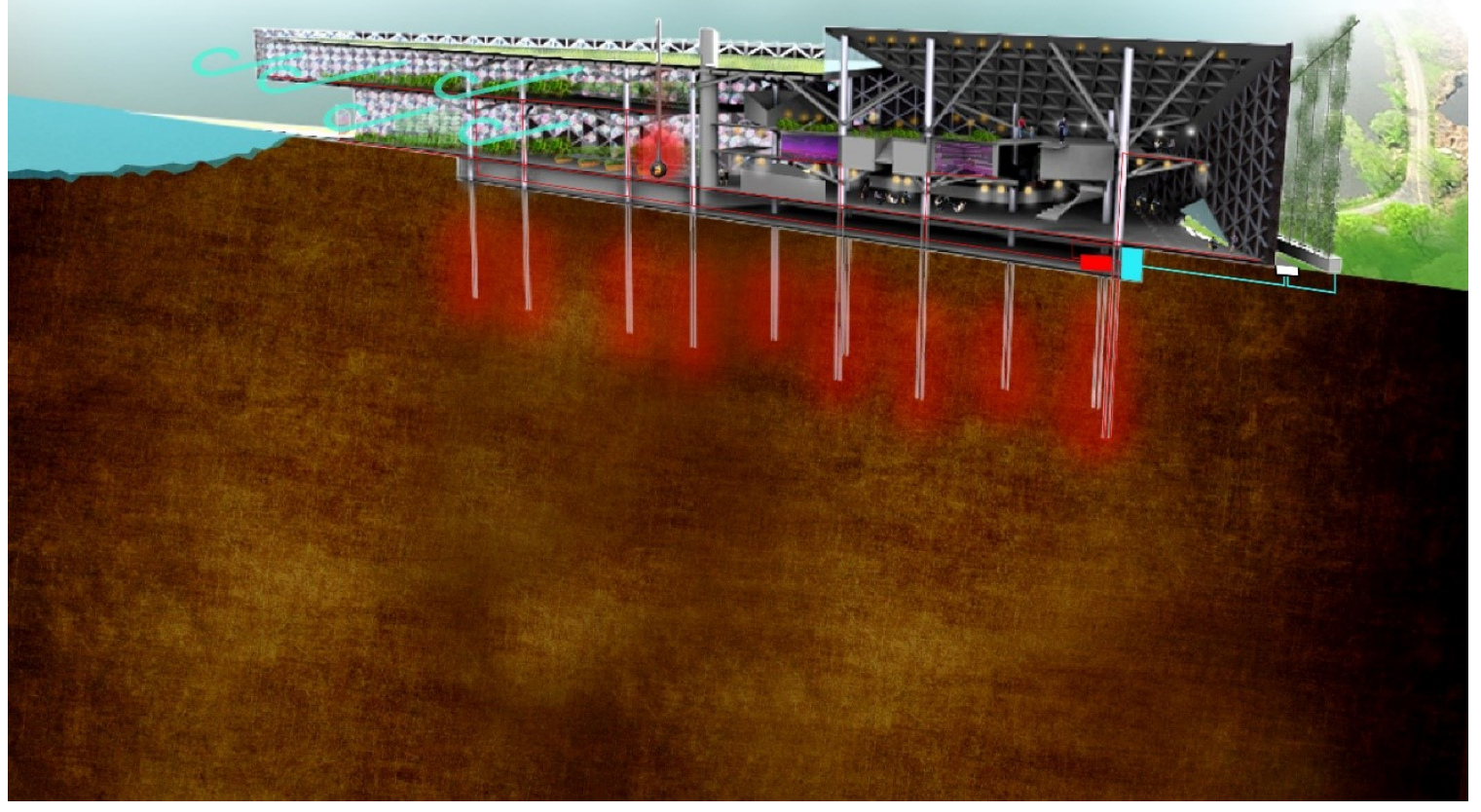

Illustration 91 Systems Diagram 


\section{Chapter: Material Selection \& Fabrication}

\subsection{Materiality Consideration}

The Latent project looked to both industry standards and innovative materials during the selection of the tectonics of building construction. The envelope of the building was of particular importance so a variety of construction methods and their associated material pallets were taken into account. Concrete, wood, metals, insulation, and fenestration types were all materials taken into account to produce the conceptual and performative qualities desired for the building.

\section{Concrete}

Concrete is made of three primary material including Portland cement, fine aggregates, and water mixtures. Formwork is required to pour the mixture in and to let cure. Reinforcing such as rebar can be added to improve the tensile strength of the concrete. Additives called admixtures are additional aggregates that alter the properties of concrete. Different elements can be added to alter the colour, freeze resistance, drying times, corrosion resistance, and workability of the concrete.. (Allen \& Iano) Concrete however is characteristically opaque, cold, and dense; all of which were not traits the Latent project wished to incorporate. LiTraCon (Light Transmitting Concrete) on the other hand offered a method to have the strength of concrete but allow for light to filter through the material. It is composed of 96 percent concrete and 4 percent fiber optics which allow light to travel through the rods without effecting the compressive strength of the concrete. ( LiTraCon $\mathrm{Kft}, 2015)$ Fiber optic rods must remain parallel to one another and the light source. The material can be prefabricated into panels and with resent estimates light can still penetrate 
though a panel up to 20 meters thick. Fabricators currently only make it in three colours including black, white, and grey.

The design of the Pine Façade incorporated LiTraCon as the main structural material as light would still be transmitted through but the panel would remain structurally sound. The design implications using this type of concrete include an awareness light source obstructions and its corresponding effects. The interior of the building was designed to replicate the experience of walking through a forest where cracks of light could penetrate through much like an overhanging tree canopy.

\section{Wood}

Timber and engineered wood were considered during the design process however sheet and plank sizes gave rise to considerable limitations that concrete and steel could accommodate. Although the material could be found readily within the region wood as the main structural system or used within the Pine Façade was not appropriate for functional and aesthetic purposes. The façade system when exposed to the elements would require considerable maintenance over time if a wood product was chosen. Additionally any wood product is opaque, which was not a desired characteristic for either the building or façade system.

\section{Metal \& Steel}

Steel was selected as the main structural system as it could replicate the structural performance of a tree in regards to spanning capabilities, act as a shaft for MEP (Mechanical, Electrical, Plumbing), and create experiential intrigue. Premanufactured steel tree column and floor supports would be coated in intumescent paint for fire rating purposes and assembled on site. 
The exterior cladding system uses a diagrid to support the Pine Façade. This was chosen to allow the interior space to rely less heavily on columns while creating a patterned structure where the Pine Façade system could be easily attached to.

\section{Insulation}

The Pine Façade was designed to transmit light through the building envelope which limited the material selection for insulation. Industry standards such as spray, batt, wool, denim, and plant based insulation were easily dismissed as they offered no new sustainable method of construction and all were opaque in nature. Aerogel was selected as the final insulation material as it was both effective in retaining heat for the building and it was translucent. (Aerogel Technologies, LLC, 2015) LiTraCon in combination with Aerogell would provide structural support that could hold the steel elements of the Pine Façade, insulate, and allow light to pass through the envelope of the building.

\section{Glass}

The glazing system for the Latent project looked to two precedents for achieving specific qualities for the interior lighting and exterior envelope system. The Harpa Reykjavik Concert Hall located in Reykjavik, Iceland the collaboration of Henning Larsen Architects and artist Olafur Eliasson created the structural quasi-brick for the exterior of the south façade of the building. (Grima, 2011) Composed of modular and stackable elements the façade system was both structural and transparent in nature. The quasi-brick used the indigenous structure of the basalt crystals to create the massing concept. The massing of the quasi-brick in repetition created volume that reflected light off of the mirrored and coloured glass panes. These techniques in combination with using the variation of sun angles create the iridescent scale like pattern along the building cladding. 
An alternative method to creating an iridescent effect is 3M's Dichroic Glass Finish. This applied film is used on the interior of the glass pane and colours changes depending on the angle of light to the viewer. The film comes in two colours Chill (cool hues) and Blaze (warm hues). (3M, 2015)

The Latent project wished to extrapolate the iridescent qualities of The Harpa Reykjavik Concert Hall and 3M's Dichroic Glass Finish. As the seasons, weather, and time of day changed the Pine Façade will accurately interact with this change and similarly so should its glazing system.

\section{CorTen Steel \& Copper}

The materiality selected for the pitched roof came down to two materials; CorTen steel and Copper. The design needed a material that was partly texturized (to help grip accumulating snow) and for it to weather with the building. Both CorTen steel and Copper both offered such capabilities but the final selection was determined based off of colour and its ability to camouflage with its surroundings during certain seasons. CorTen Steel would weather and turn an orange colour that would be ideal in autumn months but would contrast against summer and spring foliage. Copper was ultimately selected as it would camouflage with autumn hues during its initial installation but in time would blend well in spring and summer months as it turned green. Ice and snow would cover the roof during the winter to better camouflage with the site during times of high precipitation.

\subsection{Fabrication}

Although the Pine Façade was deemed unfeasible to build due to material costs, it is important to understand how both the Pine Façade and Dichroic Glazing panel systems would be fabricated, transported, and fastened to the building. 
The first step in the process would be to fabricate the two pieces of the LiTraCon panel so that the fiber optic rods aligned with one another. This would mean that the panel pieces would need to be cast using the same pour. The "stem" of the Pine Façade system would need to be embedded during the pour. Additionally the cavity needed for the aerogel insulation and the bolts needed to be fastened to the diagrid structure would be cast in place during the formation of the panel. Only after the entire panel was formed would it be cut along the exterior edge of the aerogel cavity. At this plane the aerogel would be placed within the cavity and sealed. The seam between the two panel pieces would address thermal bridges using metal frames and structural caulking at the rim of each panel. The metal frames would be periodically fastened to the rim of the LiTraCon and when placed together the metal would interlock with one another joining the pieces to form a single panel. The mechanized stem portion of the pine façade would be attached on site to avoid destruction during transportation. Due to the size and weight of each panel a crane would be needed to install each Pine Façade Panel onto the diagrid structure. Embedded bolts taken into account during the pouring process of the panel would be affixed to the structure from the inside of the building. After all the Pine Façade panels were fastened to the structure the exterior seam between each panel would be sealed. 
The trellis system component of the Pine Facade include threaded steel rods, attachment pieces, and steel beams. The vertical running steel beams would be positioned and embedded into the concrete pour of the planted box located at the base of the trellis system. Along the vertical steel beams the attachment pieces would be welded on. These attachment pieces would become the positioning points for the threaded rods of the trellis. The vertical beams would structurally tie back to the main building in two situations; along the perimeter of the flat roof, and the other along the top of the western facing LiTraCon Panels.

The dichroic glazing system would be prefabricated prior to arrival on the site. The dichroic film would be located on selected portions of the panel that would be highlighted dependent upon the time of year and sun exposure. Welded bolts on the inside of the frame would similarly attach to the diagrid structure from the interior of the building. 


\section{Chapter: Conclusion}

\subsection{The Latent Project}

This thesis is an iteration of what Climorphysiological architecture could be yet there is still more to be explored and questioned. Climorphysiological Architecture has been stated in theory to argue for an architecture that is derived \& evolves from a site's specific climatic conditions. The project both at the macroscake and microscale looked to opportunities for improving building performance and engaging with seasonal weather fluctuations. The Latent Project looked to the sites potential for collecting snow and ice for insulation, water recycling, planting for seasonal shading and its proximity to the water table for geothermal opportunities. The buildings massing and orientation was derived from the sites footprint while maximizing summer cross ventilation and protecting the building from harsh winter winds. The programs located within the building were placed dependent on the amount of light needed relative to solar orientation. Together these strategies were used to exploit the potentials that the site and specific climatic conditions attributed to the region. Although this thesis strove to establish itself as proponent of Climorphysioligcal architecture one must critically evaluate how successful both the project proposal and building details were at accomplishing this.

As the building developed its massing grew to envelope its associate programs. The building height was based upon the Pine Facades modular components and its associated angles. However for an architecture entirely related to its site the height of the building would be more contextually integrated had it lowered its height to meet the existing tree line of the park. 


\subsection{Pine Façade \& Building Details:}

The development and forward thinking nature of the Pine Façade revealed a series of limitations within the work. The Pine Façade panel and its selected materials were more futuristic and current market standards would deem this combination of materials unfeasible. The building materials LiTraCon and Aerogel are still extremely expensive in themselves and in combination would engulf any building budget. One can look to the future and hope that as these materials become more recognized by the building industry the price would drop enough where proposals such as the Pine Façade could become reality instead of a figment of the imagination. Additionally long term use of exterior latex would need to be tested more rigorously to ensure that maintenance and repair costs would not undermine the project. In an ideal situation the future would embrace this type of panel system that combines the benefits of mass production and a customized building façade.

The April $27^{\text {th }}$ defense panel in review also recommended the potential for an Iteration 5 that replaced LiTraCon panel in substitutions for structural glass and to anchor the steel stems of the Pine Façade back to the steel diagrid. The interior qualities of the wall would then allow inhabitants to fully experience the phenomenon of light filtering through the dynamic 'forest' of the metal and latex structures on the exterior of the façade, instead of silhouettes cast seen behind the LiTraCon panels.

\subsection{Potentials for Climorphysiological Architecture}

The Latent Project and its associated Pine Facade is one iteration of Climorphysioligical Architecture however there are larger global implications of this design methodology. Climorphysiological Architecture is one that lends itself for reinterpretation and experimentation on both global and regional scales. In the case of the Latent Project 
located at Dow's Lake, Ottawa, Ontario the site set up a contextual basis for climatic data in regards to temperature, solar orientation, humidity, wind patterns, and precipitation. This project looked to natural processes and living examples of how animals adapted to the extremes of an environment. On a global scale this methodology could be used to address other climate zones. In regions closer to the equator there would be no need for a Pine Façade but rather a cladding system that had more vegetation and was more porous to allow for cross ventilation. In regions towards the polar tips of the world the Pine Façade would become the primary wall component and snow accumulation for insulation would be critical. The other issue to address is that although in the case of the Latent Project the site is fairly isolated, this form of architecture has the potential to struggle with the complexities of an urban context. How would an urban versus rural site influence Climorphysiological architecture? How would Climorphysiological Architecture be translated into Climorphysiological urban planning principles? In the situation of an urban site one must analyze the context and ask what opportunities does the site possess and how can they be incorporated. At an urban planning level we must ask how symbiotic relationships can be formed within the built context of a city instead of looking to buildings as separate entities. This thesis does not begin to try to answer all of these questions but rather is a starting point for further architectural exploration in field so closely related to biomemetics, biodesign, and environmental awareness. Let each design problem encountered in the field 
of Climorphysiological Architecture be seen not as a problem but rather an opportunity or challenge to improve. 


\section{Appendices}

\section{Appendix A}

Table I: Angle of repose as a function of snow type and temperature (Trabant, Armstrong, and MeClung 1990).

\begin{tabular}{|c|c|c|}
\hline Snow Type & Temperature & Angle of Repose \\
\hline Fresh, dry & $-35^{\circ} \mathrm{C}$ & $63^{\circ}$ \\
\hline Fresh, wet & $-4^{\circ} \mathrm{C}$ & Close to $90^{\circ}$ \\
\hline Wet, $24 \%$ water & Above $0^{\circ} \mathrm{C}$ & $2^{\circ}$ \\
\hline
\end{tabular}

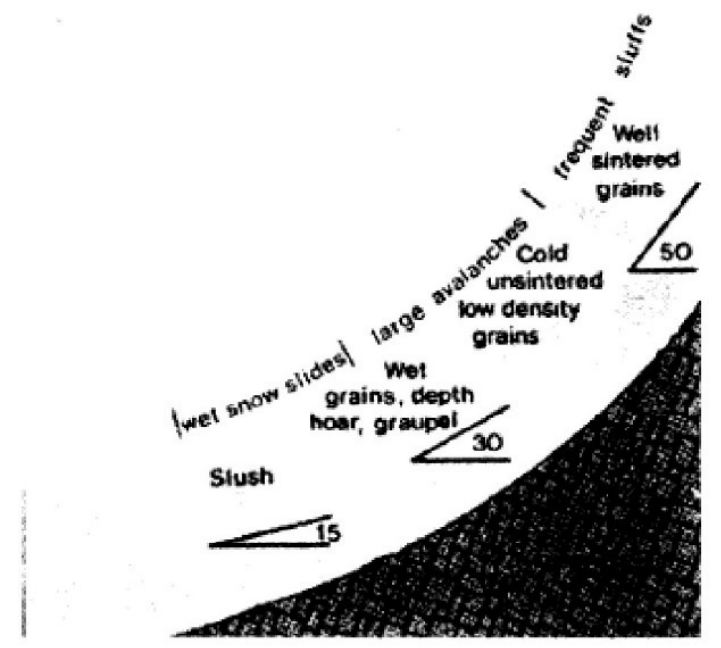

Figure 3: General breakpoints for the angle of repose under differing conditions.

Graph illustrates the angle of repose for snow.

Snow Angle of Repose

Armstrong, R. (2015, January 6). GEOG 5241: Snow \& Avalanches. Retrieved from

http://www.colorado.edu/geography/class_homepages/geog_5241_s10/5241_week4.pdf 


\section{Appendix B}

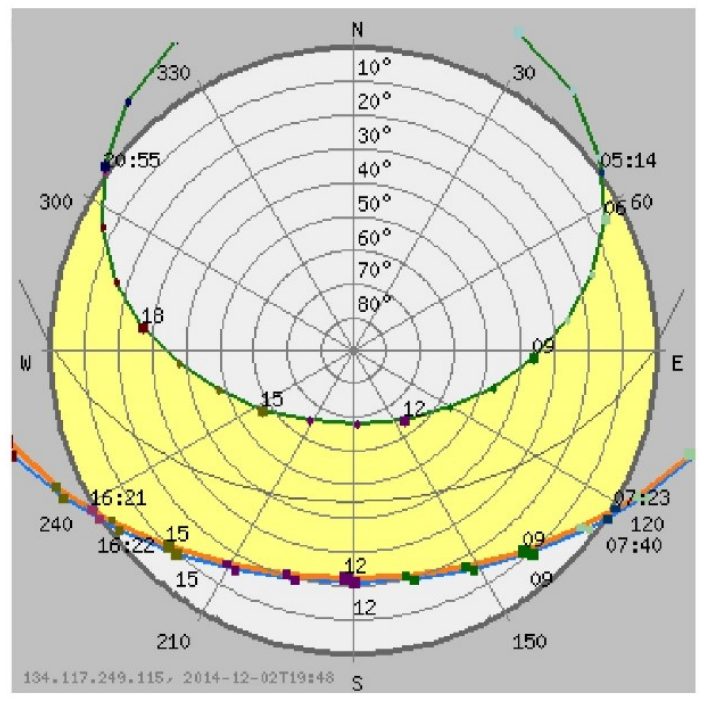

\section{B.1 Solar Orientation}

Gaisma. (2015, January 6). Ottawa, Canada - Sun path diagram. Retrieved from Gaisma: http://www.gaisma.com/en/location/ottawa.html

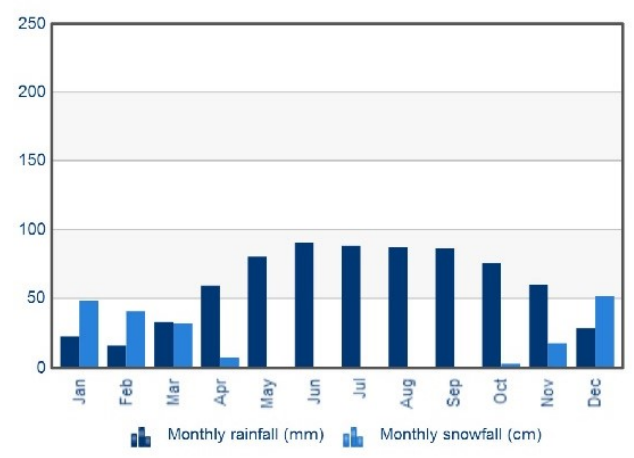

\section{B.2 Monthly Snow and Rainfall Averages}

The Weather Network. (2015, January 6). Statistics Summary . Retrieved from The Weather Network:

http://www.theweathernetwork.com/forecasts/statistics/cl6105976/caon0512?intcmp=twn _topnav_fx_stats 


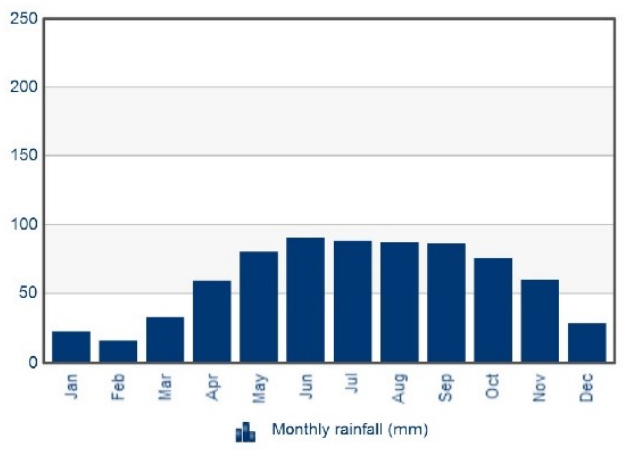

\section{B.3 Monthly Rainfall Averages}

The Weather Network. (2015, January 6). Ottawa Statistics Percipitation. Retrieved from The Weather Network:

http://www.theweathernetwork.com/forecasts/statistics/precipitation/cl6105976/caon0512

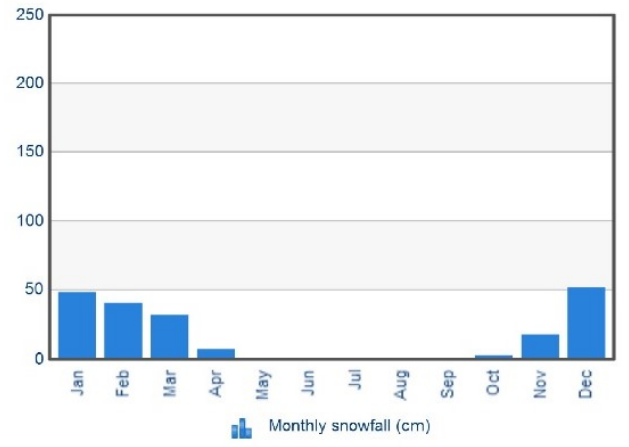

\section{B.4 Monthly Snowfall Averages}

The Weather Network. (2015, January 6). Ottawa Statistics Precipitation. Retrieved from The Weather Network:

http://www.theweathernetwork.com/forecasts/statistics/precipitation/c16105976/caon0512 


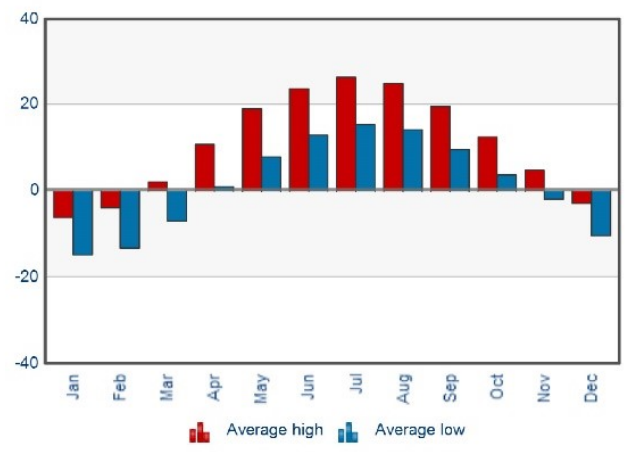

\section{B.5 Monthly Temperature Averages}

The Weather Network. (2015, January 6). Statistics Summary . Retrieved from The Weather Network:

http://www.theweathernetwork.com/forecasts/statistics/cl6105976/caon0512?intcmp=tw n_topnav_fx_stats 

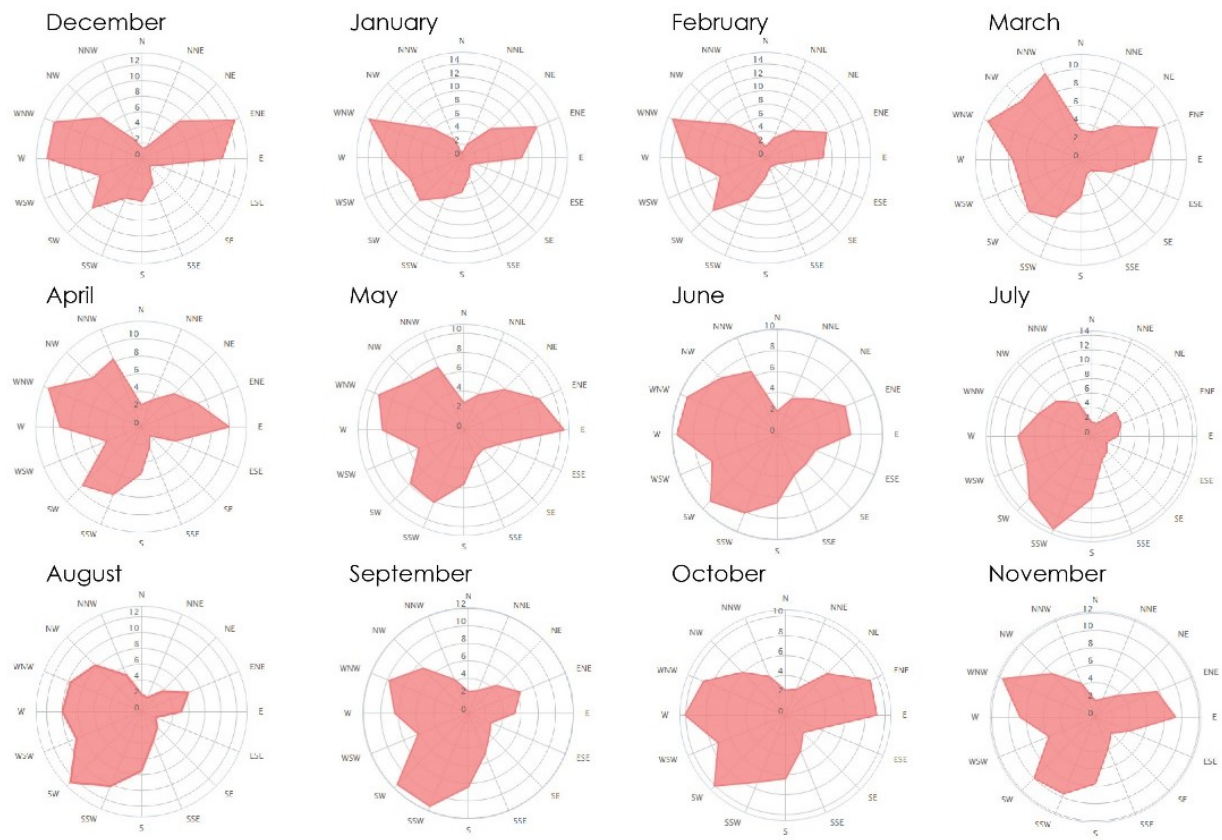

\section{B.6 Seasonal Wind Directions}

Wind Finder. (2015, January 6). Wind \& weather statistics Ottawa Airport. Retrieved from Wind Finder: http://www.windfinder.com/windstatistics/ottawa_airport 


\section{Bibliography}

LiTraCon Kft. (2015, 04 01). Litracon. Retrieved from Litracon Light Transmitting COncrete: http://litracon.hu/product.php?id=7

3M. (2015, April 01). Dichroic Glass Finishes. Retrieved from 3M:

http://solutions.3m.com/wps/portal/3M/en_US/architectural-markets/home/glassfinishes/dichroic/

Aerogel Technologies, LLC. (2015, 04 01). Lumira ${ }^{\circledR}$ Aerogel. Retrieved from Buy Aerogel.com: http://www.buyaerogel.com/product/lumira-aerogel-particles/

Allen, E., \& Iano, J. (n.d.). Fifth Edition Fundamentals of Building Construction Materials \& Methods.

Arendt, H. (1998). The Human Condition. Chicago: The University of Chicago Press.

Armstrong, R. (2015, January 6). GEOG 5241: Snow \& Avalanches. Retrieved from http://www.colorado.edu/geography/class_homepages/geog_5241_s10/5241_wee k4.pdf

AskNature. (2015, January 6). AskNature. Retrieved from AskNature: http://www.asknature.org/

Ball, P. (2004). The Self-Made Tapestry: Pattern Formation In Nature. New York: Oxford University Press.

BBC (Director). (1984). The Living Planet: Episode 3 The Northern Forests [Motion Picture]. Retrieved from http://www.youtube.com/watch?v=ds2K5qm6bZM

Beesley, P. (2010). Hylozoic Ground: Liminal Responsive Architecture. China: Riverside Architectural Press.

Blanc, P. (2012). Vertical Garden: From Nature to the City. W.W. Norton \& Co. 
Blanc, P. (2014). Vertical Garden Patrick Blanc. Retrieved from Patrick Blanc: http://www.verticalgardenpatrickblanc.com/

Brock, L. (2005). Designin The Exterior Wall: An Architectura; Guide to the Vertical Envelope. New Jersey: John Wiley \& Sons, Inc.

CASE Centre for Architecture Science and Ecology. (2014). CASE Centre for Architecture Science and Ecology. Retrieved from CASE Centre for Architecture Science and Ecology: http://www.case.rpi.edu/

Despommier, D. (2010). The Vertical Farm - Feeding The World of the 21st Century. New York: St. Martin's Press.

Detail Das Architekturportal. (2012). Cooled Conservatories at Gardens by the Bay in Singapore is the World Building of the Year. Retrieved from Detail Das Architekturportal: http://www.detail-online.com/architecture/topics/cooled- 
conservatories-at-gardens-by-the-bay-in-singapore-is-the-world-building-of-theyear-019944.html

Frampton, K. (1983). The Anti-Aesthetic: Essays on Postmodern Culture: Towards a Critical Regionalism: Six Points for an Architecture of Resistance. Port Townsen: Bay Press.

Frampton, K. (2001). Studies in Tectonic Culture: The Poetics of Construction in Nineteenth and Twentieth Century Architecture. The MIT Press; Reprint edition.

Glasgow School of Art. (2015). Charles Rennie Mackintosh. Retrieved from Glasgow School of Art: http://www.gsa.ac.uk/visit-gsa/mackintosh-building-tours/charlesrennie-mackintosh/

Google Definitions. (2015, January 6). define: Aeroponics. Retrieved from Google: https://www.google.ca/?gfe_rd=cr\&ei=ySsVJOjCoON8Qes8YHIDA\&gws_rd=ssl\#q=define:+aeroponic

Google Definitions. (2015, January 6). define: aquaponics. Retrieved from Google: https://www.google.ca/?gfe_rd=cr\&ei=5DCsVOXyBION8Qes8YHIDA\&gws_rd $=\mathrm{ssl} \# \mathrm{q}=$ define: + aquaponics

Google Definitions. (2015, January 6). define: morphology. Retrieved from Google: https://www.google.ca/?gfe_rd=cr\&ei=uBysVK7GO4WN8QfarIH4CQ\&gws_rd= ssl\#q=define:morphology

Google Definitions. (2015, January 6). define: phisiology. Retrieved from Google: https://www.google.ca/?gfe_rd=cr\&ei=FiSsVIO7NKSC8QekpYH4Dw\&gws_rd= ssl\#q=define:physiology 
Google Dictionary. (2015, January 6). define: behavioral. Retrieved from Google: https://www.google.ca/?gfe_rd=cr\&ei=WgasVPOFMmM8QeB_IGwDA\&gws_rd=ssl\#q=define:+Behavioral

Gorgolewski, Komisar, \& Nasr. (2011). Carrot City: Creatng Places For Urban Agriculture. New York: The Monacelli Press.

Grant Partnership Ltd. (2014). Gardens By The Bay - Supertrees. Retrieved from Grant Associates: http://www.grant-associates.uk.com/projects/super-trees/

Grima, J. (2011, September 08). Eliason's Kaleidoscope. Retrieved from Domus: http://www.domusweb.it/en/architecture/2011/09/08/eliasson-s-kaleidoscope.html Hopkins, G., \& Goodwin, C. (2011). Living Architecture: Green Roofs and Walls. Collingwood: Csiro Publishing.

Hoyt, A. (2014). How Igloos WorK. Retrieved from How Stuff Works: http://people.howstuffworks.com/igloo.htm

Ingold, T. (2011). Being Alive: Essays on Movement, Knowledge, And Description. New York: Routledge.

Jacobs, J. (1993). The Death \& Life of Great American Cities. New York: Random House.

Lizotte, C. (2014, June 7). Arup Develops 3D Printed Structural Steel. Retrieved from 3D Print: http://3dprint.com/5505/3d-printed-steel-arup/

McDonough, W. (2002). Cradle to Cradle: Remaking the Way We Make Things. New York: North Point Press.

McMinn, J., \& Polo, M. (2005). 41 to 66: Regional Response to Sustainable Architecture in Canada. Montreal: ABC Art Books Canada. 
Merriam-Webster. (2015, January 6). Dictionary: Geoponic. Retrieved from An Encyclopedia Britannica Company Merriam-Webster: http://www.merriamwebster.com/dictionary/geoponic

Merriam-Webster. (2015, January 6). Dictionary: Hydroponic. Retrieved from An Encyclopedia Britannica Company Merriam-Webster: 
https://www.google.ca/?gfe_rd=cr\&ei=yS-

sVJOjCoON8Qes8YHIDA\&gws_rd=ssl\#q=define:+aeroponic

MoMA. (2012). BioDesign: Nature + Science + Creativity. New York: Museum of Modern Art.

O'Neil, H. (2012, February 2012). Plant and Animals Adaptations for Cold Environments. Retrieved from Slideshare: http://www.slideshare.net/hollieoneill/lesson-2-gcse-cold-adaptations

Oxman, N. (2015, January 6). About. Retrieved from Neri Oxman: http://materialecology.com/neri-oxman

Oxman, N. (2015, January 6). Monocoque 1. Retrieved from Neri Oxman: http://materialecology.com/projects/details/monocoque-1

PlantLab. (2015, January 6). Plant Paradise: Emancipation of The Plant: The Art of Giving Plants Exactly What They Want. Retrieved from PlantLab: http://www.plantlab.nl/plant-paradise/

Russell, P. J., Wolfe, S. L., Hertz, P. E., Starr, C., Fenton, M. B., Addy, H., . . Davey, K. (2009). Biology: Exploring the Diversity of Life. Toronto: Nelson.

Sardella, F. (2014, October 20). Watershed Consciousness. Retrieved from Ferruccio Sardella: http://ferrucciosardella.wordpress.com/watershed-consciousness/

Tattersall, G. J., Withers, B. J., Fields, P. A., Seebacher, F., Cooper, C. E., \& Maloney, S. K. (2012). Coping with Thermal Challenges: Physiological Adaptations to Environmental Temperatues.

The Biomimicry Insitute. (2014, December 20). History. Retrieved from The Biomimicry Institute: http://biomimicry.org/history/ 
The Wyss Institue for Biological Inspired Engineering. (2015, January 6). About Us.

Retrieved from The Wyss Institue for Biological Inspired Engineering:

http://wyss.harvard.edu/viewpage/about-us/about-us

The Wyss Institute for Biologically Inspired Engineering. (2015, January 6). Our Work. Retrieved from The Wyss Institute for Biologically Inspired Engineering: http://wyss.harvard.edu/viewpage/our-work/our-work

World Science Festival (Director). (2014). Quantum Biology and the Hidden Nature of Nature [Motion Picture]. 


\section{Illustrations Bibliography}

Illustration 1 Tim Ingold's Being Alive

Ingold, T. (2013). Figure 9.2, Being Alive. New York: Routledge

Illustration 2 Definition of Climorphysiological Architecture

Murphy, Cassandra. 2015.

Illustration 3 Scales of Exploation

Murphy, Cassandra. 2015.

Illustration 4 Waste of Climatic Resources

Murphy, Cassandra. 2015.

Illustration 5 Disconnected Placemaking

Murphy, Cassandra. 2015.

Illustration 6 Visualization fo Seasonal Architecture

Murphy, Cassandra. 2015.

Illustration 7 Mechanisms For Temperate and Cold Climate Adaptations

Murphy, Cassandra. 2015.

Illustration 8 Section of Igloo

Murphy, Cassandra. 2015.

Illustration 9 Animal Behavioral Mechanisms

Murphy, Cassandra. 2015.

Illustration 10 Deciduous \& Coniferous Tree Morphological Mechanisms

Murphy, Cassandra. 2015.

Illustration 11 Tundra Plant Morphological Mechanims

Murphy, Cassandra. 2015.

Illustration 12 Animal Morpholigcal Mechanisms

Murphy, Cassandra. 2015.

Illustration 13 Section of Coniferous Needle 1

McCauley, B. (2015, January 6). Seed Plant Anatomy: Leaves. Retrieved from DeAnza College Biology 6A: http://www.deanza.edu/faculty/mccauley/6a-labs-plants-04.htm 
Illustration 14 Section of Coniferous Needle 2

McCauley, B. (2015, January 6). Seed Plant Anatomy: Leaves. Retrieved from DeAnza College Biology 6A: http://www.deanza.edu/faculty/mccauley/6a-labs-plants04.htm

Illustration 15 Section of Deciduous Leaf 1

McCauley, B. (2015, January 6). Seed Plant Anatomy: Leaves. Retrieved from DeAnza College Biology 6A: http://www.deanza.edu/faculty/mccauley/6a-labs-plants04.htm

Illustration 16 Section fo Deciduous Leaf 2

McCauley, B. (2015, January 6). Seed Plant Anatomy: Leaves. Retrieved from DeAnza College Biology 6A: http://www.deanza.edu/faculty/mccauley/6a-labs-plants04.htm

Illustration 17 Deciduous Tree Physiological Mechanisms

Murphy, Cassandra. 2015.

Illustration 18 Coniferous Tree Physiological Mechanisms

Murphy, Cassandra. 2015.

Illustration 19 Animal Physiological Mechanisms

Murphy, Cassandra. 2015.

Illustration 20 Face-Sealed Barrier Wall

Brock, L. (2005). Designing The Exterior Wall: An Architectural Guide to the Vertical Envelope. New Jersey: John Wiley \& Sons, Inc.

Illustration 21 Internal Drainage Plane Wall 
Brock, L. (2005). Designing The Exterior Wall: An Architectural Guide to the Vertical Envelope. New Jersey: John Wiley \& Sons, Inc.

Illustration 22 Drainage Cavity Wall

Brock, L. (2005). Designing The Exterior Wall: An Architectural Guide to the Vertical Envelope. New Jersey: John Wiley \& Sons, Inc.

Illustration 23 Pressure-Equalized Rain-Screen Wall

Brock, L. (2005). Designing The Exterior Wall: An Architectural Guide to the Vertical Envelope. New Jersey: John Wiley \& Sons, Inc.

Illustration 24 Green Facades \& Green Wall Types

Murphy, Cassandra. 2015.

Illustration 25 Image of Supertrees

Grant Associates. (2015, January 6). Supertree Evolution. Retrieved from Grant Associates: http://www.grant-associates.uk.com/approach/supertree-evolution/

Illustration 26 Supertree Systems Diagram

Dezeen Magazine. (2015, January 6). Gardens by the Bay by Grant Associates and Wilkinson Eyre Architects. Retrieved from Dezeen Magazine: 
http://www.dezeen.com/2012/06/19/gardens-by-the-bay-by-grant-associates-andwilkinson-eyre-architects/

Illustration 27 Inside Trunk of Supertree

Grant Associates. (2015, January 6). Supertree Evolution. Retrieved from Grant Associates: http://www.grant-associates.uk.com/approach/supertree-evolution/

Illustration 28 Exterior Trunk of Supertree

Grant Associates. (2015, January 6). Supertree Evolution. Retrieved from Grant Associates: http://www.grant-associates.uk.com/approach/supertree-evolution/

Illustration 29 Construction of Supertree

Grant Associates. (2015, January 6). Supertree Evolution. Retrieved from Grant Associates: http://www.grant-associates.uk.com/approach/supertree-evolution/

Illustration 30 Watershed Consciousness

Sardella, F. (2015, January 6). Watershed Consciousness. Retrieved from Ferruccio Sardella: https://ferrucciosardella.wordpress.com/watershed-consciousness/

Illustration 31 Watershed Consciousness 2

Sardella, F. (2015, January 6). Watershed Consciousness. Retrieved from Ferruccio Sardella: https://ferrucciosardella.wordpress.com/watershed-consciousness/

Illustration 32 Quai Branly Museum

Blanc, P. (2015, January 6). Quai Branly Museum. Retrieved from Vertical Garden Patrick Blanc: http://www.verticalgardenpatrickblanc.com/realisations/paris/quaibranly-museum

Illustration 33 One Central Park 
Blanc, P. (2015, January 6). One Central Park, Sydney. Retrieved from Vertical Garden Patrick Blanc:

http://www.verticalgardenpatrickblanc.com/realisations/sydney/one-central-park-sydney

Illustration 34 Geoponic System

Butterfield, M. (2015, January 6). How To Grow Your Own Food: Garden Chores. Retrieved from Mavis Butterfield: http://www.onehundreddollarsamonth.com/how-to-grow-your-own-food-gardenchores/

Illustration 35 Hydroponic System

Hydroponic Supplies Warehouse. (2015, January 6). What is Hydroponics? Retrieved from Hydroponic Supplies Warehouse: http://hydroponicsupplieswarehouse.com/what-is-hydroponics/

Illustration 36 Aeroponic System

Grow Make Give. (2013, January 13). Aeroponic Nursery. Retrieved from Grow Make Give: http://growmakegive.com/2013/01/19/grow-make-give-top-10-posts-ofyear/greenh2ouse-041/

Illustration 37 Aquaponic System

Mikel, C. (2015, January 6). Indoor Aquaponics, Outdoor Aquaponics, Raising Talipia, Growing Vegetables. Retrieved from Cheryl Mikel: http://www.cherylmikel.com/aquaponics.html

Illustration 38 Programmatic Equation Murphy, Cassandra. 2015.

Illustration 39 Reinterpretation of Ingold Drawing 
Murphy, Cassandra. 2015.

Illustration 40 Pine Façade Iteration 1 Components

Murphy, Cassandra. 2015.

Illustration 41 Pine Façade Spring

Murphy, Cassandra. 2015.

Illustration 42 Pine Façade Summer

Murphy, Cassandra. 2015.

Illustration 43 Pine Façade Autumn

Murphy, Cassandra. 2015.

Illustration 44 Pine Façade Winter

Murphy, Cassandra. 2015.

Illustration 45 Static Pine Facade

Murphy, Cassandra. 2015.

Illustration 46 Closed Dynamic Pine Facade

Murphy, Cassandra. 2015.

Illustration 47 Open Dynamic Pine Facade

Murphy, Cassandra. 2015.

Illustration 48 Pine Façade Iteration 2 Summer Elevation

Murphy, Cassandra. 2015.

Illustration 49 Pine Façade Iteration 2 Winter Elevation

Murphy, Cassandra. 2015.

Illustration 50 Pine Façade Iteration 3 Components 1

Murphy, Cassandra. 2015. 
Illustration 51 Pine Façade Iteration 3 Components 2

Murphy, Cassandra. 2015.

Illustration 52 Pine Façade Iteration 3 Stage 1

Murphy, Cassandra. 2015.

Illustration 53 Pine Façade Iteration 3 Stage 2

Murphy, Cassandra. 2015.

Illustration 54 Pine Façade Iteration 3 Stage 3

Murphy, Cassandra. 2015.

Illustration 55 Pine Façade Iteration 3 Stage 4

Murphy, Cassandra. 2015.

Illustration 56 Pine Façade Iteration 3 Stage 5

Murphy, Cassandra. 2015.

Illustration 57 Pine Façade Iteration 4 Components

Murphy, Cassandra. 2015.

Illustration 58 Pine Façade Iteration 4 Stage 1

Murphy, Cassandra. 2015.

Illustration 59 Pine Façade Iteration 4 Stage 2

Murphy, Cassandra. 2015.

Illustration 60 Pine Façade Iteration 4 Plan

Murphy, Cassandra. 2015.

Illustration 61 Pine Façade Iteration 4 Elevations

Murphy, Cassandra. 2015.

Illustration 62 Pine Façade Iteration 4 Section 
Murphy, Cassandra. 2015.

Illustration 63 Site Plan2

Murphy, Cassandra. 2015.

Illustration 64 Schematic Massing Model Image 1

Murphy, Cassandra. 2015.

Illustration 65 Schematic Massing Model Image 2

Murphy, Cassandra. 2015.

Illustration 66 Schemativ Massing Model Image 3

Murphy, Cassandra. 2015.

Illustration 67 Roof Plan

Murphy, Cassandra. 2015.

Illustration 68 Reflected Ceiling Plan 1

Murphy, Cassandra. 2015.

Illustration 69 Reflected Ceiling Plan 2

Murphy, Cassandra. 2015.

Illustration 70 Third Floor Plan

Murphy, Cassandra. 2015.

Illustration 71 Second Floor Plan

Murphy, Cassandra. 2015.

Illustration 72 Ground Floor Plan

Murphy, Cassandra. 2015.

Illustration 73 Basement Floor Plan

Murphy, Cassandra. 2015. 
Illustration 74 South Elevation

Murphy, Cassandra. 2015.

Illustration 75 South West Elevation

Murphy, Cassandra. 2015.

Illustration 76 North Elevation

Murphy, Cassandra. 2015.

Illustration 77 Rendering of Latent Project Spring

Murphy, Cassandra. 2015.

Illustration 78 Rendering of Latent Project Summer

Murphy, Cassandra. 2015.

Illustration 79 Rendering of Latet Project Autumn

Murphy, Cassandra. 2015.

Illustration 80 Rendering of Latent Project Winter

Murphy, Cassandra. 2015.

Illustration 81 Rendering of Latent Project at night

Murphy, Cassandra. 2015.

Illustration 82 Systems Diagram

Murphy, Cassandra. 2015. 